Universidade de São Paulo

Instituto de Física de São Carlos

\title{
Desenvolvimento de um Instrumento Percirúrgico para Ceratografia
}

\author{
Luis Alberto V. de Carvalho
}

Tese apresentada ao Instituto de Física de São Carlos-USP, para obtenção do título de Doutor em Física Aplicada.

Orientador: Prof. Dr. Jarbas Caiado de Castro 


\section{UNIVERSIDADE DE SÃO PAULO \\ INSTITUTO DE FÍSICA DE SÃO CARLOS \\ DEPARTAMENTO DE FÍSICA E CIÊNCIA DOS \\ MATERIAIS}

\section{"DESENVOLVIMENTO DE UM INSTRUMENTO PERCIRÚRGICO PARA CERATOGRAFIA"}

\section{LUIS ALBERTO VIEIRA DE CARVALHO}

Tese apresentada ao Instituto de Física de São Carlos, Universidade de São

Paulo, para obtenção do título de Doutor em Ciências "Física Aplicada"

\section{USP/IFSC/SBI}

Orientador:

Prof. Dr. Jarbas Caiado de Castro Neto

Comissão Julgadora:

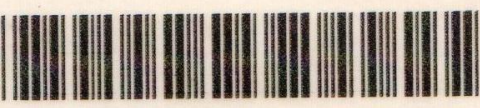

8-2-001384

Prof. Dr. Jarbas Caiado de Castro Neto (IFSC-USP)

Prof. Dr. Jan Frans Willem Slaets (IFSC-USP)

Prof. Dr. Luciano da Fontoura Costa (IFSC-USP)

Prof. Dr. Harley Edison Amaral Bicas (FMRP-USP)

Dra. Fátima Maria Mitsue Yasuoka ( Opto Eletrônica S/A)

São Carlos - São Paulo

2001 
CARVALHO, LUIS ALBERTO VIEIRA DE

"DESENVOLVIMENTO DE UM INSTRUMENTO PERCIRÚRGICO PARA CERATOGRAFLA"/LUIS

ALBERTO VIEJRA DE CARVALHO-SÃO CARLOS, 2001

TESE (DOUTORADO) - INSTITUTO DE FISICA DE SÃO CARLOS DA UNIVERSIDADE DE SÃO PAULO, 2001 PAGINAS: 89

AREA: FISICA APLICADA

PROF. DR. JARBAS CALADO DE CASTRO NETO

1. TOPOGRAFLA DA CÓRNEA, 2. CERATOMETRIA, 3. ASTIGMATISMO RESIDUAL

1. TÍTULO 


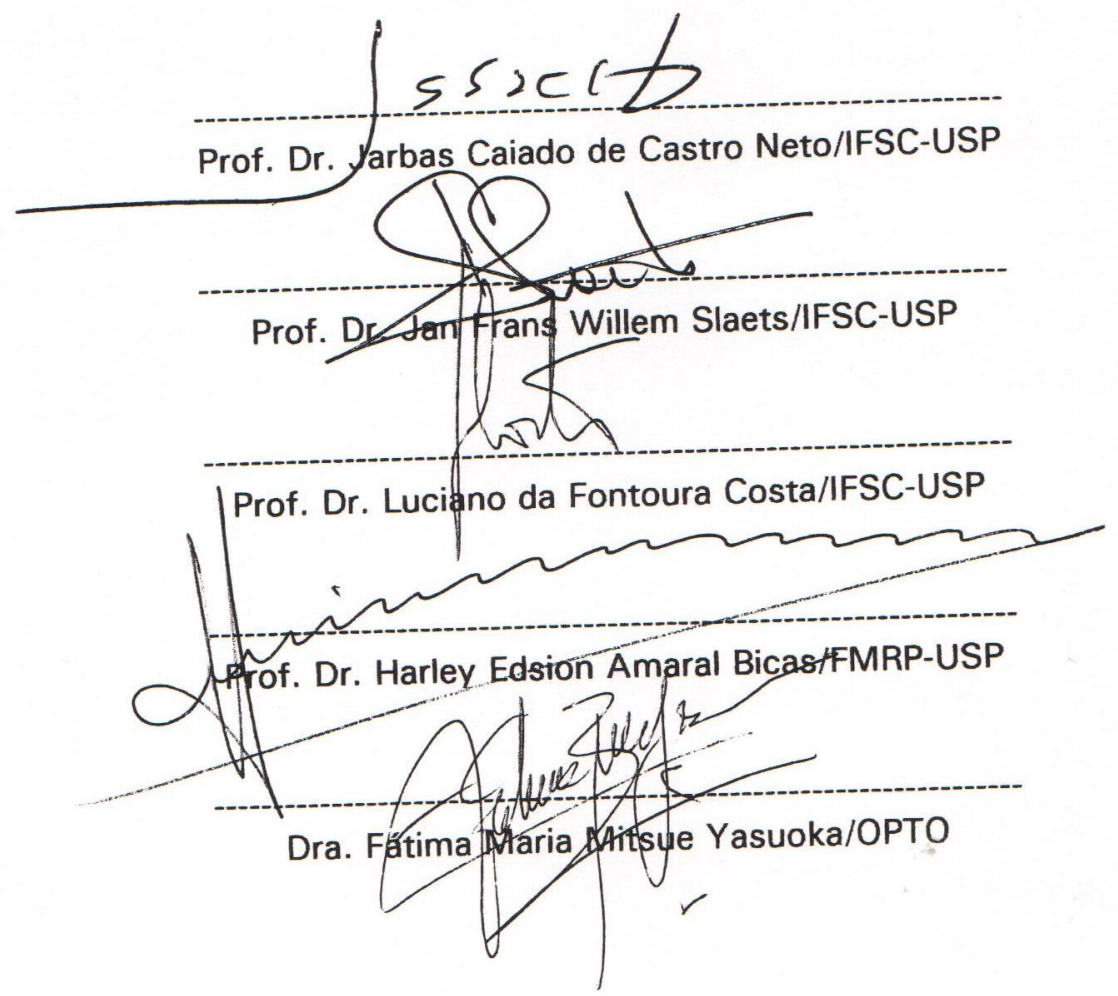




\section{Dedicatória}

Ao meu pai, Prof. Dr. Luiz Antônio Vieira de Carvalho, que faz da ciência uma filosofia de vida. 


\section{Agradecimentos}

Ao Prof. Dr. Jarbas C. Castro meu agradecimento muito especial pela orientação, pela infinita vontade e crença de que tudo sempre daria certo, pela contagiante positividade e pela amizade.

Aos meus orientadores na University of Califonia, Berkeley, Prof. Dr. Stanley A. Klein, Prof. Dr. Robert Mandell, Prof. Dr. Brian Barsky, que me apoiaram muito além do tempo disponível e que me fizeram sentir-se em casa.

Aos brilhantes colegas Dr. Wallace Chamon e Dr. Paulo Schor pelo apoio constante, pela abertura das portas da UNIFESP ao pessoal do IFSC, Opto e Eyetec, e pelas idéias sempre originais.

Aos colegas de trabalho Silvio Tonissi, Luiz Eduardo, Ernany, Liliane Ventura, Antonio Carlos Romão, Antonio Cesar, Rui, os quais contribuiram, dia a dia, de maneira indispensável à realização deste trabalho.

A todos os colegas de graduação, Casé, Cleber Mendonça, Fábio Oliveira, Maximiliam Luppe, Regiane, Sandra, Chris, Ednalva, Nório, Marquinho, Cri-cri, Marcelo Mineiro, Marconi, Abdala, entre tantos outros.

Aos colegas da Opto Eletrônica Elizeu Ramos, Fátima Yasuoka, Fontana, Djalma, Maurici, e tantos outros que estão sempre dispostos a ajudar.

Aos colegas da Eyetec Equipamentos Oftálmicos, Romão, Silvio Tonissi, Marquinhos.

Aos colegas e professores do Departamento de Computação-USP-SC, Rosane Minguim e Gustavo Nonato, Maria Cristina Ferreira de Oliveira, pelas idéias e troca de informações pertinentes.

Aos meus pais e minha família pelo eterno apoio e por sempre acreditaram muito no sucesso deste trabalho.

À Valéria, minha esposa, pelo apoio e incentivo constantes, pelo enorme carinho e amizade, e pela alegria de todos os dias.

Aos amigos que fiz na University of Califórnia, Berkeley: Jacob, Dan Garcia, Thom Carney, Shahram, Jhon Corzine, Henry, Steve.

À Alecsandra, minha querida irmã, que recentemente se casou e foi morar tão longe. Desejo-te muito boa sorte na sua nova vida. 


\title{
Resumo
}

Neste trabalho foi desenvolvido um novo instrumento para monitoramento computadorizado da curvatura da região central anterior da córnea humana durante cirurgias refrativas. Através da projeção de um disco de Plácido na córnea, imagens dos reflexos são digitalizadas e processadas. Algoritmos baseados em técnicas de visão computacional e óptica geométrica determinam a curvatura da região central $(\sim 7 \mathrm{~mm}$ em diâmetro), com alta precisão e desempenho. Mapas coloridos com códigos de cor em dioptrias (proporcionais ao inverso do raio de curvatura) são gerados para auxiliar o oftalmologista durante a cirurgia.

\begin{abstract}
In this work we have developed a new instrument for computerized monitoring of corneal central curvature during surgery. By projecting Placido Rings on the cornea, images of the reflections are digitized and processed. Algorithms based on computational vision and optical geometry determine the central curvature $(\sim 7 \mathrm{~mm}$ in diameter), with high performance and precision. Color coded maps in diopters (proportional to the inverse of the radius of curvature) are generated to aid the ophthalmologist during surgery.
\end{abstract}




\section{Objetivos do trabalho}

O conceito de refração é essencial para compreendermos a importância da córnea na qualidade visual do olho. Podemos, de maneira resumida, afirmar que a refração é a capacidade que um meio óptico tem de causar mudança na direção de propagação da luz que por ele atravessa. Portanto, a capacidade de refração é que permite às lentes e outros sistemas ópticos transferir sinais luminosos do espaço objeto para o espaço imagem, ou seja, a refração é a propriedade óptica que permite aos dispositivos ópticos, como uma câmera fotográfica, por exemplo, formar imagens do mundo exterior no plano de um filme.

Não por coincidência, nosso olho, como instrumento óptico que é, depende também da refração para permitir a formação de imagens do mundo exterior em nossos fotorreceptores (localizados na retina). É claro então que nossos olhos são dotados de órgãos biológicos que agem como componentes ópticos, onde deve ocorrer a refração para a formação das imagens. Os dois principais componentes são: córnea e cristalino.

Como córnea e cristalino são os principais componentes da refração do olho, é de se esperar que a maior parte dos problemas de visão (ametropias) esteja relacionada à uma desarmonia entre estes componentes e as dimensões do olho. Sendo assim, se o conjunto córnea-cristalino refratar com muita intensidade os raios de luz, estes se cruzam antes da retina, causando miopia; e vice-versa para a hipermetropia. Se o poder refrativo varia para diferentes meridianos do conjunto córnea-cristalino, então o sistema óptico pode ser caracterizado como astigmático.

Sabemos da óptica geométrica que o poder refrativo de uma superfície dióptrica é dado por

$$
D=\frac{(n-1)}{r}
$$

onde $D$ é o poder refrativo em Dioptrias, $n$ é o índice de refração da lente e $r$ é o raio de curvatura da superfície. Se considerarmos esta equação para cada uma das interfaces arcórnea-humor aquoso - cristalino - humor vítreo (considerando dados médios para espessura e raio de curvatura) com os respectivos índices de refração para cada um deles [1], vamos obter um poder de refração total de aproximadamente 60D. Mas somente na interface ar-córnea, o poder para uma córnea de raio mediano $(7.8 \mathrm{~mm})$ é de aproximadamente 43D. Ou seja, a superfície anterior da córnea contribui com aproximadamente $70 \%$ de toda refração do olho. Este único aspecto já torna esta superfície um importante objeto de estudo, pois sua forma é crucial para a qualidade de visão. Além disso, há fatores externos que tornam importante conhecer a forma da córnea, como cirurgias de catarata e transplantes de córnea.

Dadas estas considerações iniciais, podemos afirmar que o objetivo fundamental deste trabalho é o desenvolvimento de um vídeo-ceratógrafo percirúrgico, para medidas do poder dióptrico da córnea em situações de cirurgia. A originalidade deste trabalho reside no fato de que outros sistemas disponíveis comercialmente realizam exames somente fora da cirurgia, não permitindo ao médico o monitoramento da córnea conforme o progresso da cirurgia. Nosso objetivo aqui não foi comprovar a utilidade deste equipamento nas diversas situações possíveis, mas mostrar a viabilidade de construí-lo com tecnologia totalmente nacional. Esperamos que trabalhos futuros de 
outros pesquisadores realizem os testes de eficácia deste equipamento, como, por exemplo, na diminuição de astigmatismos residuais.

\section{Conceitos básicos}

\subsection{Aberrações oculares e ametropias}

Por ser o meio de maior contribuição para a refração total do olho, a córnea pode estar associada ou pode levar a defeitos ópticos no olho, normalmente denominados ametropias oculares, ou, de maneira mais precisa, de aberrações oculares. Faremos aqui uma definição mais rigorosa do conceito de defeito óptico, utilizando princípios de óptica física.

As correções para miopia e hipermetropia são lentes esféricas divergentes e convergentes, respectivamente. Para o astigmatismo, faz-se necessária uma lente de poder negativo ou positivo num certo meridiano, mas sem poder no meridiano perpendicular a este, ou seja, uma lente cilíndrica. Para a correção de um misto destas ametropias, utiliza-se lentes que são a soma de lentes esféricas e cilíndricas, denominadas tóricas ou esfero-cilíndricas. No entanto, se fizermos uma análise mais criteriosa, baseada nas definições de aberrações para sistemas ópticos em geral [2, 3], percebemos que estas três ametropias são apenas algumas das manifestações de aberrações ópticas do olho. Assim como em sistemas ópticos complexos, formados por um conjunto de lentes e meios de índice de refração diferentes, o olho humano também apresenta uma série de outras anomalias na formação das imagens na retina. A seguir, vamos formalizar a definição de aberrações de frente de onda e dar exemplos de vários tipos de aberrações, bem como descrevê-las.

\section{Definição de aberração de frente de onda}

A figura 2.1 (lado esquerdo) ilustra uma frente de onda divergindo do ponto objeto fora do eixo óptico do espaço-objeto e em direção à pupila de entrada de um sistema óptico. Por causa da natureza física da propagação de onda, a frente de onda é esférica e centrada em relação ao ponto $Q$. A figura 2.1 (lado direito) ilustra a frente de onda, depois de emergir da pupila de saída do sistema óptico. Se este sistema fosse completamente livre de aberrações, a frente de onda seria perfeitamente esférica e centrada com relação ao ponto-imagem $Q^{\prime}$. Devido às aberrações, a frente de onda geralmente não é esférica e os raios de luz não convergem necessariamente sobre o mesmo ponto-imagem. Para especificar a natureza de uma frente de onda real, esta é geralmente comparada a uma frente de onda perfeitamente esférica de um sistema óptico livre de aberrações. A frente de onda perfeitamente esférica é uma superfície hipotética denominada de esfera de referência. A distância da esfera de referência à frente de onda real ao longo de um determinado raio de luz é definida como aberração da frente de onda ou distorção da frente de onda. O seu valor numérico é correspondente à diferença de distância no caminho óptico entre a frente de onda real e a esfera de referência, que é obtido ao multiplicar a distância geométrica ao longo do raio de luz pelo índice de refração do meio. 


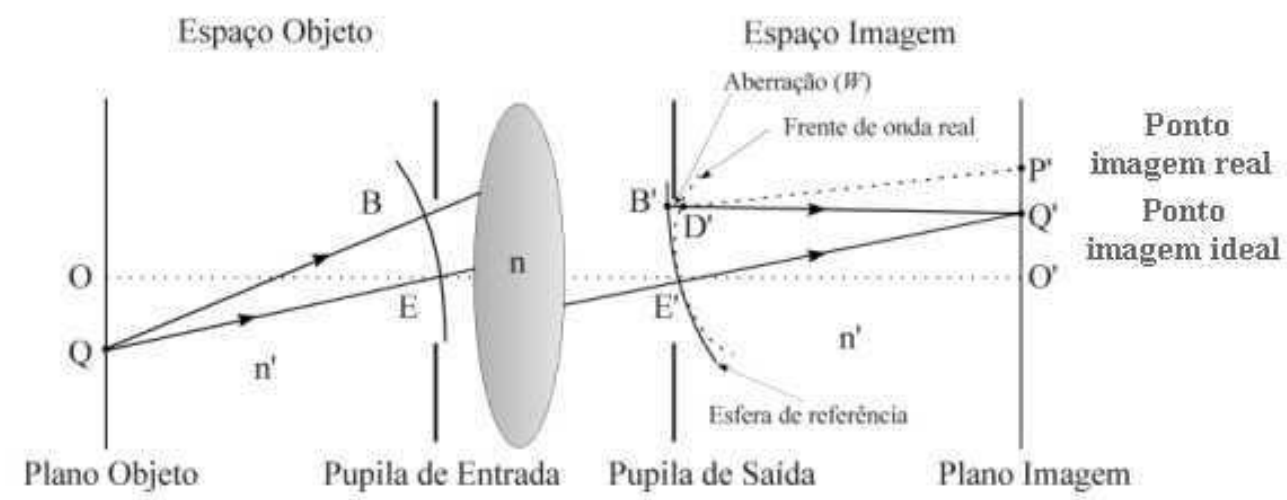

Figura 2.1. Diagrama esquemático para definição da função aberração óptica $(W)$. A linha OO' define o eixo óptico do sistema. A lente ao centro do diagrama representa o componente óptico que irá refratar a luz e induzir as aberrações ópticas (poderia ser um conjunto de lentes, prismas, etc. de índices de refração diferentes). Os raios QB e QE representam a frente de onda esférica, sem aberrações, que emerge do ponto objeto Q. Esta frente de onda passa pela pupila de entrada, sofre a refração na lente e emerge pela pupila de saída. $\mathrm{O}$ raios D'P' e E'Q' representam a frente de onda real, com aberrações. O raio D'P' converge para o ponto imagem real (P'), e o raio E'Q' converge para o ponto imagem ideal (Q'). Repare que isso ocorre pelo fato dos raios QE e E'Q' caracterizarem o raio principal e portanto não sofrem desvio em sua direção. Portanto a distância P'Q' caracteriza a aberração óptica do sistema. Outra maneira de mensurar a aberração óptica, e que usamos neste trabalho, é com relação a uma esfera de referência. Os raios B'Q' e E'Q' representam a frente de onda de referência (esférica), que coincidiria com a frente de onda real se o sistema óptico fosse completamente livre de aberrações. Definimos a distância B'D' vezes o índice de refração n' como a função aberração óptica $(W)$, que pode ser descrita em função das coordenadas do sistema (veja sistema de coordenadas no canto superior esquerdo).

Na figura 2.1, $n^{\prime}$ vezes a distância entre $B^{\prime}$ e $D^{\prime}$ define a quantidade de aberração de frente de onda, sendo $n^{\prime}$ o índice de refração no meio do espaço-imagem. A aberração é positiva quando a frente de onda real estiver à frente da frente de onda de referência. A aberração da frente de onda, a qual simbolizamos por $W$, pode ser descrita como uma função de coordenadas cartesianas ou cilíndricas:

$$
W=W(x, y)=W(\theta, \rho)
$$

onde

$$
\begin{aligned}
& x=\rho \cos \theta \\
& y=\rho \sin \theta
\end{aligned}
$$

\section{Exemplos de aberrações}

Como exemplos de aberrações de sistema ópticos em geral, vamos ilustrar a seguir os casos mais comuns e outros ditos de "ordem mais alta": 

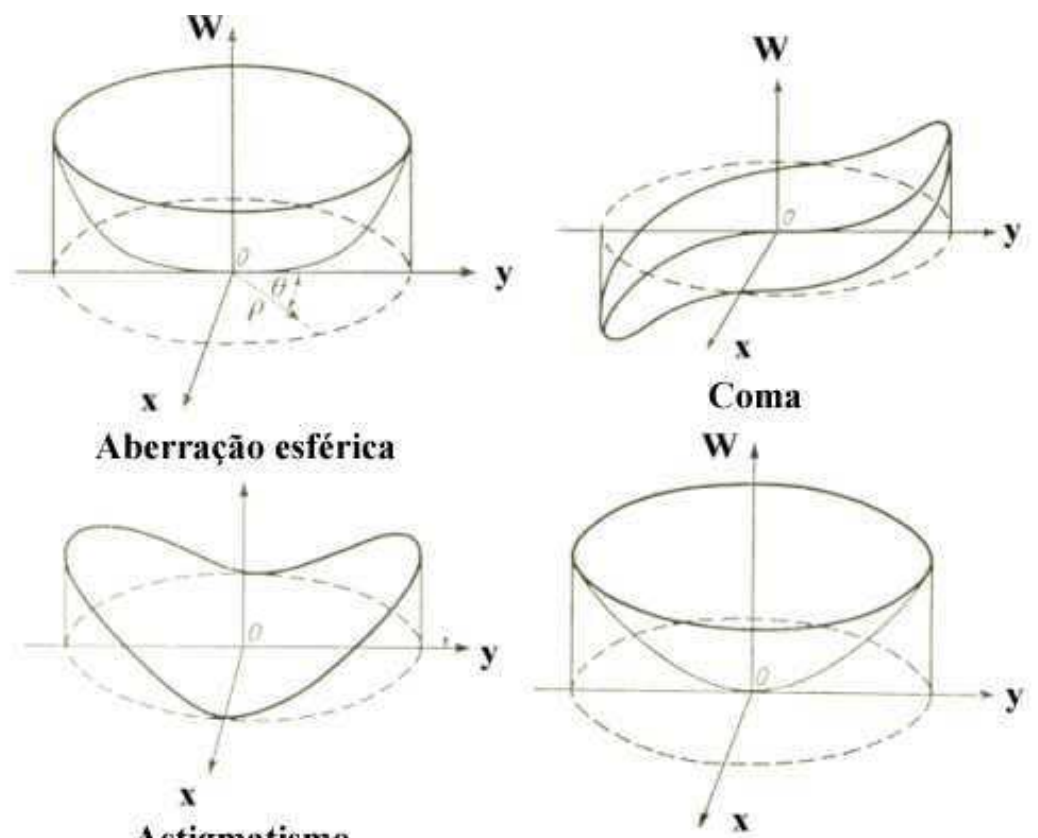

Astigmatismo

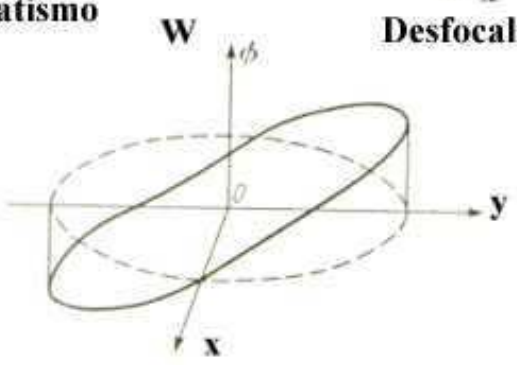

Distorção

Figura 2.2. Ilustrações tridimensionais de vários tipos de aberrações. Cada uma delas causa um padrão de deformação na formação da imagem, sendo que a desfocalização (miopia ou hipermetropia) e o astigmatismo são as aberrações mais comuns do olho humano. A distorção, aberração esférica e o coma são mais comuns em sistemas ópticos de instrumentos como microscópios, lâmpadas de fenda, entre outros.

As aberrações mostradas na figura 2.2 são apenas algumas daquelas existentes no olho e sistemas ópticos em geral. Mas normalmente a aberração esférica, o astigmatismo, a desfocalização e o coma são as mais comuns.

Ametropias oculares são geralmente definidas através da projeção no olho de raios paralelos provindos de uma fonte pontual de luz posicionada no infinito. Se a imagem desta fonte de luz formar-se na retina, o olho é dito emétrope e, se for posicionada antes ou depois é dito míope ou hipermétrope, respectivamente. Pode-se dizer que para o emétrope o sistema óptico do olho tem um poder de convergência ideal; para o míope é muito forte e para o hipermétrope é muito fraco. Agora, imaginando uma situação oposta, onde uma fonte pontual de luz é localizada na retina e os raios emergem em direção ao exterior do olho, para o olho emétrope, teremos raios emergentes paralelos, convergentes para o míope, e divergentes para o hipermétrope (veja figura 2.3). 


\subsection{Instrumentos para exame da córnea}

\section{Os Primeiros Sistemas de Análise Topográfica da Córnea}

A córnea é responsável pela maior parte do poder de refração total do sistema óptico do olho. Há 150 anos pesquisadores têm tentado descrever suas características topográficas $[4,5]$. O método mais antigo de análise topográfica utiliza as características especulares de reflexão da superfície de lágrima que se forma sobre a porção anterior da córnea. Assim, esta pode ser tratada opticamente como um espelho. Diversos tipos de imagens, em formato de linhas, quadrados, e anéis concêntricos, eram projetadas na superfície anterior para que, através de análises subjetivas, a topografia desta região pudesse ser investigada.

Em 1820, o oftalmologista francês
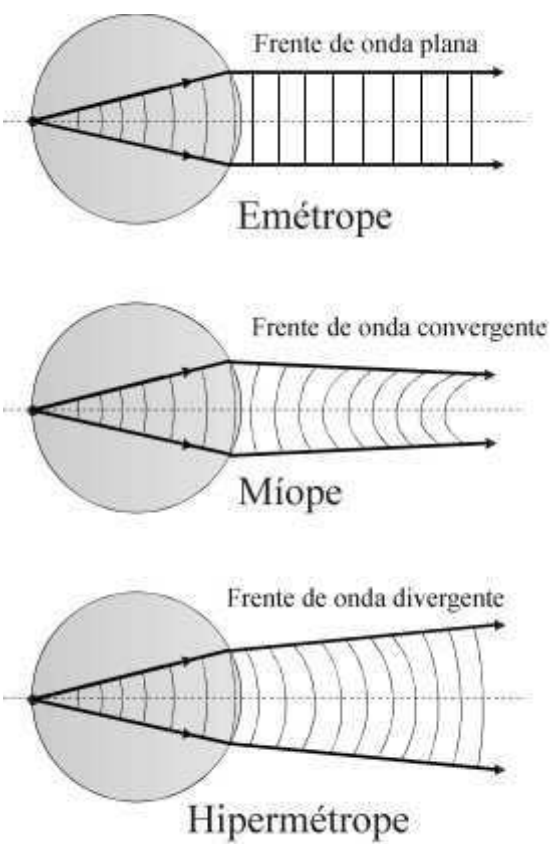

Figura 2.3. Uma fonte pontual de luz na retina gera uma frente de onda esférica dentro do olho, que pode emergir parapela se este for emétrope, convergente se for míope e divergente se for hipermétrope.

Ferdinand Cuignet propôs o primeiro método par estudar as imagens refletidas pela superfície anterior da córnea, designando o nome da nova técnica de "ceratoscopia". No seu sistema, uma luz era projetada num anteparo colocado em frente ao olho do paciente. $\mathrm{O}$ sistema de iluminação, paciente e observador eram posicionados de tal maneira que este último pudesse visualizar as imagens refletidas pela córnea. Distorções dessas imagens, indicando uma topografia anormal da córnea, poderiam então ser qualitativamente interpretadas pelo observador. Havia vários problemas com este sistema. $\mathrm{O}$ processo de alinhamento dependia muito da habilidade do observador e não havia nenhum sistema óptico de aumento, o que dificultava a análise das imagens refletidas.

Em 1880, o português A. Plácido [6] desenvolveu um sistema de projeção que está em uso até os dias de hoje. O projetor era um disco com anéis brancos e pretos alternados, com um furo ao centro por onde o observador poderia visualizar a córnea do paciente (figura 2.4(a)). Este sistema melhorou bastante o processo de alinhamento, pois bastava o paciente fixar a visão ao centro do projetor para que este estivesse alinhado ao eixo de visão. Se o padrão refletido fosse o de anéis aproximadamente circulares e concêntricos, a córnea poderia ser interpretada como aproximadamente esférica (figura 2.4(b)); do contrário, a topografia seria de uma superfície distorcida (figura 2.4(c)). 


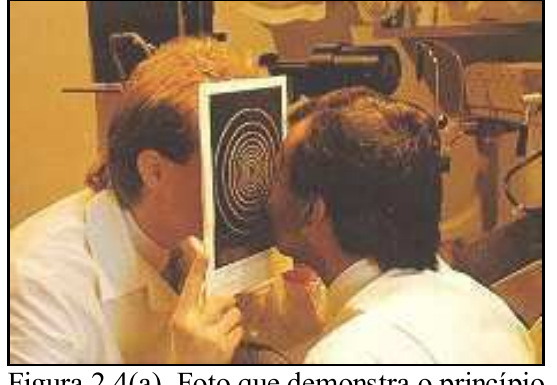

Figura 2.4(a). Foto que demonstra o princípio incicar aproximadame una cón anomalias na topografia da córnea.

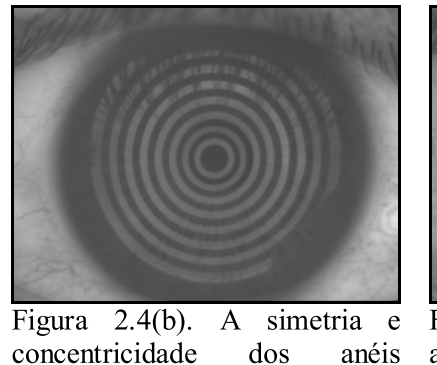

concentricidade dos anéis anéis refletidos indicam ser esta são características uma córnea com uma topografia aproximadamente esférica.

irnea irregular.

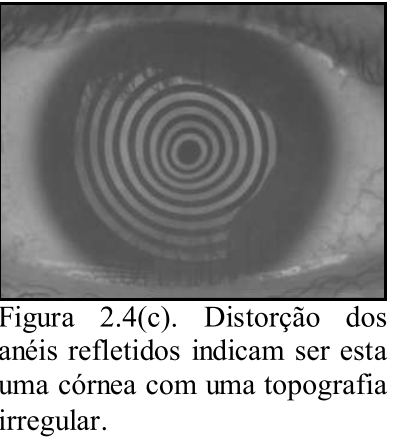

Apesar do método de Plácido melhorar substancialmente o processo de alinhamento, a dificuldade em observar pequenas distorções ainda existia pois este sistema, assim como o anterior, não continha dispositivo óptico de magnificação das imagens.

A necessidade de um sistema de magnificação na ceratoscopia começou a ser resolvida por E. Javal ao final da década de 1880 [7]. Utilizando o princípio dos discos de Plácido e do ceratômetro, Javal desenvolveu um instrumento com sistema telescópico na ocular, permitindo uma magnificação das imagens refletidas pela córnea. Javal ainda sugeriu que sistemas que pudessem fotografar tais imagens proporcionariam análises mais precisas.

Consciente das possibilidades sugeridas por Javal, A. Gullstrand [5] foi o primeiro a implementar fotografia à ceratoscopia, chamada de ceratografia. As ceratografias eram utilizadas para análise da topografia da córnea com maior precisão. Sabendo-se o grau de magnificação era possível realizar medidas nas fotos e saber o valor correspondente em milímetros. Anéis muito próximos uns dos outros significavam altas curvaturas, e anéis espaçados significavam curvaturas suaves.

A popularidade desse sistema e dos sistemas anteriores para medida da topografia esbarrou durante décadas em um aspecto crucial: a objetividade das medidas. Por mais preciso que fosse o sistema de alinhamento e por maior que fosse a magnificação, a ceratoscopia ainda era essencialmente um método qualitativo. Gullstrand ainda implementou um método para calcular a curvatura de pares de pontos para cada meridiano, mas o processo era muito demorado e não muito prático para o oftalmologista.

$\mathrm{Na}$ década de 20 foram feitas várias tentativas de quantificação das ceratografias. No final da década de 40 e no começo dos anos 50, ceratografias de córneas eram comparadas com ceratografias de esferas de raio conhecido. As distâncias radiais de discos na ceratografia da córnea eram comparadas, para cada meridiano, com as distâncias na ceratografia da esfera. Repetindo este processo para cada disco e meridiano e comparando com as várias esferas obtinha-se os raios de curvatura para vários pontos da córnea.

No final dos anos 60, H. Bicas [8] apresenta em sua tese de Doutorado um novo princípio de ceratometria, tratando com maior rigor matemático as equações da óptica geométrica para cálculo objetivo dos raios de curvatura da córnea. Já nesta época o autor sugere a adaptabilidade dos ceratômetros aos microscópios cirúrgicos.

Nos anos 70 e 80 surgem vários modelos de ceratômetros percirúrgicos de

diferentes fabricantes [9]. Alguns, mais baratos, utilizam princípios 
qualitativos e portanto, de precisão limitada; outros, mais caros, têm escalas analógicas ou digitais e indicam quantitativamente a ceratometria.

Em 1996, Carvalho [10] apresenta em sua tese de mestrado um ceratômetro percirúrgico computadorizado, que utiliza princípios do videoceratógrafo.

Em 1997, P. Schor apresenta em sua tese de doutorado [11] um ceratômetro quantitativo para uso durante a cirurgia. Realiza testes e comprova a viabilidade de se construir modelos analógicos de baixo custo e boa precisão.

\section{O Fotoceratoscópio}

As repetidas tentativas de desenvolvimento de métodos quantitativos mais eficientes que permitissem medidas mais confortáveis para o paciente e mais práticas e objetivas para o oftalmologista deram origem a uma série de instrumentos, hoje generalizados pelo nome de fotoceratoscópio. Vários instrumentos deste tipo foram desenvolvidos e testados nas últimas décadas [12, 13, 14], cada um com algumas vantagens em relação ao outro (figuras 2.5 (a), (b), (c)). O princípio óptico do fotoceratoscópio pode ser visto na figura $2.5(\mathrm{~d})$. 


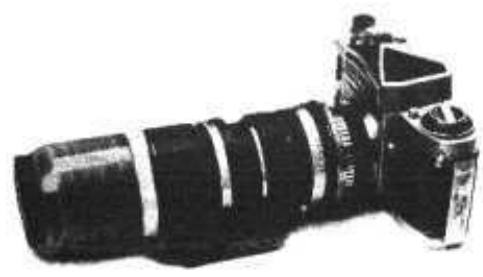

(a)

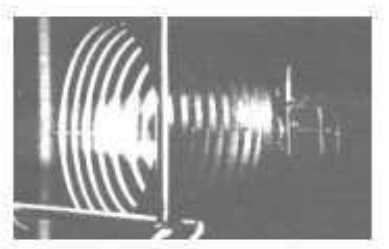

(b)

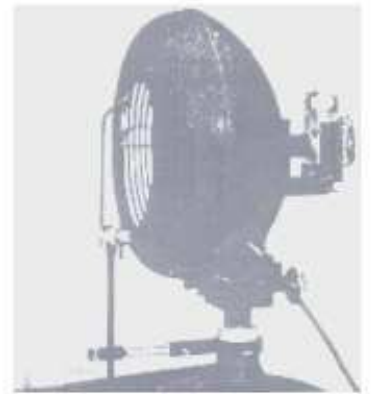

(c)

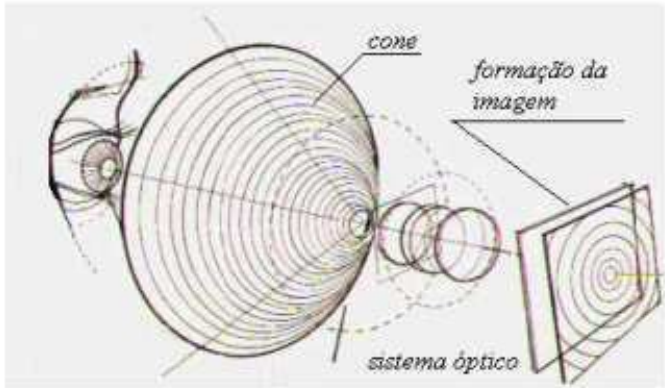

(d)

figura 2.5. (a) Fotoceratoscópio com sistema de projeção acoplado à câmara fotográfica; (b) Fotoceratoscópio convencional, com projetor em forma de cone e câmara fotográfica acoplada na parte traseira; (c) Fotoceratoscópio que utiliza um sistema de projeção hemisférico; (d) Princípio óptico de projeção de anéis utilizado pelo topógrafo e fotoceratoscópio. Anéis de luz concêntricos são projetados na córnea do paciente. A imagem refletida é focalizada na matriz de um CCD, ou no filme de uma máquina fotográfica, as quais ficam acopladas ao projetor.

Com o barateamento e compactamento de sistemas computacionais a partir da década de 80, a possibilidade de análises da topografia da córnea com auxílio de instrumentos computadorizados começou a tornar-se uma realidade. Uma série de benefícios eram vislumbrados. As medidas seriam feitas com maior rapidez e dependeriam cada vez menos da habilidade do oftalmologista. As imagens seriam processadas computacionalmente em um tempo muito menor do que nos fotoceratoscópios. A disposição da curvatura em milhares de pontos sobre a córnea poderia ser feita na tela do computador, facilitando o diagnóstico. Além da "explosão" computacional, outros fatores favoreciam o desenvolvimento de instrumentos dessa natureza. $\mathrm{O}$ crescente desenvolvimento de técnicas de cirurgias refrativas necessitava de sistemas que pudessem avaliar o sucesso das cirurgias, com análises precisas pré e póscirúrgicas. A estes novos instrumentos computadorizados deu-se o nome de Topógrafos de Córnea. A seguir descrevemos em detalhe o princípio de funcionamento destes instrumentos. Isto deve ser feito já que nossas técnicas de topografia intracirúrgicas terão como base princípios do funcionamento desses instrumentos.

\section{Topógrafos de Córnea}


Os primeiros topógrafos de córnea começaram a surgir na metade da década de 80 e no início dos anos 90. Klyce [15], Koch et. al. [16], El Hage [17], Mammone et. al.[18], e Belin et. al. [19] são alguns dos pioneiros no desenvolvimento e divulgação desses sistemas. O princípio básico de funcionamento do topógrafo de córnea pode ser entendido com ajuda do diagrama da figura 2.6 (a). Na figura 2.6 (b) podemos ver fotos típicas de sistemas topográficos.

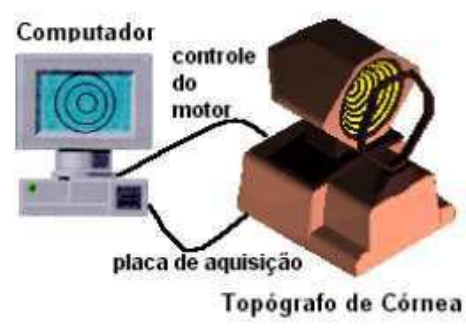

(a)

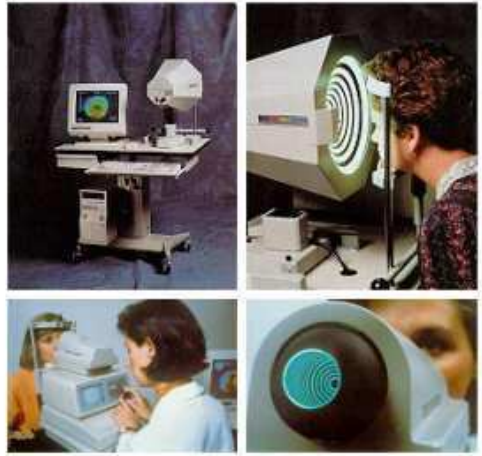

(b)

Figura 2.6. (a) Diagrama geral do funcionamento do topógrafo. O computador controla a aquisição de imagens da córnea, através de uma placa digitalizadora. Controla também os motores de posicionamento do sistema; 2.6 (b) Exemplo de alguns sistemas.

O sistema de projeção de anéis é geralmente cônico. O cone é normalmente feito em acrílico translúcido com anéis circulares concêntricos pintados em preto onde não se deseja que a luz passe. A iluminação é feita por uma lâmpada em forma de "biscoito" acoplada na parte traseira do cone. Por trás do projetor, ao longo do eixo deste, existe um sistema óptico de magnificação das imagens refletidas pela córnea (figura 2.5 (d)). Tais imagens são focalizadas numa câmara CCD monocromática acoplada ao sistema óptico e também alinhada com o eixo deste. O sinal do CCD é enviado a uma placa de aquisição ("frame grabber") instalada no micro-computador. Desta maneira imagens extremamente nítidas e com alta magnificação podem ser digitalizadas (figuras 2.4 (b), (c)). Após a digitalização, as imagens passam por processamentos computacionais para detecção das bordas dos anéis (figura 2.7). Os valores obtidos nesta etapa são inseridos em algoritmos de reconstrução da topografia da córnea [18,20-26], cujo resultado é geralmente impresso na tela do computador em forma de mapas topográficos com códigos de cores (figura 2.8). Cada cor da escala representa uma curvatura determinada, ou seja, um certo poder de refração (em Dioptrias). Cores quentes (vermelho, laranja e amarelo) representam altos graus de curvatura. Os tons em verde representam valores médios enquanto cores frias (azul, azul escuro) estão associadas a curvaturas menores. 


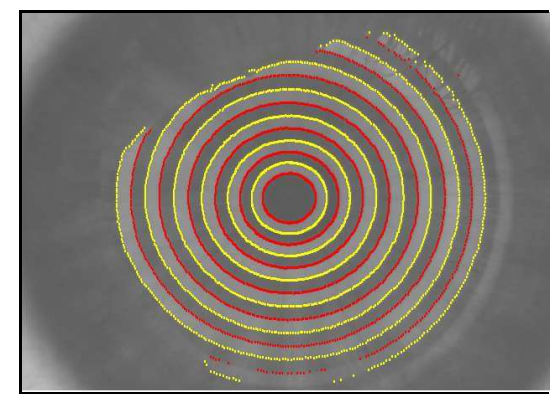

Figura 2.7. As imagens refletidas são digitalizadas e processadas computacionalmente para detecção de bordas.

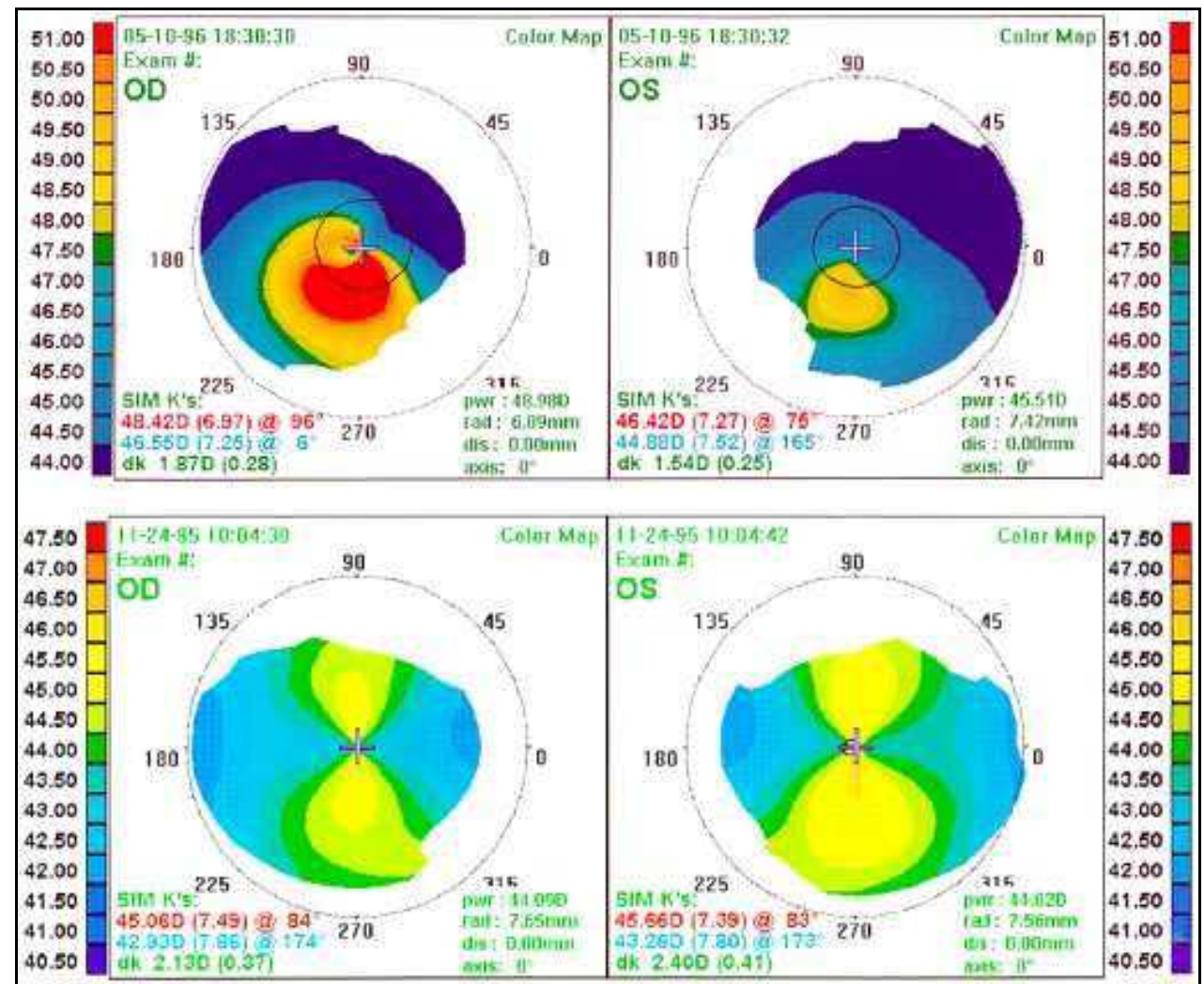

Figura 2.8. Exemplos de mapas topográficos. Valores no canto inferior direito de cada mapa indicam, de baixo para cima e com relação ao cursor: dioptria, raio de curvatura, distância ao centro, eixo. Valores no lado oposto referem-se ao eixo e grau de astigmatismo. Os mapas de cima são de um paciente com ceratocone (altas curvaturas localizadas). Os mapas abaixo evidenciam um caso típico de astigmatismo a favor da regra.

\section{Aplicações da Topografia de Córnea}

Citamos brevemente que um dos motivos que impulsionaram o surgimento de topógrafos de córnea foi o crescente desenvolvimento de cirurgias refrativas. A seguir vamos analisar esta e algumas outras aplicações do topógrafo a fim de saber qual a importância deste instrumento para o oftalmologista. 
Há três fatores determinantes no poder total de focalização do sistema óptico do olho: a córnea, o cristalino e o comprimento axial. Destes três, o mais conveniente de ser modificado é a córnea. O cristalino só pode ser alterado por meio de cirurgia intraocular ou transplante. O comprimento axial do olho não pode ser modificado. Hoje em dia a córnea é a melhor opção para correção de erros refrativos.

A ceratotomia radial é um dos métodos cirúrgicos mais utilizados até hoje para correção de miopia. De maneira resumida, cortes radiais são feitos na córnea com a utilização de um bisturi. O objetivo principal é provocar um achatamento da região central da córnea, diminuindo o poder de refração desta região e fazendo o sistema óptico do olho focalizar a imagem sobre a retina. Enquanto muitos pacientes ficam satisfeitos com os resultados da cirurgia, uma minoria experimenta hiper-correção ou sub-correção, ou até mesmo distorção na córnea. A utilização da topografia de córnea proporciona um maior potencial de previsão para o cirurgião ao determinar a estratégia para a cirurgia. Além disso permite um acompanhamento e avaliação pós-cirúrgicos (figura 2.9). A figura 2.9 mostra o olho direito de um paciente com 3 graus de miopia. No canto superior esquerdo vemos o mapa topográfico pré-cirúrgico. Trata-se de uma córnea com curvaturas mais elevadas na região central. $\mathrm{O}$ mapa no canto superior direito mostra a córnea depois de uma semana da cirurgia. Como esperado, a região central está mais achatada que a periferia. Este resultado é consistente com o procedimento de ceratotomia radial, onde a região central tem normalmente a tendência de achatar, enquanto na periferia ocorre um aumento na curvatura. $\mathrm{O}$ mapa abaixo na figura é relativo à córnea depois da cicatrização. Percebe-se uma mudança de poder variando entre 3 e 3.6 dioptrias, bem simétrica e centrada com relação ao eixo visual. Isto indica uma ceratotomia radial bem sucedida.

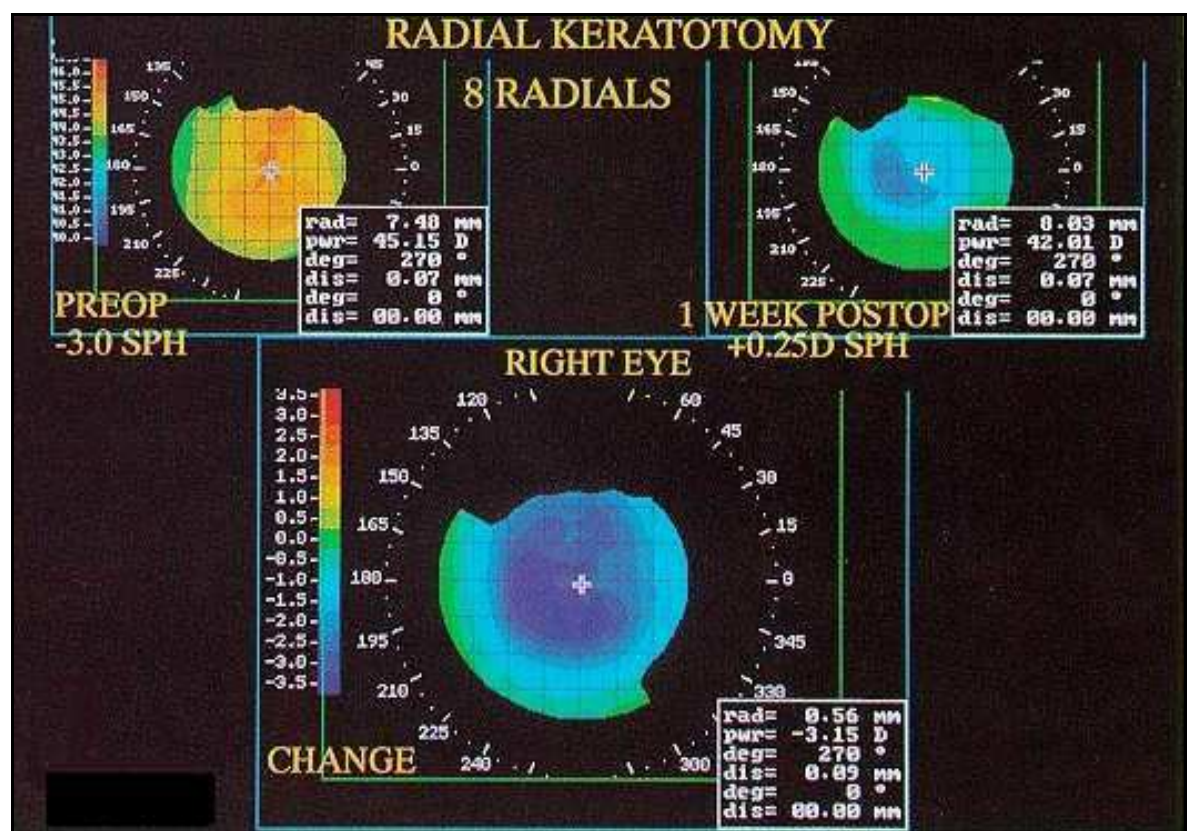

Figura 2.9. Exemplo do progresso de uma ceratotomia radial visando uma correção de aproximadamente $3 \mathrm{D}$. No canto superior esquerdo observa-se uma córnea com alta curvatura na região central, antes da cirurgia. À direita, após uma semana, a córnea está "achatada" na região central, com a correção muito próximo do desejado. Abaixo, após a cicatrização, percebe-se uma correção variando de 3 a $3.6 \mathrm{D}$, bem centrada e simétrica, indicando o sucesso da cirurgia. 


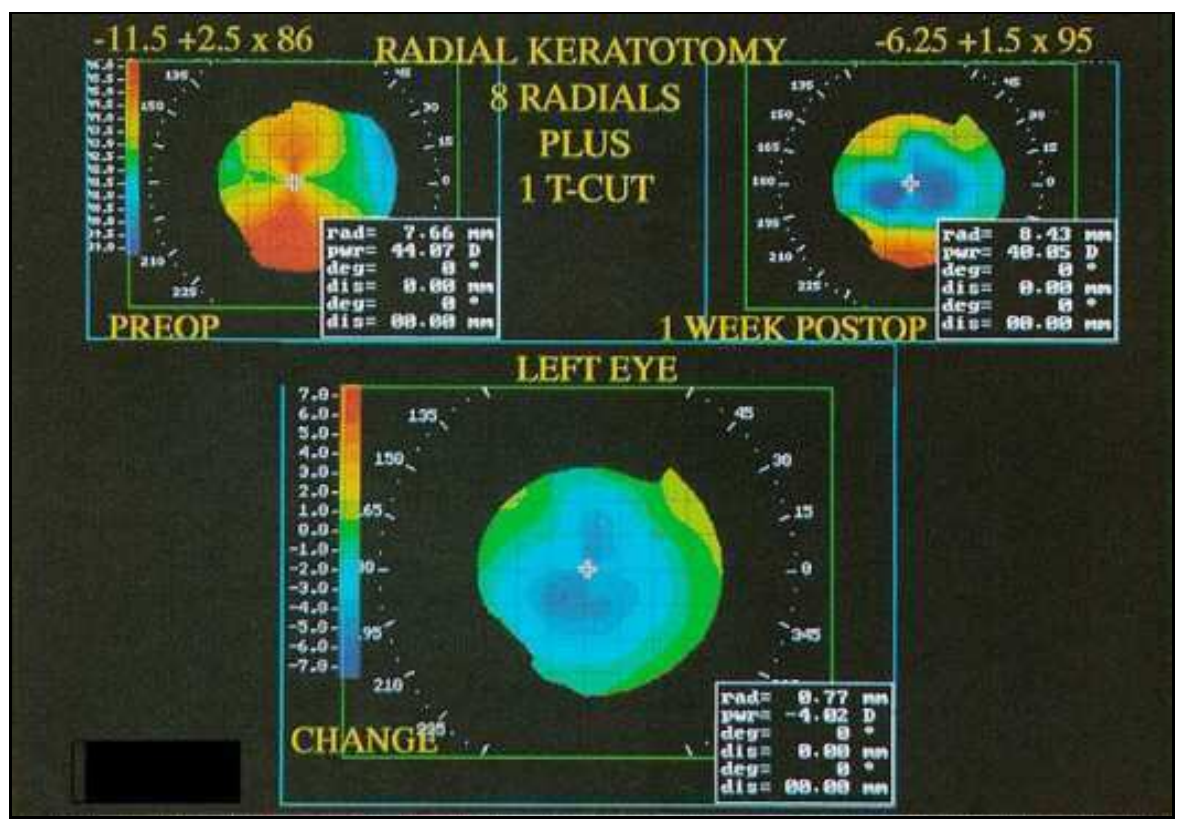

Figura 2.10. Astigmatismo hiper-corrigido por ceratotomia astigmática. $\mathrm{O}$ astigmatismo a favor de regra transformou-se num leve astigmatismo contra a regra.

Outra técnica cirúrgica beneficiada pela topografia de córnea é a ceratotomia astigmática, a qual utiliza princípios parecidos com a ceratotomia radial, mas com o objetivo final de corrigir o astigmatismo. A figura 2.10 mostra o pré e pós-operatórios para um caso deste tipo onde o astigmatismo foi hiper-corrigido.

Além de auxiliar em cirurgias refrativas convencionais como a ceratotomia radial e astigmática, a topografia também tem grande utilidade em cirurgias refrativas que utilizam técnicas mais modernas, como a ceratotomia fotorefrativa por "laser excimer". Trata-se de uma técnica relativamente recente para correção de miopia e astigmatismo [27], a qual utiliza um feixe de "laser" para moldar a superfície da córnea no formato desejado. Na figura 2.11 pode-se observar a topografia pré-operatória de uma córnea míope. Deseja-se diminuir a curvatura da região central de aproximadamente $3 \mathrm{D}$. Os resultados pós-cirúrgicos são mostrados para períodos de 1, 3 e 6 meses após a cirurgia.

Há certos procedimentos cirúrgicos cujo principal objetivo não é a alteração da topografia da córnea. Mas, por necessitar, de uma maneira ou de outra, realizar incisões na superfície da córnea, distorções indesejadas são induzidas. Mesmo após cuidadosos pontos de sutura, algumas distorções são praticamente inevitáveis. Alguns exemplos disso são as cirurgias de transplante de córnea (ceratoplastia) e as cirurgias de catarata.

Seja qual for o motivo do transplante de córnea, a porção transplantada terá que ser costurada e adaptada à região retirada do paciente. Existem diversas técnicas para dar os pontos de sutura, mas nenhuma delas garante a ausência de astigmatismo residual. Aliás, o astigmatismo residual é geralmente bastante alto na maioria dos casos. O procedimento que se tem feito para contornar este problema é o ajuste da tensão dos pontos de sutura após a cirurgia, enquanto as incisões ainda estão cicatrizando. Através destes ajustes pode-se diminuir bastante e, em alguns casos, até zerar o astigmatismo residual. A topografia de córnea tem desempenhado um papel muito importante no processo de ajuste dos pontos de sutura de córneas transplantadas (figura 2.12) e em cirurgias de catarata. 

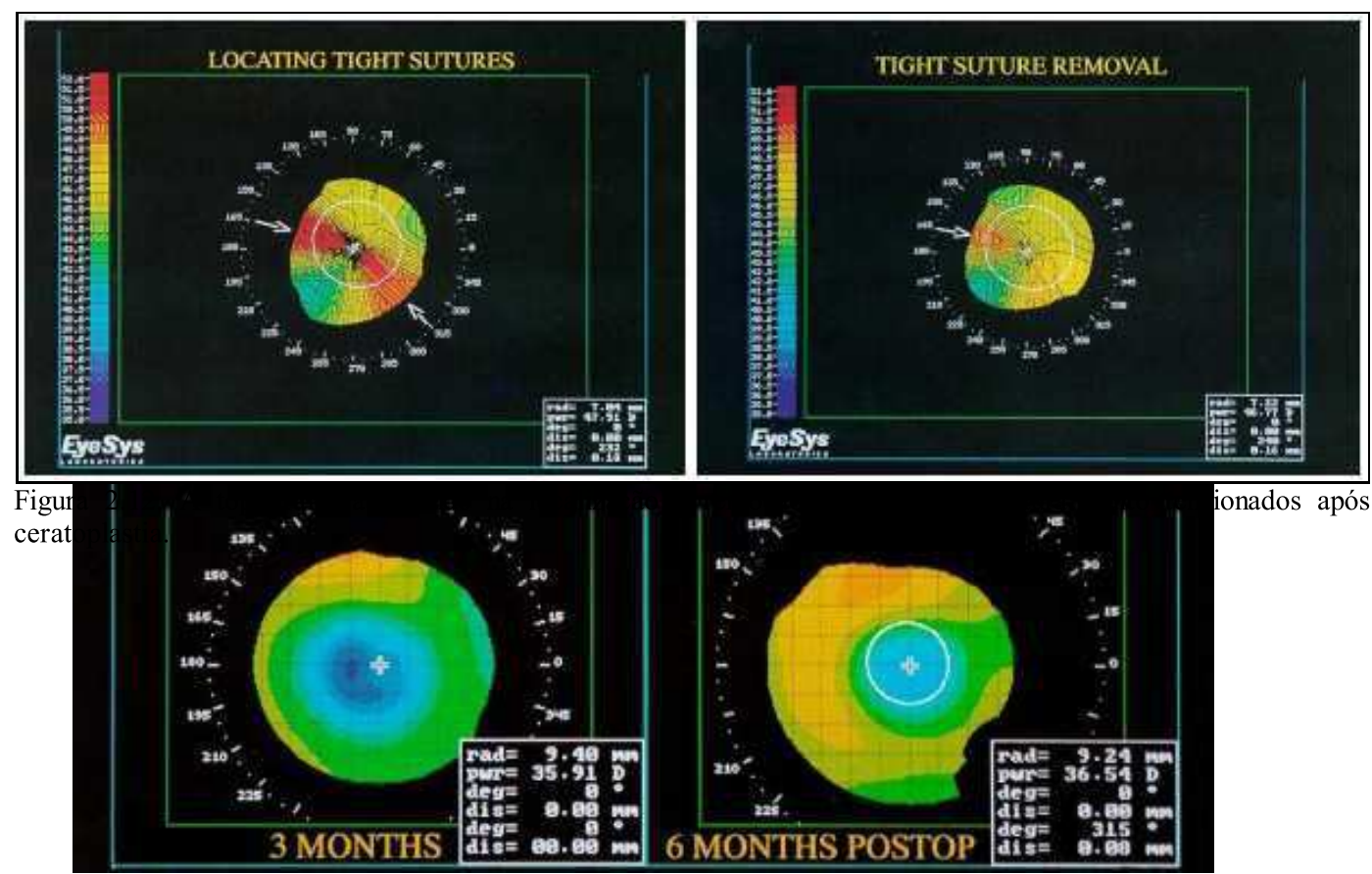

Figura 2.11. Progresso de uma cirurgia fotorefrativa a laser para correção de 3 graus de miopia. Percebe-se pela diferença de dioptrias pré e pós-cirúrgicos, e pelo formato da região modificada, uma cirurgia bem sucedida.

\subsection{Importância de equipamentos percirúrgicos}

\section{Princípio da Ceratometria e Ceratometria Intracirúrgica}

O ceratômetro é um instrumento para medida do raio de curvatura de alguns pontos sobre a córnea, geralmente num diâmetro de 3 a $4 \mathrm{~mm}$ da região central. Não faz portanto uma análise topográfica da córnea, no entanto é importante entender o princípio de funcionamento. Nosso trabalho anterior de ceratometria intracirúrgica computadorizada $[10,28,29]$ baseou-se nestes princípios e foram encontrados na literatura alguns ceratômetros percirúrgicos qualitativos e quantitativos que também utilizam os princípios dos ceratômetros convencionais [9].

A invenção do primeiro ceratômetro é atribuída a Helmholtz [7]. Desde então diversos outros instrumentos foram desenvolvidos para o mesmo fim. Cada um dispõe de algum princípio óptico ou mecânico diferente, mas a maioria faz a mesma aproximação. A córnea é opticamente simplificada como sendo um espelho esférico, e então, através da óptica geométrica calcula-se o raio de curvatura ao longo do meridiano desejado.

A figura 2.13 mostra a óptica geométrica utilizada. Supondo que temos o objeto, e que este é um dos pontos do projetor anelar, baseados na figura 2.13, podemos calcular o raio de curvatura: 
Por semelhança de triângulos temos

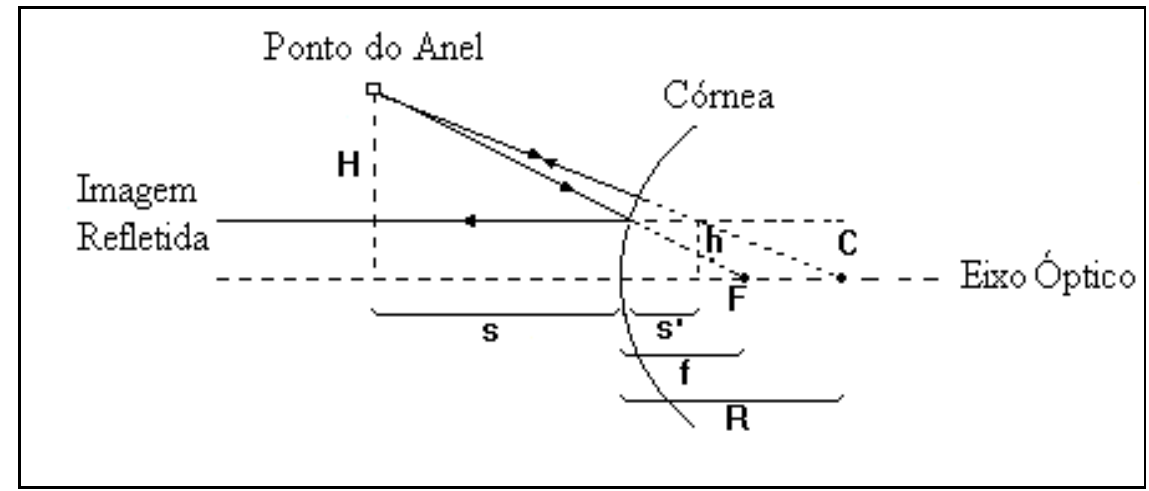

Figura 2.13. Esquema óptico para cálculo do raio de curvatura baseado no princípio da ceratometria.

$$
\frac{h}{H}=\frac{R-S^{\prime}}{R+S}
$$

Fazendo a aproximação de que $S \gg R$ e sabendo que para objetos distantes também podemos fazer $S^{\prime} \approx R / 2$, resolvendo a equação para $R$ temos:

$$
R=\frac{2 S}{H} h
$$


Troutman et. al.[30] publicaram em 1977 os resultados obtidos com um instrumento percirúrgico que utilizava princípios da ceratometria. $\mathrm{O}$ instrumento foi chamado de Ceratômetro de Troutman. Um projetor anelar é acoplado à objetiva do microscópio cirúrgico (figura 2.14). Ao longo do perímetro interno do projetor existem 12 pequenos círculos igualmente espaçados, formados por terminações de milhares de fibras ópticas. Estas fibras são levadas por um fino cabo até uma fonte de luz fria. Um pequeno filtro verde é inserido no encaixe do cabo de fibra com o projetor. Isto garante que os reflexos do projetor na córnea terão cor diferente de outros eventuais reflexos. Através do ajuste na fonte pode-se regular a intensidade de luz nos pequenos círculos. No tubo da ocular acopla-se um retículo para auxílio na medida.

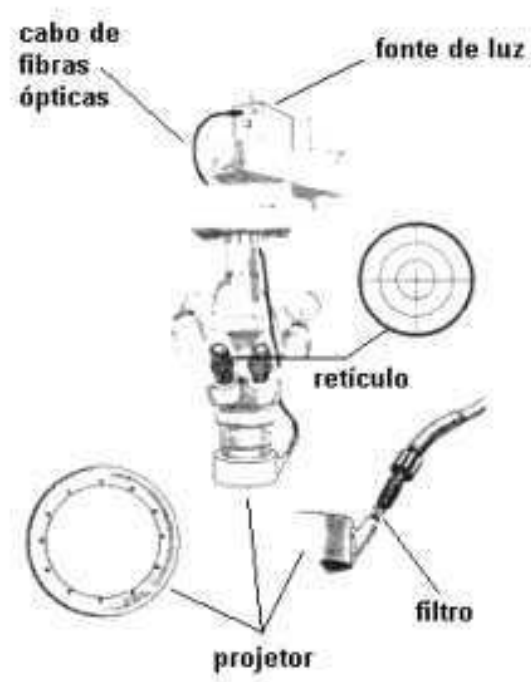

(a)

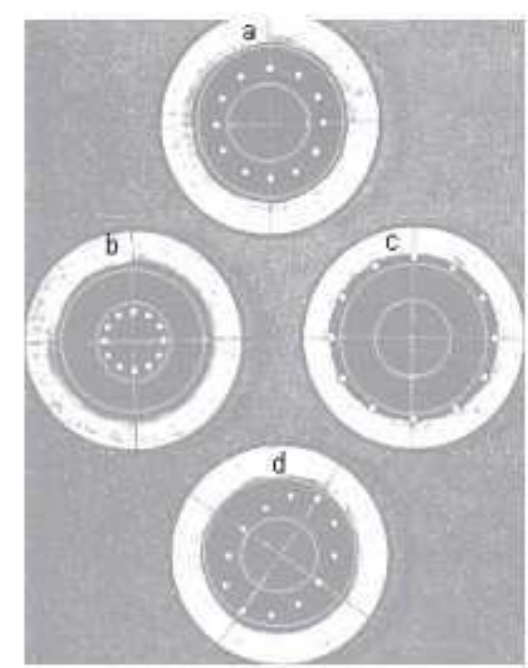

(b)

Figura 2.14. (a) Ceratômetro de Troutman; (b) alguns padrões de reflexos da córnea para o ceratômetro de Troutman: (a) estimando a dioptria; (b) alta curvatura central; (c) córnea achatada; (d) estimando o astigmatismo.

Uma estimativa qualitativa do poder pode ser feita através da comparação dos reflexos do projetor na córnea com o retículo. De 42 a 45 dioptrias (com uma magnificação de 20 vezes), o anel refletido estará localizado entre os dois círculos do retículo (figura 2.14 (b) - (a)). Para uma córnea com maior curvatura o anel refletido aparece no limiar ou dentro do círculo menor (figura 2.14 (b) - (b)), enquanto o reflexo para uma córnea mais achatada localiza-se sobre ou para fora do anel mais externo (figura 2.14 (b) - (c)). O ângulo de astigmatismo pode ser estimado girando a cruz no retículo de tal maneira a deixar um dos eixos sobre a região de maior diâmetro no anel refletido (figura 2.14 (b) - (d)).Troutman realizou medidas com esse instrumento em 184 casos, sendo 125 casos de catarata, e 59 casos de transplante de córnea. Para cada caso foi separado um grupo de controle, 57 para catarata e 27 para transplante. Nos pacientes de controle não foi utilizado o ceratômetro percirúrgico. Tanto para os casos de catarata como para transplante obteve-se uma redução significativa do astigmatismo residual.

\section{Instrumento desenvolvido}


Como vimos na seção anterior, a topografia computadorizada é um ramo dentro da oftalmologia que tem se desenvolvido bastante. As vantagens de se poder medir com precisão a maior parte da superfície da córnea, antes e depois da cirurgia, estão cada vez mais evidentes. Com os mapas topográficos do pré e pós-operatórios os médicos podem questionar as atuais técnicas, propor novos métodos e depois testá-los com precisão. A facilidade e a rapidez das medidas topográficas incentiva o uso em larga escala desta técnica, permitindo que o oftalmologista tenha informações estatísticas palpáveis para poder averiguar o sucesso de suas cirurgias.

Além disso, percebe-se que o ceratômetro de Troutman $[7,30]$ e outros sistemas percirúrgicos análogos [9] trazem benefícios pós-cirúrgicos imediatos, mesmo antes da retirada de pontos de sutura. A diminuição do astigmatismo residual foi comprovada para os casos mais comuns, de catarata e transplante de córnea. Isto demonstra uma real utilidade de instrumentos desta natureza, pois muitas vezes a cicatrização permite apenas ajustes finos após a cirurgia, e a eliminação completa do astigmatismo residual é praticamente inviável.

Dados estes fatores percebe-se que existem atualmente duas técnicas de diagnóstico muito úteis. Uma técnica pré e pós-cirúrgica quantitativa, objetiva e que mede praticamente toda a superfície da córnea, com boa precisão. E outra técnica percirúrgica, subjetiva, que mede somente a região central, e que tem baixa precisão. Portanto, a idéia central do método que estamos propondo é unir as qualidades quantitativas da topografia computadorizada de córnea aos benefícios de um instrumento percirúrgico como o ceratômetro de Troutman.

O princípio geral do sistema é análogo ao trabalho de mestrado [10, 28, 29] (figura 3.1). A primeira parte do sistema a ser desenvolvida foi o projetor anelar. Testes preliminares foram realizados para comprovar a boa intensidade de luz e a região da córnea que será abrangida. Este primeiro projetor contém 3 anéis concêntricos e é acoplado à objetiva de um microscópio cirúrgico nacional (cedido pela empresa Opto Eletrônica, www.opto.com.br). No "carona" (divisor de feixes) do microscópio acoplase um adaptador no qual, por sua vez, é acoplada uma câmara CCD monocromática. O sinal da câmara de vídeo é enviado para uma placa de aquisição instalada num microcomputador, onde é feito todo o processamento das imagens e dos mapas topográficos.

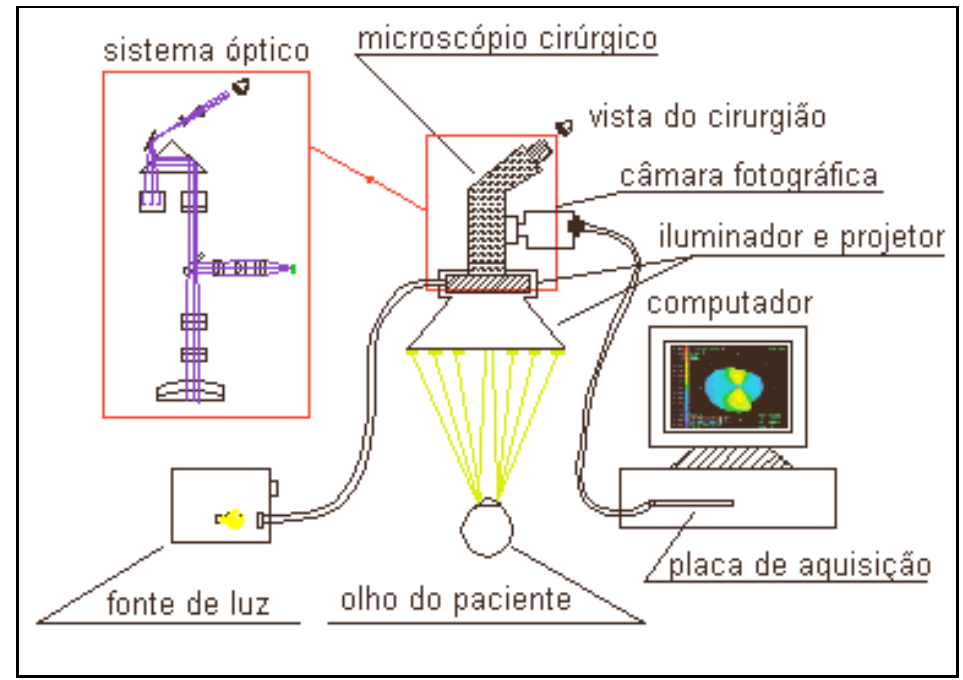

Figura 3.1. Diagrama ilustrando o princípio geral do ceratógrafo percirúrgico. O paciente é posicionado de tal maneira que o eixo óptico do microscópio coincida com o eixo óptico do olho. A imagem virtual formada pelos reflexos dos anéis do projetor é focalizada em dois lugares: na ocular e no CCD de uma câmera monocromática acoplada ao divisor de feixes do microscópio. 


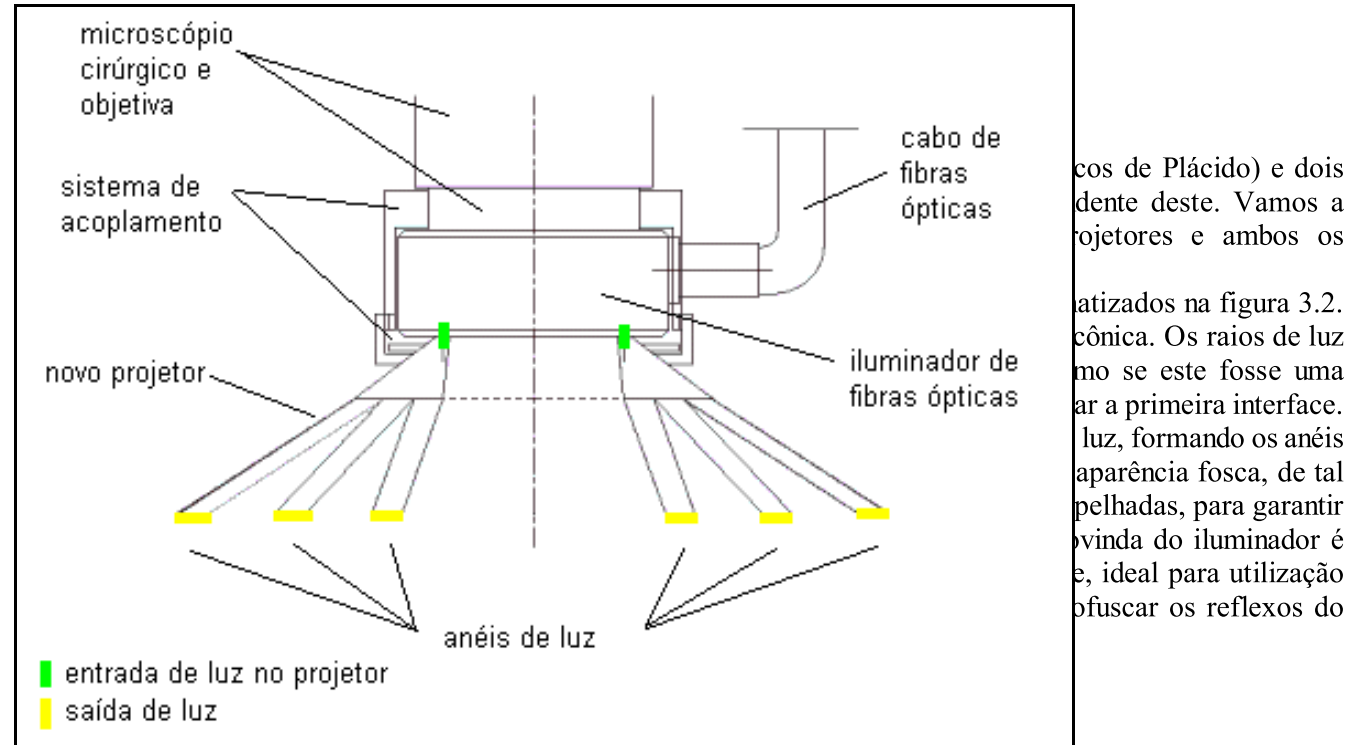

Figura 3.2. Esquema básico do primeiro projetor de anéis. O iluminador de fibras ópticas é preso na lente objetiva do microscópio. A luz que sai do iluminador (em verde) ilumina e reflete em todo interior dos cones que formam os três Discos de Plácido (em amarelo). Este sistema é bastante eficiente, embora sua confecção envolva processos complexos.

\subsection{Partes mecânica, óptica e eletrônica}

\subsubsection{Discos de Plácido e sistema óptico}

\section{Construção e testes preliminares do projetor}

Este projetor é formado basicamente por três cones e uma estrutura de acoplamento dos cones ao iluminador de fibras ópticas. Os cones e esta estrutura são confeccionados em acrílico translúcido. A rosca do sistema de acoplamento do projetor na objetiva é feita em alumínio. Os cones foram usinados na Oficina Mecânica do IFSC. $\mathrm{Na}$ figura 3.4 (esquerda) podemos ver as peças depois de usinadas e polidas. 

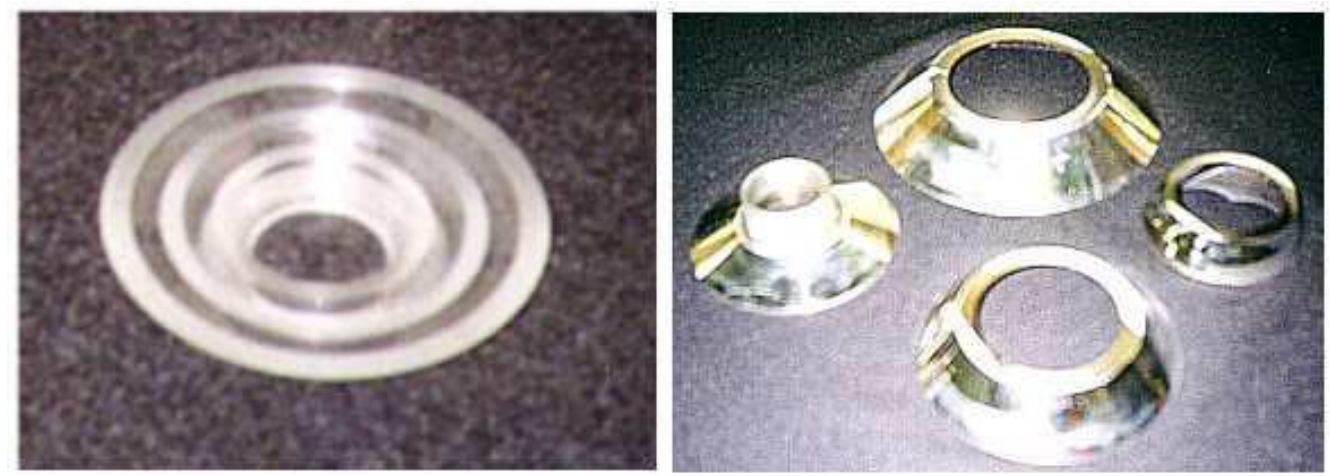

Figura 3.4. (esquerda) Cones em acrílico do primeiro projetor depois de usinados e polidos no torno da Oficina Mecânica-IFSC-USP; (direita) as várias peças que compõem parte do projetor.

Após a etapa de usinagem e polimento, as faces dos cones foram espelhadas na evaporadora. Isto garante que a luz proveniente do iluminador será transmitida pelo interior dos cones como se estes fossem enormes fibras ópticas. Isto evita perdas de luz e promove aumento na intensidade dos anéis. O processo de espelhamento foi realizado na evaporadora da Oficina de Óptica do IFSC. Nesta etapa nos deparamos com

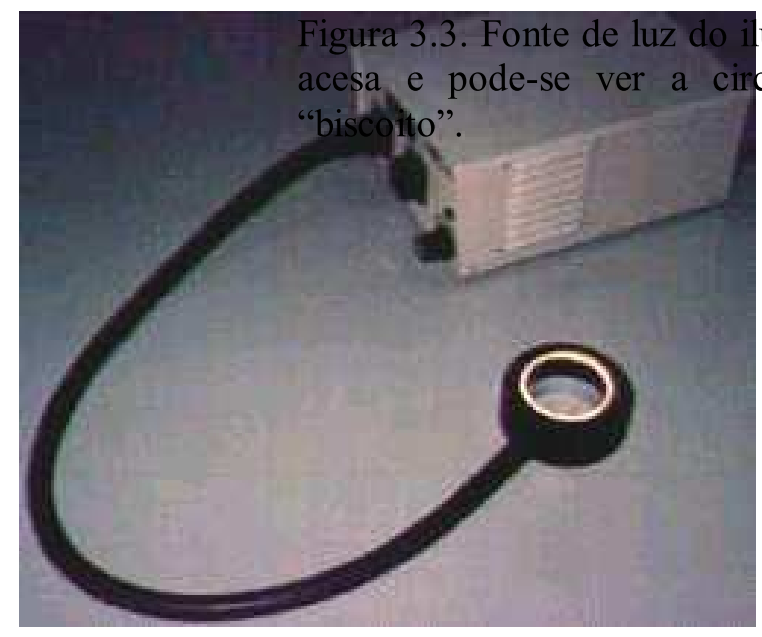

uminador conectada ao cabo de fibras ópti cunferência de luz formada na estrutur:

problemas no processo de evaporação. Durante a deposição, a má regulagem da evaporadora resultava na oxidação do espelhamento no lado em contato com a face dos cones. Nas três tentativas que fizemos ao longo de algumas semanas o espelhamento pelo lado de fora do material tinha a aparência esperada, mas do lado em contato com a face polida percebia-se nitidamente um tom bastante amarelado. Fizemos medidas de intensidade de luz saindo dos cones espelhados e constatamos que estavam menos intensas do que antes do espelhamento. 
Para contornar este problema enquanto fazíamos outros testes de deposição, utilizamos papel alumínio como substituto para o espelhamento. E depois cobrimos as faces forradas com papel alumínio e cartolina preta. Na figura 3.4 (direita) podemos ver os cones e a peça de acoplamento, depois de espelhados.

Acoplamos este primeiro modelo do projetor num microscópio SM 2000 da Opto Eletrônica (endereço na internet: www.opto.com.br) (veja figura 3.5). Para simulação da superfície da córnea foram usadas esferas de calibração (feitas em vidro). E uma maca foi instalada no laboratório para os primeiros testes in vivo.

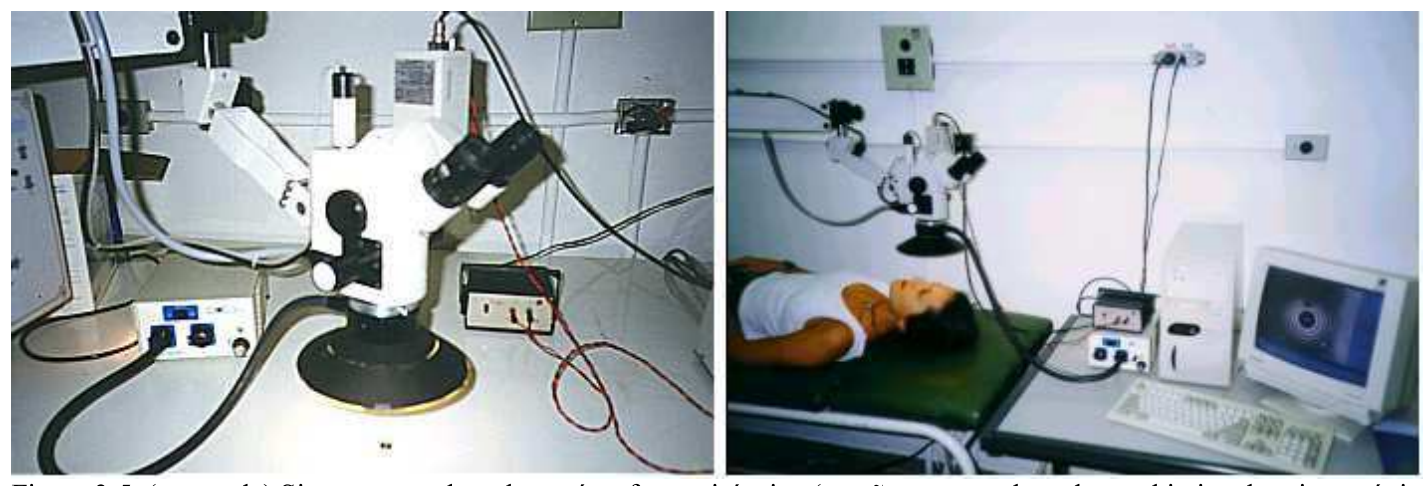

Figura 3.5. (esquerda) Sistema completo do topógrafo percirúrgico (versão que acopla na lente objetiva do microscópio cirúrgico). Ao centro podemos ver o microscópio cirúrgico. Sua estrutura é suspensa por um braço móvel que está preso a um eixo. O eixo acopla-se a uma base com rodinhas, as quais permitem a locomoção do microscópio. À esquerda do microscópio está a fonte do iluminador de fibras ópticas. O cabo com mais de 15000 fibras ópticas sai da fonte e termina na cabeça do iluminador. O iluminador por sua vez está preso entre o projetor e a rosca em alumínio. Esta rosca prende todo sistema do projetor na objetiva do microscópio. Por trás do microscópio e acima podemos ver a câmera CCD acoplada no "beam-splitter" (divisor de feixe). O sinal do CCD é enviado à placa de aquisição instalada num PC-IMB compatível que não está sendo mostrado. A pequena caixa do lado direito do microscópio é a fonte construída para alimantar a câmera CCD. Logo abaixo dos cones do projetor está uma das esferas de vidro, quase imperceptível; (direita) disposição geral do sistema para testes in vivo. Pode-se ver: à esquerda — "paciente" deitado na maca, braço e cabeça do microscópio com projetor acoplado; ao centro — fonte da câmera e do projetor, gabinete vertical do computador; à direita — monitor com imagem em tempo real dos Discos de Plácido.

O processo de construção do primeiro projetor é bastante demorado e caro pois exige etapas longas de usinagem, polimento e espelhamento. Criamos um outro projetor de construção mais simples e tão eficiente quanto o primeiro (figura 3.6), via usinagem de anéis num bloco único de acrílico. O processo consiste basicamente na usinagem de uma peça cônica, mas desta vez maciça. Depois pinta-se a superficie em branco e na seqüência em preto. Após a secagem a peça volta para o torno e então são usinados cada

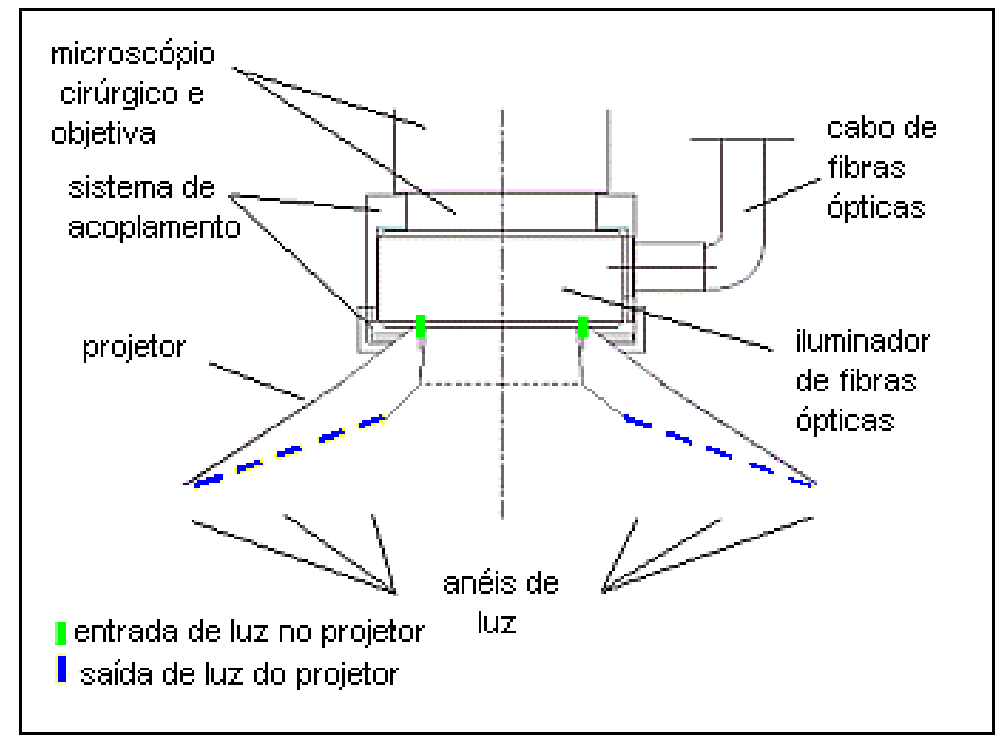

Figura 3.6. Projetor de anéis construído a partir de uma única peça. A luz que sai do iluminador (verde) caminha por dentro do acrílico e reflete nas superfícies internas, até sair pela região onde a tinta foi desbastada (azul). 
um dos Discos de Plácido, através do desbaste da camada de tinta. Este processo se mostrou muito mais econômico pois é feito a partir de uma única peça, não necessita de evaporadora para espelhamento, e permite a usinagem de diferentes quantidades de anéis com diferentes espessuras.

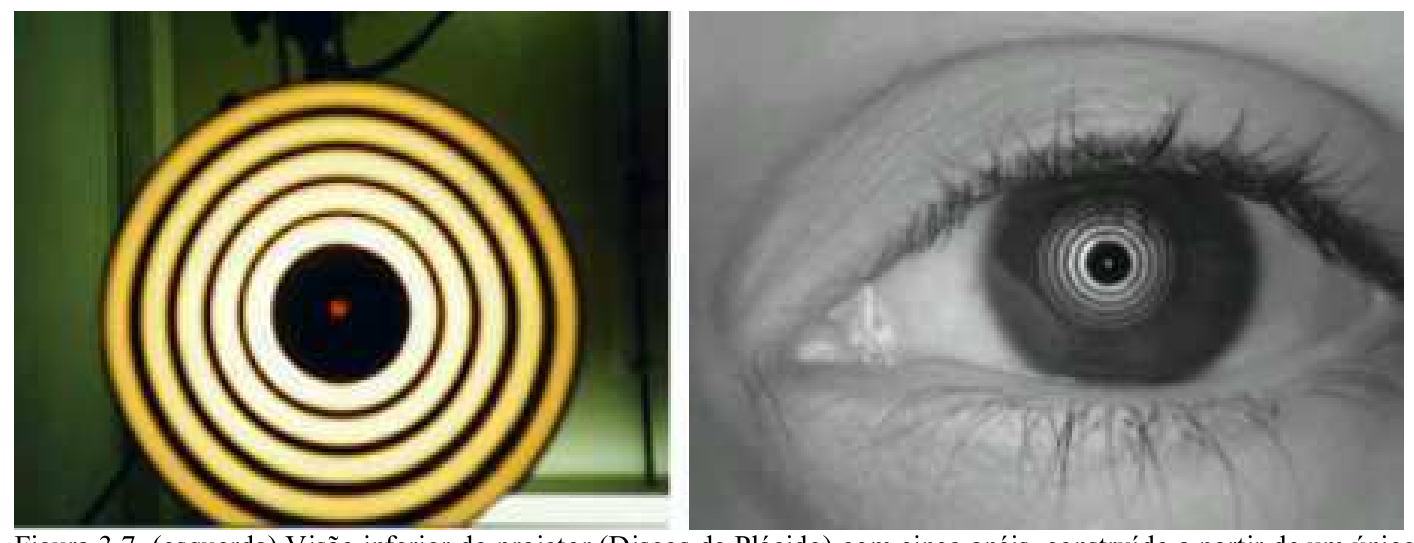

Figura 3.7. (esquerda) Visão inferior do projetor (Discos de Plácido) com cinco anéis, construído a partir de um único bloco de acrílico; (direita) Fotografia digitalizada da córnea de um voluntário submetido a testes com este projetor.

Mais adiante, na seção 3.2, mostramos o processamento das imagens obtidas com estes projetores. Em termos gerais, a qualidade das imagens obtidas por ambos projetores permite a detecção das bordas dos anéis por parte do "software".

\section{Versão independente do microscópio}

Construímos também uma versão independente da óptica e mecânica do miscroscópio cirúrgico. As possíveis vantagens de um sistema como este são a independência das dimensões e da marca do miscroscópio, do tipo de óptica (ou seja, se existe divisor de feixes e se é possível encaixar um adaptador). Por outro lado ocupa muito mais espaço (veja figura 3.8) na sala de cirurgia. O sistema tem uma base de alumínio que suporta toda a parte eletrônica e de motores para controle dos micromovimentos do braço. Ao final do braço acoplamos o sistema óptico do projetor e da câmera CCD. Com este sistema o médico fica a maior parte do tempo sem intervenção do ceratógrafo. Quando decide fazer uma medida, puxa o braço do sistema e depois faz o ajuste fino via "software" ou um sistema de pedais. 


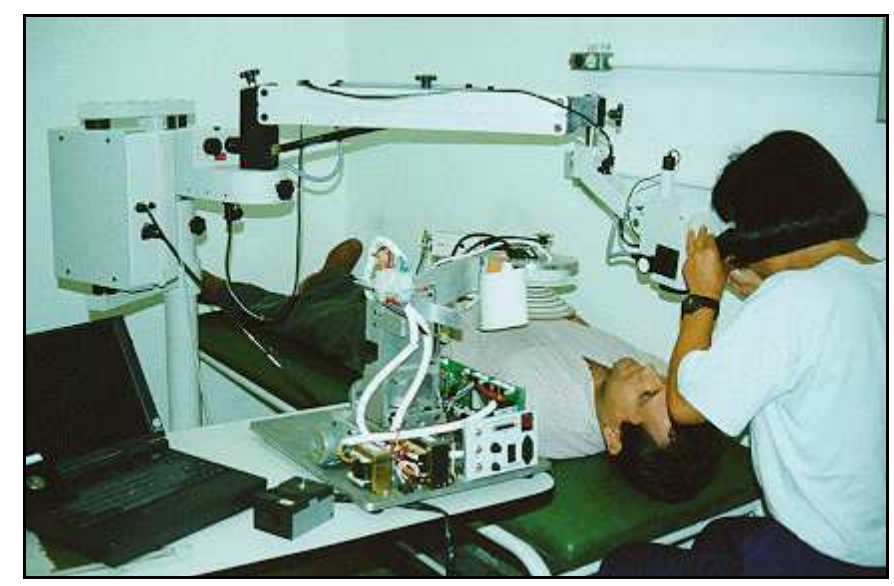

Figura 3.8. Ceratógrafo percirúrgico com base fixa e braço móvel. O projetor e parte óptica são independentes do microscópio, podendo ser utilizados em momentos específicos durante a cirurgia. O projetor de anéis é parecido com aquele da figura 3.6, mas utiliza uma lâmpada alógena em forma de biscoito, localizada atrás do cone.

\subsubsection{O Computador, periféricos e câmera CCD}

O computador utilizado no sistema é um IBM compatível com processador Pentium II Intel de $300 \mathrm{MHz}$. O sistema operacional utilizado é o Microsoft Windows 95 e como ferramenta de programação utilizamos o Delphi 3.0 da Borland (endereço na internet: www.borland.com), cuja linguagem de programação é o Pascal (para maiores informações sobre algoritmos e a linguagem Pascal favor consultar [31]); e o Matlab (www.mathworks.com) para simulações de modelos da córnea.

Durante o período de mestrado, utilizamos uma placa de captura de imagens bastante limitada (modelo RT300 da Creative Labs (endereço na internet: www.empresa que fabrica placas de circuito impresso para trabalhar com som e imagens em microcomputadores)). Permitia a captura de imagens somente com baixa resolução (320x240 pixels, 16 bits-colorido) e transmitia somente 15 quadros por segundo (do inglês, FPS- "frames per second"). Portanto esta placa não permitia transferência em tempo real, a qual se caracteriza a partir de 24 FPS. Este fator limitante dificultava muito o processo de focalização das imagens. As mudanças nas imagens não eram imediatamente enviadas para a tela do monitor. Para solucionar este problema, desde o 
início do doutorado passamos a utilizar uma placa de aquisição mais versátil. Esta placa é o modelo Meteor da fabricante canadense Matrox (endereço na internet: www.matrox.com). Ela tem características específicas para desenvolvimento e pesquisa na área de processamento de imagens. Captura imagens de alta resolução (-até 32 bitstrue color), com transferência em tempo real (30 FPS ou superior) e tem um custo relativamente baixo.Utilizamos uma câmera CCD marca LG, monocromática modelo GC135E-A-G, com resolução 640x480.

\subsection{Digitalização e processamento de imagens}

Em trabalhos do grupo na área de topografia convencional (não percirúrgica) [32-34], foram implementados algoritmos para detecção de bordas de vários anéis [35] (total de 8 anéis, 16 bordas para cada semi-meridiano, 32 bordas para cada meridiano). No entanto, o projetor utilizado é de natureza diferente. As imagens refletidas pela córnea (ou pelas esferas teste) têm características como intensidade, contraste, número de anéis e bordas, entre outros, diferentes daquelas do projetor anelar percirúrgico.

Para implementar tais mudanças foram realizados diversos testes preliminares com as imagens. O histograma (número de pixels versus intensidade de nível de cinza) das imagens indica claramente alguns fatores importantes (figura 3.9). Os picos de intensidade próxima do branco (256) correspondem aos anéis e os picos próximos do preto (0) correspondem ao fundo da imagem. Analisando histogramas de várias imagens, para diferentes níveis de iluminação, pode-se chegar a valores médios dos picos correspondentes aos anéis e ao fundo. Estes valores são importantes para as modificações no algoritmo de detecção. Em seguida, foram usados algoritmos de uso comum em processamento de imagens [36], como binarização (transormação dos 256 níveis de cinza em 2 níveis - preto e branco, detectores de bordas como Sobel, Roberts, Gradiente). Estes algoritmos permitem uma analise preliminar das características das bordas nos anéis (figura 3.10). Fornecem os parâmetros para otimização da detecção de borda).

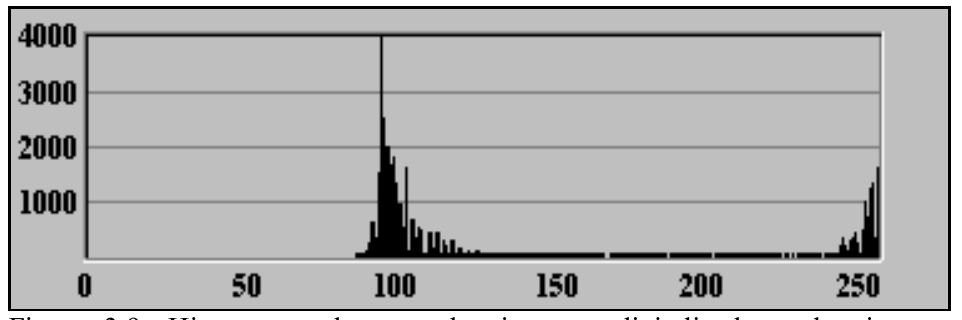

Figura 3.9. Histograma de uma das imagens digitalizadas pelo sistema. Observa-se claramente um padrão em torno do cinza escuro $(\sim 100)$, referente ao fundo, e um outro em torno do branco $(\sim 250)$, referente aos anéis. 
Se estes algoritmos gerais e preliminares não evidenciassem as bordas, certamente teríamos que fazer mudanças no projetor. Na figura 3.10 podemos ver que as bordas ficaram bastante nítidas após a aplicação destes filtros generalizados. Isto indicou que estávamos em condições de realizar a detecção de bordas com nosso

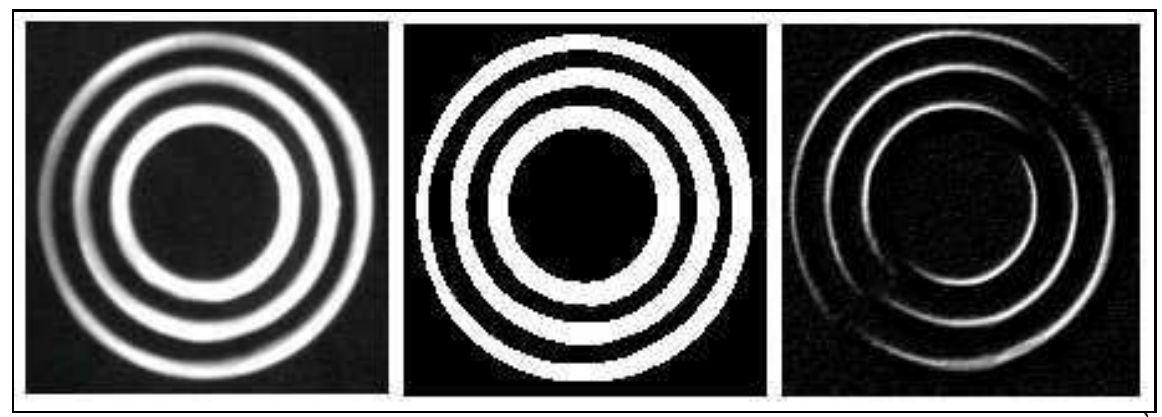

Figura 3.10. Exemplo de alguns processamentos preliminares para análise das bordas. A esquerda temos a imagem original. Ao centro a imagem "binarizada" (dois níveis de cinza preto e branco) e à direita utilizamos o detector de borda Sobel [36]. Cada filtro aplicado na imagem nos fornece informações importantes. Estas informações são utilizadas para realizar as modificações no algoritmo de detecção de bordas.

algoritmo. A seguir descrevemos como funciona este algoritmo e em seguida mostramos os resultados para as imagens.

No momento de implementar um algoritmo específico para detecção de bordas, duas questões são essenciais: (1) quais os dados extraídos das imagens que são utilizados pelos modelos matemáticos da topografia da córnea?; (2) qual a velocidade de processamento necessária? No caso da primeira questão, como veremos mais adiante, a maioria dos modelos matemáticos utiliza os valores das bordas da seguinte maneira: partindo-se da região central percorre-se a imagem radialmente para 360 graus, de um em um grau. Para cada ângulo calcula-se a distância radial da borda até o centro. Sendo assim, para cada ângulo temos um conjunto de $n$ distâncias de borda (onde $n$ é igual ao número de discos de Plácido vezes dois, pois cada disco tem duas bordas, uma interna e outra externa). Estas distâncias são armazenadas numa matriz bidimensional (angulo versus anel; observação: na nomenclatura que estamos usando cada Disco de Plácido tem dois anéis (bordas)) e depois inseridas nos algoritmos dos modelos matemáticos de topografia. No caso da segunda questão, para instrumentos de topografia as medidas têm que ser rápidas, especialmente as percirúrgicas. Durante a cirurgia o médico está ocupado com diversos instrumentos. Não seria conveniente que ficasse esperando o resultado da topografia. $\mathrm{O}$ processamento tem que ser extremamente rápido, na ordem de segundos.

$\mathrm{Na}$ figura 3.11(b) temos uma imagem capturada num instrumento convencional (não percirúrgico) desenvolvido em nosso laboratório [32-35]. Na figura 3.11 (a) podemos ver a imagem deste instrumento, hoje fabricado pela empresa Eyetec Equipamentos Oftálmicos (endereço na internet: www.eyetec.com.br). Inicialmente são realizadas duas varreduras, uma no eixo x (horizontal) e outra no eixo y (vertical), passando pela região central da córnea. Assim, determina-se um ponto dentro do anel central. A partir deste ponto e da borda interna deste primeiro anel, determina-se o centro geométrico desta primeira borda. Este será o ponto de referência no momento de se calcular as distâncias radiais para cada borda. 


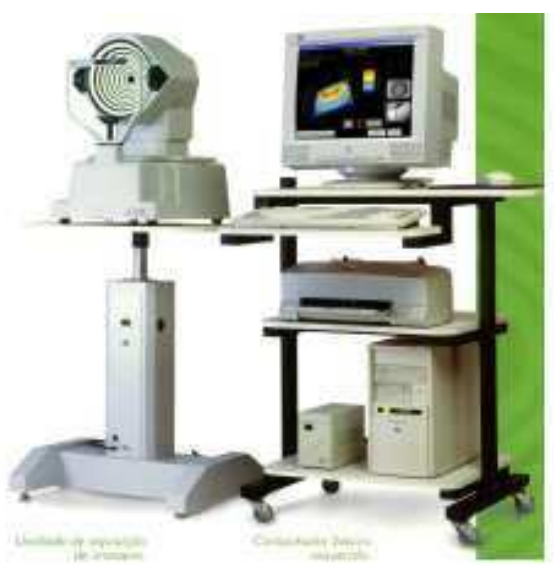

(a)

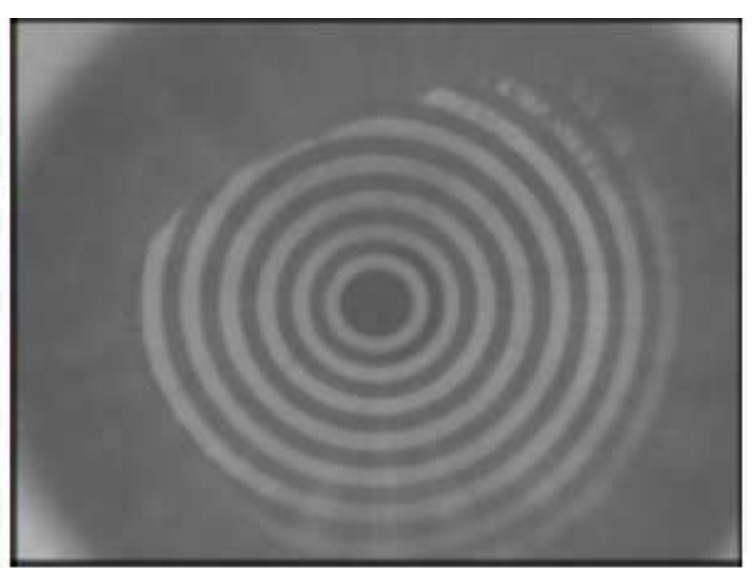

(b)

Figura 3.11. (a) Topógrafo de córnea convencional desenvolvido no Laboratório de Óptica Oftálmica do IFSC e hoje produzido pela Eyetec Equipamentos Oftálmicos; (b) imagem do reflexo dos Dicos de Plácido digitalizados neste equipamento.

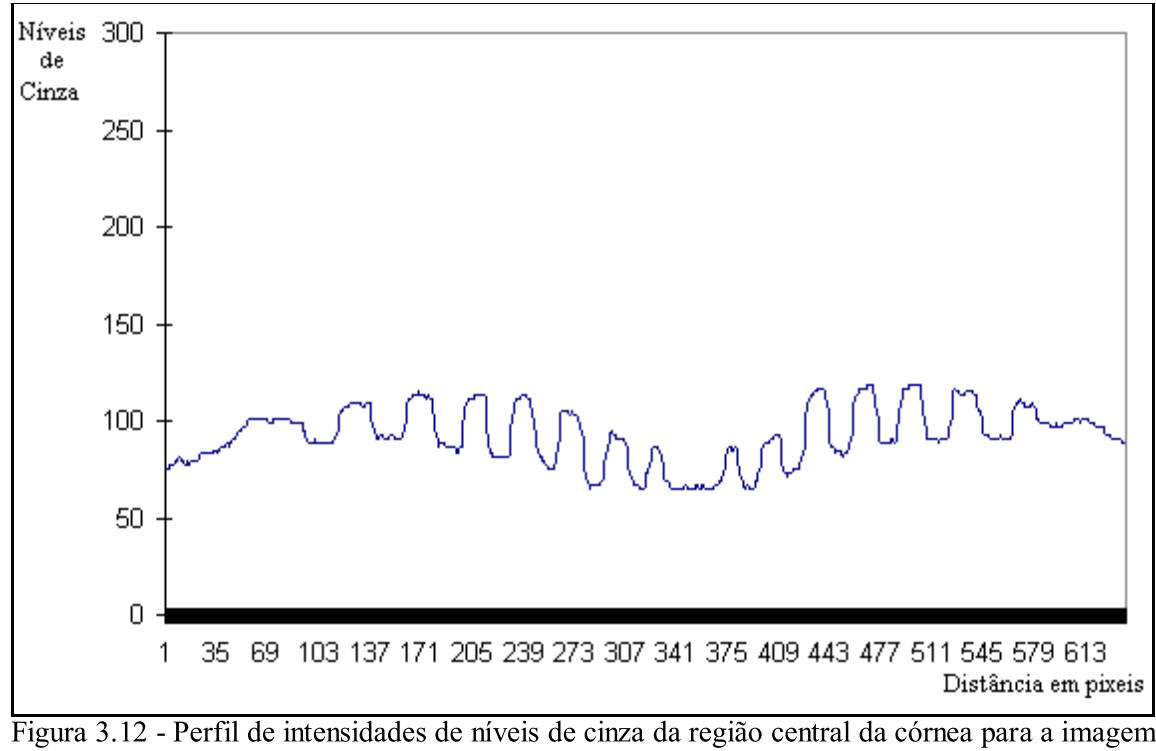

3.11(b), para todo meridiano a 90 e 270 graus.

O princípio básico da detecção das bordas pode ser visto na figura 3.12. Partindo do ponto central de referência, percorre-se a imagem radialmente para cada um dos 360 ângulos e para cada meridiano imprime-se um gráfico de intensidade de cinza versus posição.

Para a determinação das bordas dos anéis, calcula-se a derivada ponto a ponto neste gráfico. Entretanto, para evitar a presença de ruídos faz-se uma suavização dos pontos, de acordo com a equação abaixo:

$$
I(\text { dist })=0.5 * I(\text { dist })+0.25 *(I(\text { dist }+1)+I(\text { dist }-1))
$$

onde $I($ dist $)$ corresponde à intensidade do ponto de distância dist. 
Para melhor expor a metodologia, na figura 3.13 apresentamos a detecção do contorno dos anéis. A linha 1 mostra as derivadas positivas, pintadas em amarelo, e na linha 2 as derivadas negativas, cor vermelha.

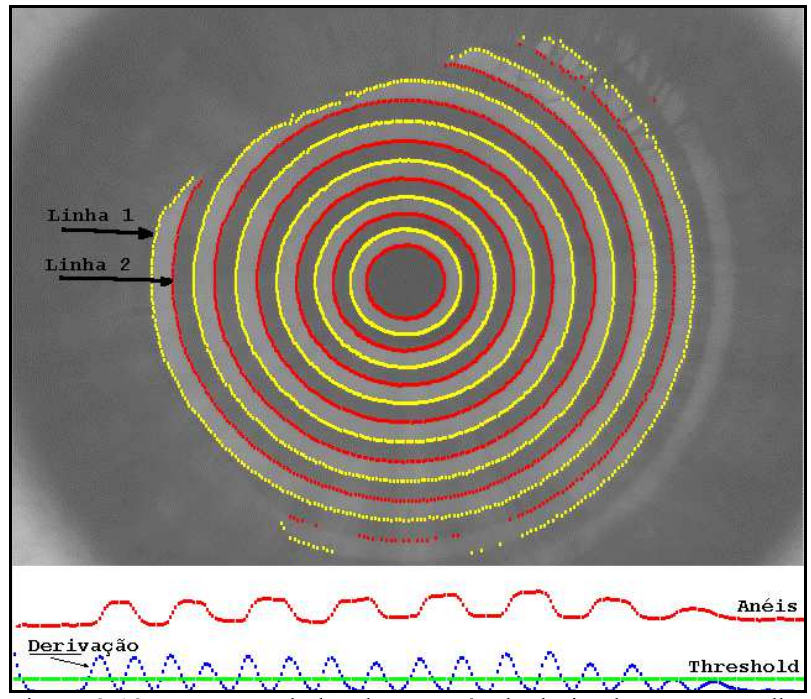

Figura 3.13. Detecção de bordas através da derivada. Em vermelho temos o perfil do nível de cinza para um dos meridianos (análogo ao da figura 8, mas com suavização). Em azul temos o módulo da derivada ao longo do perfil. Em verde temos o limiar, ou seja, o nível de cinza que vamos considerar para as bordas. A intersecção entre verde e azul fonece todos os pontos de borda para o meridiano.

Após a extração do módulo da derivada, aplica-se um "threshold" (limiar) para limitar a quantidade de dados e evitar ruídos. Assim, com esse algoritmo obtém-se a localização das bordas dos anéis com precisão.

Aplicamos esta mesma metodologia nas imagens obtidas com o primeiro projetor anelar percirúrgico, com algumas variações no algoritmo. Os resultado para a esfera de raio $8.91 \mathrm{~mm}$ pode ser visto na figura 3.14 . 


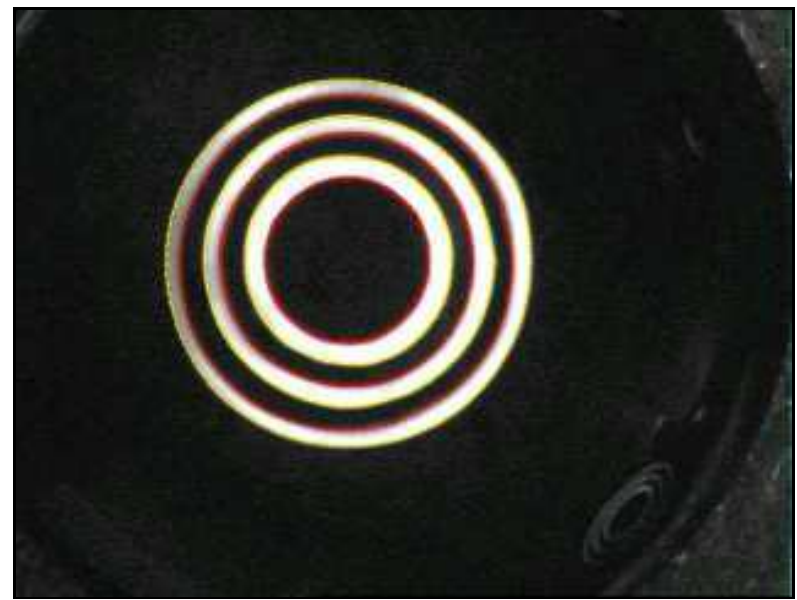

Figura 3.14. Resultado do algoritmo para detecção de bordas para a esfera de $8.91 \mathrm{~mm}$ de raio. Observe que todas as bordas foram detectadas sem problemas de ruído. Para as outras esferas e olhos o resultado foi análogo. Para o segundo projetor, com 5 Discos de Plácido, o resultado foi análogo.

\subsection{Algoritmos para ceratografia}

\subsubsection{Diferentes parâmetros relacionados à córnea e a importância de cada um}

Inicialmente vamos descrever, com auxílio da figura 3.15, o que cada um dos métodos matemáticos para topografia de córnea mede. O chamado modelo Axial (figura 3.15 (a)) interpola cada ponto da superfície da córnea pela melhor esfera com centro sobre o eixo óptico; já o modelo Tangencial (figura 3.15 (b)) mede a curvatura real (instantânea) naquele ponto, logo o raio de curvatura não necessariamente está centrado sobre o eixo óptico; o modelo refrativo procura simular na córnea a refração dos raios de luz usando a Lei de Snell (figura 3.15 (c)). Podemos ver na figura 3.15 (d, e, f) que o modelo de elevação (topografia de córnea propriamente dita) mede as elevações reais de cada ponto da superfície, e pode ser relativo a três superfícies: um plano (d), uma esfera maior que a córnea (e) e uma esfera menor que a córnea (f). 


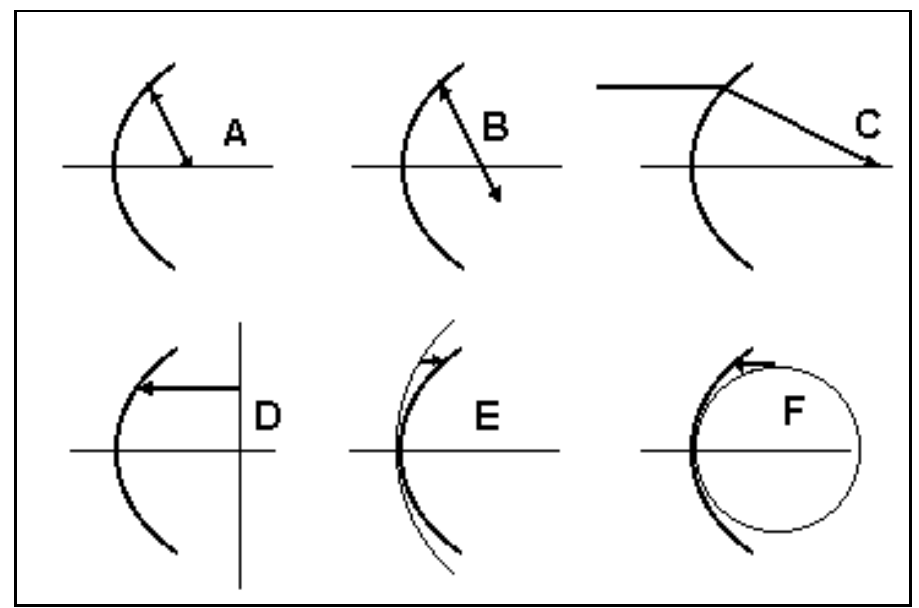

Figura 3.15. Os diferentes modelos para descrição da superfície da córnea. Cada um tem vantagens e desvantagens no momento de se avaliar a qualidade óptica da córnea. Uma análise detalhada destes fatores foi feita por Salmon [37] e Klein [38].

Cada um destes modelos exige cálculos e algoritmos diferentes. A seguir vamos apresentar os algoritmos desenvolvidos para cada modelo.

\subsubsection{Cálculos matemáticos e algoritmos}

O estudo da topografia da córnea tem sido feito por diversos pesquisadores [1226]. Não é uma tarefa simples, pois a córnea não é comparável a nenhum material sintético conhecido, portanto não sabemos as relações entre as diferentes tensões superficiais e os possíveis formatos que a córnea pode assumir, tornando extremamente difícil qualquer tipo de previsão. A seguir, faremos uma descrição detalhada, com deduções matemáticas, dos vários modelos para descrição da superfície da córnea. Ao final da tese temos um apêndice com deduções de algumas fórmulas mais complexas.

\section{Modelo do Espelho Convexo Esférico (Axial)}

Um dos primeiros métodos, e também o mais simplificado deles, considera a superfície anterior da córnea como sendo esférica e especular, ou seja, comportando-se como um espelho convexo esférico. Trata-se do princípio de Helmholtz [3] e aplica-se com maior freqüência a instrumentos como o ceratômetro ou projetores de apenas um anel (como no projeto de mestrado). Da óptica geométrica elementar, sabe-se muito bem como se comportam os raios incidentes numa superfície com estas características e pode-se calcular, fazendo-se algumas aproximações, o raio de curvatura (veja Capítulo II, página 19).

Durante o mestrado este método também foi implementado com aproximações mais precisas [10], diferentes daquelas descritas na página 19 do Capítulo II. Sabendose que para um espelho esférico $f=2 R$, obtivemos a seguinte expressão para o raio de curvatura (veja parâmetros da equação na página 19 do capítulo II): 


$$
R=2 f=\frac{2 S h^{2}+2 h H \sqrt{S^{2}+H^{2}-h^{2}}}{\left(H^{2}-h^{2}\right)}
$$

Após este modelo simplificado, o que tem sido feito com freqüência são desenvolvimentos de modelos matemáticos para projetores com vários Discos de Plácido. Nestes modelos, tenta-se achar curvas algébricas que possam se aproximar do contorno da córnea. Os primeiros modelos consideravam que os contornos poderiam ser aproximados por semicircunferências. Isto significa que se fizéssemos cortes na córnea com planos que contivessem o eixo óptico, poderíamos traçar segmentos circulares que aproximassem as interseções destes planos com a córnea.

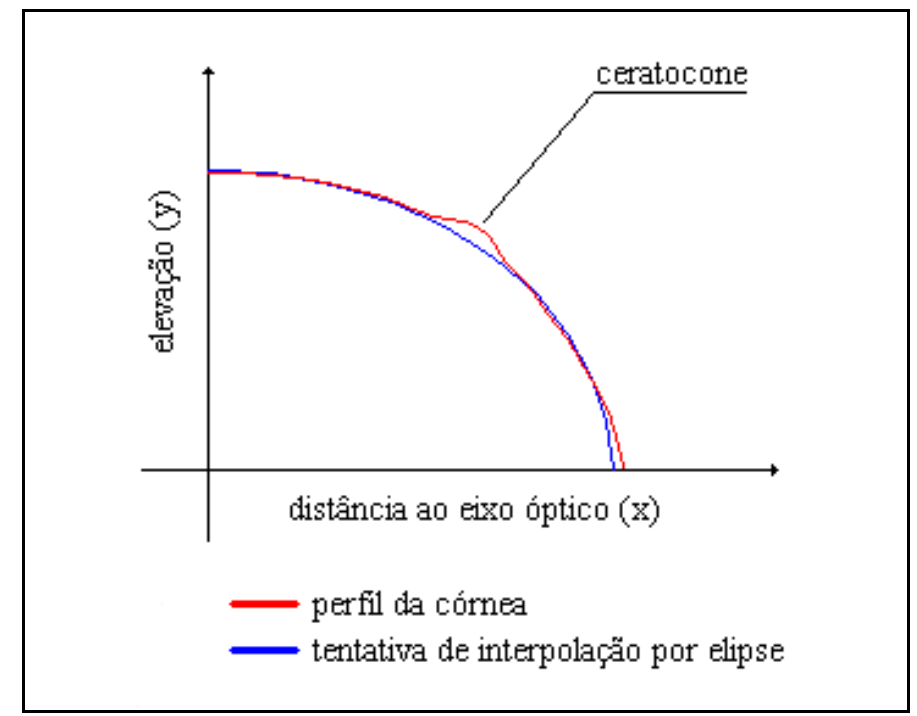

Figura 3.16. A elipse consegue descrever somente o contorno de córneas que tenham curvaturas muito suaves.

\section{Modelo Elíptico}

Sabe-se hoje que a simplificação do modelo esférico tem somente bons resultados para regiões centrais de córneas com poucas irregularidades. Em direção à periferia os erros aumentam. Descobriu-se que a maior parte das córneas tende a se achatar na periferia [20]. Outros modelos matemáticos foram desenvolvidos para tentar levar este achatamento em consideração, originando a idéia de se aproximar o contorno por elipses [18]. Através do ajuste da excentricidade e do raio apical das elipses, tentase achar a melhor elipse para cada semimeridiano. Obtidas as melhores curvas calculase a dioptria associada a cada ponto.

Um dos problemas do modelo elíptico surge quando aplicado a córneas com altas curvaturas localizadas, cujo caso mais típico é o ceratocone. A figura 3.16 ilustra o que acontece. Como pode ser visto pelo contorno azul, a elipse não consegue acompanhar o "cone" local que existe na córnea com ceratocone (contorno vermelho). Portanto a aplicação deste modelo em qualquer córnea que não tenha contornos suaves acarretará erros que podem chegar a várias dioptrias. Num trabalho recente de nosso laboratório [35], implementamos o modelo elíptico sugerido por Mammone et. al. [18] e comprovamos a ineficiência deste método para córneas com ceratocone. 


\section{Modelo com Utilização de Parâmetros de Esferas de Calibração (Axial)}

Outro método para calcular o raio de curvatura axial é baseado em esferas de calibração (em parte descrito por Halstead et. al. em [25]). O princípio de funcionamento é basicamente o seguinte: várias esferas de vidro (normalmente são quatro) de raios conhecidos são colocadas em um suporte e as bordas das imagens são processadas e armazenadas no computador. Quando se quer medir uma córnea, os parâmetros da imagem desta córnea são comparados com aqueles das esferas e o raio de curvatura de cada ponto da córnea é calculado. Em termos gerais, é como se a cada ponto sobre um anel na imagem refletida pela córnea correspondesse uma esfera cujo valor do raio deve estar entre o menor e maior raio das esferas de calibração. $O$ algoritmo para este método, muitas vezes chamado de modelo axial, é apresentado a seguir (obs: incluímos o algoritmo resumido a seguir somente por motivos de complementação, pois a explicação detalhada deste modelo é exposta na página 50 deste capítulo, em Algoritmos para o Modelo Axial ):

Algoritmo. Considere um conjunto $\left\{S_{k}: k=1 \ldots n\right\}$, de $n$ esferas de calibração com raio $R_{k}, K=1 \ldots n$, onde $R_{k}<R_{k+1}$. Devido à simetria, uma esfera alinhada com o eixo do videoceratômetro gera uma imagem na qual as curvas $C_{1}, \ldots, C_{16}$ são circulares. Considere o raio da curva $C_{j}$ gerado pela esfera $S_{k}$ como $c_{k}^{j}$. Considere os pontos $p_{i}^{j}, i=1 . .360, j=1 . .16$ pertencentes a uma imagem arbitrária. Calcule $h_{i}^{j}$, a distância entre $p_{i}^{j}$ e o centro estimado das curvas. Para cada $h_{i}^{j}$ para o qual existe um l tal que $h_{i}^{j}$ esteja no intervalo $\left[c_{l}^{j}, c_{l+1}^{j}\right]$, calcule $\alpha$ tal que $h_{i}^{j}=(1-\alpha) c_{l}^{j}+\alpha \cdot c_{l+1}^{j}$. Então o valor do raio $r_{i}^{j}$ correspondente ao ponto $p_{i}^{j}$ da imagem em questão é dado por $(1-\alpha) R_{l}+\alpha \cdot R_{l+1}$.

O algoritmo acima está intimamente relacionado com o modelo esférico visto anteriormente. Vamos mostrar isto em seguida:

Da equação válida para o modelo esférico com aproximação:

$$
R=\frac{2 S}{H} h
$$

e de acordo com o algoritmo sempre vai ser possível encontrar um $\alpha$ tal que

$$
h_{i}^{j}=(1-\alpha) c_{l}^{j}+\alpha \cdot c_{l+1}^{j}
$$

Dado que o R na equação (3.3) é equivalente ao $r_{i}^{j}$ do algoritmo, podemos escrevê-la como:

$$
r_{i}^{j}=\frac{2 S}{H} h_{i}^{j}
$$

e, segundo a definição de $c_{l}^{j}$ e $c_{l+1}^{j}$ podemos também escrever 


$$
\begin{gathered}
R_{l}=\frac{2 S}{H} c_{l}^{j} \\
R_{l+1}=\frac{2 S}{H} c_{l+1}^{j}
\end{gathered}
$$

isolando $c_{l}^{j}, c_{l+1}^{j}$ e $h_{i}^{j}$ das equações acima e substituindo em (3.6) obtemos

$$
r_{i}^{j}=(1-\alpha) R_{l}+\alpha \cdot R_{l+1}
$$

que é exatamente a equação exposta no algoritmo.

Uma das críticas que se faz a este modelo é a sua imprecisão para medir córneas numa região de diâmetro maior que $6 \mathrm{~mm}$ [39]. Apesar desta limitação, acreditamos que, dos modelos estudados, seria este o mais interessante de se implementar. O motivo disto é o fato de que nosso sistema permite a análise de regiões centrais de não mais que $6 \mathrm{~mm}$ em diâmetro. Nestas regiões este modelo aplica-se bem para a maioria das córneas. Além disso, baseado no algoritmo deste modelo, sabe-se que o custo computacional é pequeno. Isto significa que seria possível obter mapas topográficos durante a cirurgia na ordem de segundos. Como mencionado anteriormente, este é um fator crítico durante a cirurgia.

\section{Modelo Tangencial}

Este modelo foi originalmente proposto por por Doss et. al. [21] e depois aprimorada por Wang et. al. [22] e van Saarlos et. al. [23]. Trata-se de um modelo que, ao contrário dos anteriores, não faz pressuposição a respeito da curva que melhor descreve o contorno da córnea. Aliás, como veremos, o modelo é independente de qualquer curva analítica. É implementado através de um processo iterativo utilizando uma equação recursiva, ou seja, cujo valor de profundidade $y$ para um certo ponto depende do anterior. Tal equação foi deduzida traçando-se arcos circulares entre os pontos refletidos dos anéis e fazendo o valor da tangente em cada um destes pontos coincidir (veja dedução desta equação no apêndice):

$$
y_{i}=y_{i-1}-\frac{\left(x_{i-1}-x_{i}\right)\left(\cos t_{i-1}-\cos t_{i}\right)}{\operatorname{sent}_{i-1}-\operatorname{sent}_{i}}
$$

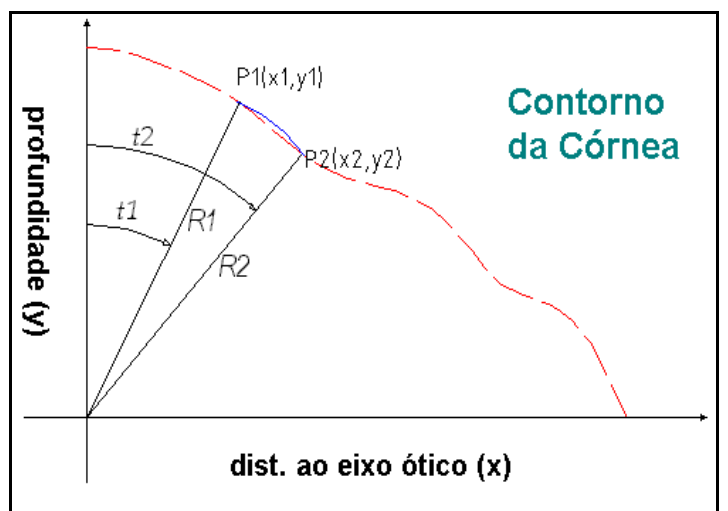

Figura 3.17. Traçando arcos para descrever uma superfície desuniforme. 
Estas grandezas estão representadas na figura 3.17. O coeficiente $i$ refere-se ao ponto do anel considerado $\left(\mathrm{P}_{i}\right), y$ é a altura da superfície da córnea, $x$ é a distância até o eixo óptico e $t$ é o ângulo entre $R_{i}$ e o eixo $y$.

Pela equação recursiva necessitamos sempre da coordenada $x, y$ de um ponto para poder calcular aquela correspondente ao ponto posterior. Vamos fazer uma análise da

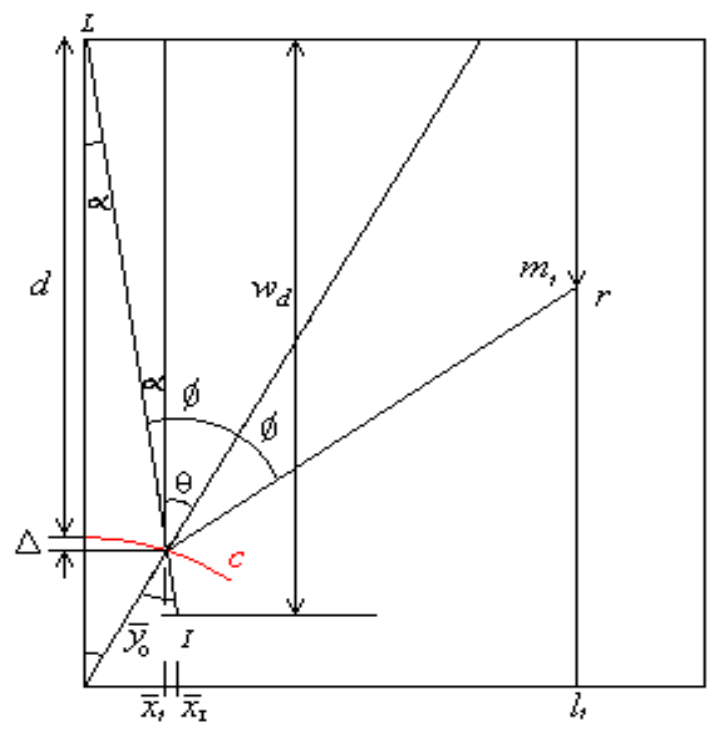

Figura 3.18. Geometria óptica utilizada por van Saarlos para calcular a curvatura média da região apical da córnea.

óptica geométrica envolvida neste caso para que possamos calcular um primeiro valor para o par $\left(x_{i}, y_{i}\right)$, com $i=0$. A figura 3.18 mostra o caminho óptico e as distâncias consideradas para este modelo: $r$ é um dos pontos do projetor anelar, distando $m_{1}$ do plano da lente $L$. Um raio de luz, proveniente de $r$ incide na córnea $C$ e é refletido em direção à lente $L$ (considerada aqui como pontual). $\bar{y}_{0}$ é a grandeza que estamos querendo determinar, ou seja, o raio para a região central, para que a partir dele possamos calcular os outros valores. $w_{d}$ é a distância focal da lente, $\Delta$ é a distância sagital, $\bar{x}_{1}$ e $\bar{x}_{I}$ são as distâncias do ponto de incidência na córnea e da imagem $I$ formada, respectivamente. Utilizando equações simples da geometria, baseadas na figura 3.18, obtém-se uma equação para $\bar{y}_{0}$ em função de todos esses parâmetros descritos (veja dedução no apêndice):

$$
\bar{y}_{0}=\frac{\bar{x}_{1}}{\sin \left\{\frac{1}{2}\left[\tan ^{-1}\left(\frac{l_{1}-\bar{x}_{1}}{d+\Delta-m_{1}}\right)-\tan ^{-1}\left(\frac{\bar{x}_{I}}{w_{d}}\right)\right]\right\}}
$$

Estima-se um valor inicial de $\bar{y}_{0} \approx 7,8 \mathrm{~mm}$. Sem muita perda na precisão, podemos fazer $\Delta=0$ e $d=w_{d}-7,8 / 2$ na equação (3.12). $\bar{x}_{I}$ é obtido da imagem digitalizada e $\bar{x}_{1}$ é calculado através das equações:

$$
\tan \alpha=\frac{\bar{x}_{I}}{w_{d}}
$$




$$
\bar{x}_{1}=(d+\Delta) \tan \alpha
$$

Calculam-se os pares ordenados $\left(x_{0}, y_{0}\right)$ para os 360 semi-meridianos, fazendo $x_{0}$ sempre igual a zero, para depois chegar a um valor médio de $\bar{y}_{0}$, o qual será utilizado na equação de recorrência para dar início aos cálculos da curvatura para cada semimeridiano. van Saarlos simulou computacionalmente uma superfície cujo contorno é descrito por um polinômio de quinto grau e, através de técnicas de "ray tracing" (traçado de raio: técnica comum utilizada em projetos ópticos), obteve o padrão da imagem que seria refletida por tal superfície. Aplicou os cálculos que acabamos de descrever e obteve erros menores que $0,01 \mathrm{~mm}$. Este método não foi utilizado pelos autores para construir mapas topográficos da córnea, mas desenvolvido originalmente para aplicação no Fotoceratoscópio (veja capítulo II, página 12).

\section{Modelos Tangencial (mais simples e eficiente que o anterior), Refrativo, Elevação} Relativa

Mostramos até aqui algoritmos para cálculo de curvatura Axial e instantânea (Tangencial), poder refrativo convencional (usando a fórmula do ceratômetro e o raio de curvatura axial para cálculo do poder dióptrico (equação 1.1, capítulo I). Vamos aqui apresentar mais dois métodos de quantificação da superfície da córnea que podem, juntamente com aqueles já apresentados, auxiliar no diagnóstico.

O modelo tangencial apresentado anteriormente envolve vários cálculos baseados numa seqüência iterativa. Os parâmetros físicos como dimensão dos anéis de Plácido e distância do ápice da córnea até o sistema óptico são necessários e devem ser medidos com precisão. Vamos apresentar aqui um modelo que calcula a curvatura Tangencial a partir da curvatura Axial. Sendo a curvatura Axial baseada em esferas de calibração, através deste método não se necessita entrar com estas distâncias, eliminando um fator de erro.

\section{Modelo Tangencial simplificado}

Vamos apresentar aqui a dedução de um modelo Tangencial cujo cálculo é mais simples quando comparado com o modelo Tangencial apresentado anteriormente. No modelo anterior é necessária a exata dimensão de todos os parâmetros envolvidos, como dimensão dos Discos de Plácido no cone e na imagem virtual, distância do ápice da córnea até o CCD e etc. Uma alternativa interessante é a possibilidade de correlacionamento do poder Axial ao poder Tangencial e vice-versa [40]. A vantagem de se poder calcular o poder Tangencial a partir do Axial reside fundamentalmente no fato de que o modelo Axial é baseado nos dados colhidos a partir de esferas de calibração. Colher dados de esferas para utilizar as distâncias das bordas na geração de arquivos de calibração é muito mais prático e preciso do que tentar determinar dimensões do sistema com alta precisão [40]. A seguir mostramos a dedução das equações que correlacionam estes dois poderes.

A figura 3.19 mostra uma seção transversal (plano que contém o eixo óptico) com as quantidades $r_{i}$ (raio de curvatura instantâneo), $d_{a}$ (distância axial), $y$ (distância do ponto analisado ao eixo óptico), $\theta$ (ângulo de inclinação entre $r_{i}$ ou $d_{a}$ e o eixo óptico) e $h$ (distância vertical do centro de curvatura até o eixo óptico). 


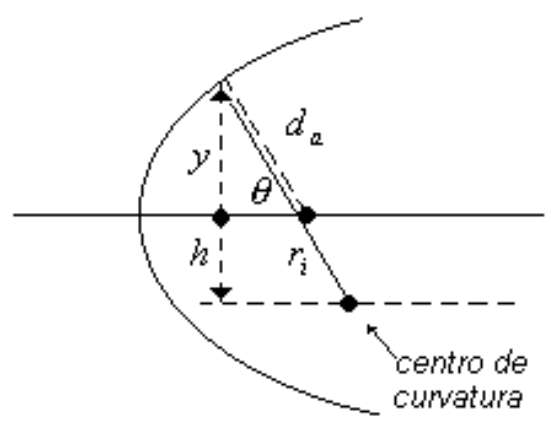

Figura 3.19. Seção transversal da córnea com parâmetros para especificação dos poderes Axial e Instantâneo (tangencial).

O poder Axial é definido como

$$
P_{a}=\frac{(n-1)}{d_{a}}
$$

pela figura vemos que

$$
d_{a}=\frac{y}{\sin (\theta)}
$$

e o poder Instantâneo (Tangencial) é dado por

$$
P_{i}=\frac{(n-1)}{r_{i}}
$$

Eliminando a distância axial das equações (3.13) e (3.14) encontramos uma conexão direta entre o poder Axial e a tangente à superficie:

$$
(n-1) \sin (\theta)=y P_{a}
$$

A grandeza à esquerda também pode ser relacionada à curvatura da córnea considerando o triângulo maior na figura 3.19:

$$
\sin (\theta)=(y+h) / r_{i}
$$

derivando ambos os lados desta equação com relação à $y$ leva ao resultado simples:

$$
\frac{d}{d y} \sin (\theta)=\frac{1}{r_{i}}
$$


$\mathrm{O}$ conceito de $r_{i}$ e $h$ estarem instantaneamente fixos pode ser entendido através das deduções em [40]. Multiplicando ambos os lados da equação (3.18) por $(n-1)$ nos fornece a seguinte relação entre $P_{i}$ e $\theta$ :

$$
(n-1) \frac{d(\sin (\theta))}{d y}=P_{i}
$$

Combinando as equações (4) e (7) nos fornece a relação entre o poder Axial e Instantâneo:

$$
\begin{gathered}
P_{i}(y)=\frac{d\left(P_{a}(y) y\right)}{d y} \\
P_{i}(y)=P_{a}(y)+y \frac{d P_{a}(y)}{d y}
\end{gathered}
$$

nestas duas equações a dependência do poder com relação a $y$ ficou explicita pela notação $P(y)$. A relação inversa dando $P_{a}$ em termos de $P_{i}$ é:

$$
P_{a}(y)=\frac{1}{y} \int_{0}^{y} P_{i}(y) d y
$$

A equação (3.22) nos fornece a principal relação que estávamos procurando. Ela nos diz que para calcular o poder Instantâneo (modelo Tangencial) num ponto basta somar o poder Axial $P_{a}(y)$ do mesmo ponto ao segundo termo da parte direita da equação. Este termo é $y$ vezes a derivada do poder axial com relação a $y$. Para calcular esta derivada, $d P_{a}(y) / d y$, basta saber o comportamento da curva $P_{a}$ versus $y$. Mas esta relação é obtida simplesmente pela interpolação dos valores que o modelo Axial já nos fornece, logo pode ser calculada com relativa facilidade.

\section{Modelo de Elevação Relativa}

O termo topografia de córnea é normalmente utilizado sem muito critério no meio oftalmológico e até mesmo no meio científico. A rigor, o termo mais correto para a maioria dos instrumentos que analisam a curvatura da córnea seria Ceratógrafo, ou simplesmente Videoceratógrafo. Com o advento de modelos matemáticos mais sofisticados que calculam elevação real e não somente curvatura da superfície, o termo topografia de córnea passa a não ser tão inadequado, já que normalmente entende-se por topografia, expressão comumente utilizada em engenharia civil, o cálculo de elevações de uma dada superfície (um terreno por exemplo) em função da posição.

Vamos em seguida descrever um modelo recentemente publicado por Klein [41] e que pudemos estudar junto ao próprio autor na University of Califórnia - Berkeley, durante o período de doutorado "sandwich" (1998). 


\section{Geometria}

Começamos analisando a geometria usada para descrever a córnea. O único elemento necessário do Topógrafo é o eixo óptico (mesmo eixo do cone), o qual define o eixo $z$ de nosso sistema de coordenadas. A localização do ponto da córnea de interesse é dada pela equação (veja figura 3.20):

$$
r=(x, y, z)=(r \cos (\phi), r \sin (\phi), h)
$$

onde $r$ é a distância do ponto sobre a córnea até o eixo e $\phi$ é o meridiano. A posição da córnea (elevação) pode ser expressa em coordenadas cartesianas, $h(x, y)$ ou coordenadas cilíndricas, $h(r, \phi)$.

O versor normal pode ser escrito como:

$$
\hat{n}=\left(\operatorname{sen}(\sigma) \cos \left(\phi_{n}\right), \operatorname{sen}(\sigma) \operatorname{sen}\left(\phi_{n}\right), \cos (\sigma)\right)
$$

onde $\sigma$ é o ângulo que o eixo óptico faz com o versor normal (do inglês, "slant"), e $\theta_{n}$ é o ângulo meridional do versor normal quando olhamos o eixo de frente, como mostra a figura 3.20 . 


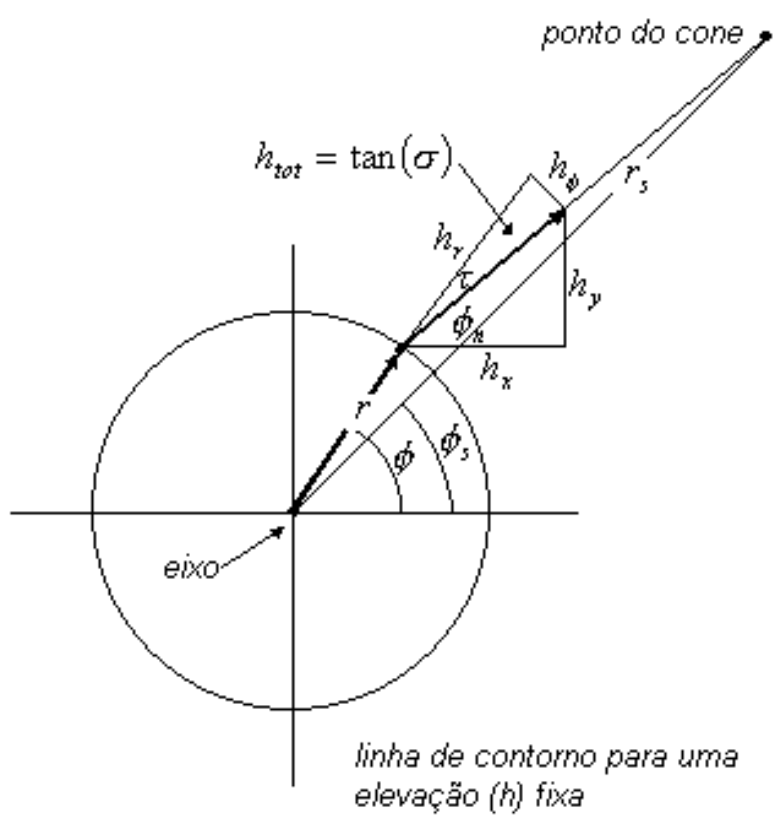

Figura 3.20. Uma visão da córnea olhando ao longo do eixo do topógrafo. O ponto sobre a córnea é especificado em coordenadas cilíndricas pelo par $(r, \phi)$, e o ponto do anel sobre o cone é especificado por $\left(r_{s}, \phi_{s}\right)$. A normal à córnea é especificada pelas coordenadas cilíndricas,$\left(h_{r}, h_{\phi}, 1\right)$, ou coordenadas cartesianas $\left(h_{x}, h_{y}, 1\right)$, como indicado na figura. Este ponto de visão deixa claro a conexão entre os ângulos $\tau, \phi$ e $\phi_{n}$ que especificam a normal. $\mathrm{O}$ "tilt", $\tau$, é o ângulo entre a normal e o plano meridional. Relações do tipo $\quad \tan (\tau)=h_{\phi} / h_{r}$ e $\cos (\tau)=h_{r} / h_{\text {tot }}$ podem $\quad$ ser $\quad$ vistas diretamente na figura.

É conveniente passarmos para um sistema de coordenadas rotacionado em torno do eixo $z$ por um ângulo $\phi$ de tal maneira que o ponto considerado sobre a córnea tenha $y=0$, isto é, $r=(r, 0, h)$. Neste caso a normal se torna:

$$
\hat{n}=(\operatorname{sen}(\sigma) \cos (\tau), \operatorname{sen}(\sigma) \operatorname{sen}(\tau), \cos (\sigma))
$$

onde o ângulo $\tau$ é conhecido como "tilt" e é dado por:

$$
\tau=\phi_{n}-\phi
$$

Estas relações podem ser vistas na figura 3.20.

É geralmente comum normalizar o vetor normal de tal maneira que tenha módulo 1 na direção $z$ :

$$
n=(\tan (\sigma) \cos (\tau), \tan (\sigma) \operatorname{sen}(\tau), 1)
$$


A relação entre a normal e as derivadas com relação à elevação $z=h(r, \phi)$ são:

$$
\begin{gathered}
n=\left(h_{r}, h_{\phi}, 1\right) \\
h_{r}=\frac{\partial h}{\partial r} \\
h_{\phi}=\frac{1}{r} \frac{\partial h}{\partial \phi}
\end{gathered}
$$

Trigonometria simples revela a conexão entre as derivadas e os ângulos "slant" $(\sigma)$ e "tilt" $(\tau)$ :

$$
\tan (\sigma)=h_{t o t}=\left(h_{r}^{2}+h_{\phi}^{2}\right)^{1 / 2}
$$

$\mathrm{e}$

$$
\tan (\tau)=\frac{h_{\phi}}{h_{r}}
$$

Se a normal à córnea estivesse contida no plano meridional, $h_{\phi}$ seria zero, de tal maneira que $\tau$ seria zero e $\phi_{n}$ seria igual a $\phi$. Na figura 3.20, $\phi_{n}$ é diferente de $\phi$, de tal maneira que a normal não está contida no plano meridional.

Baseado na figura 3.20 a localização do ponto sobre o anel do cone é:

$$
\begin{aligned}
& x_{s}=x+\tan (2 \sigma)\left(z_{s}-h\right) \cos \left(\phi_{n}\right) \\
& y_{s}=y+\tan (2 \sigma)\left(z_{s}-h\right) \sin \left(\varphi_{n}\right)
\end{aligned}
$$

onde

$$
\begin{aligned}
& \cos \left(\phi_{n}\right)=h_{x} / h_{t o t} \\
& \sin \left(\phi_{n}\right)=h_{y} / h_{t o t}
\end{aligned}
$$

Em termos do sistema com rotação em torno de $\mathrm{z}$ em que o plano meridional está em $y=0$, as coordenadas do anel no cone são:

$$
\begin{array}{r}
x_{s}=r+\tan (2 \sigma)\left(z_{s}-h\right) \cos (\tau) \\
y_{s}=\tan (2 \sigma)\left(z_{s}-h\right) \sin (\tau)
\end{array}
$$


Similarmente às equações (3.35) e (3.36) temos:

$$
\begin{aligned}
& \cos (\tau)=h_{r} / h_{t o t} \\
& \sin (\tau)=h_{\phi} / h_{t o t}
\end{aligned}
$$

O raio do anel do cone é calculado pelas equações (3.37) e (3.38):

$$
\begin{gathered}
r_{s}=\left(x_{s}^{2}+y_{s}^{2}\right)^{1 / 2} \\
=\left(r^{2}+2 r \tan (2 \sigma)\left(z_{s}-h\right) \cos (\tau)+\tan (2 \sigma)^{2}\left(z_{s}-h\right)^{2}\right)^{1 / 2}
\end{gathered}
$$

Ao invés de girar o plano meridional nas equações (3.39) e (3.40), é instrutivo girar a figura 3.20 de $\phi_{n}$, ao invés de $\phi$. Neste sistema de coordenadas, a localização do ponto sobre a córnea é:

$$
r=(x, y, z)=(r \cos (\tau), r \sin (\tau), h)
$$

E a normal à córnea é dada por

$$
\hat{n}=(\sin (\sigma), 0, \cos (\sigma))
$$

Com esta rotação, a localização do ponto do cone é dada por:

$$
\begin{gathered}
x_{s}=r \cos (\tau)+\tan (2 \sigma)\left(z_{s}-h\right) \\
y_{s}=-r \sin (\tau)
\end{gathered}
$$

E a equação (3.42) pode ser reescrita como:

$$
r_{s}^{2}=\left(r \cos (\tau)+\tan (2 \sigma)\left(z_{s}-h\right)\right)^{2}+(r \sin (\tau))^{2}
$$

e a equação exata para a tangente de $2 \sigma$ é obtida diretamente da equação (3.47):

$$
\tan (2 \sigma)=\left(\left(r_{s}^{2}-r^{2} \sin ^{2}(\tau)\right)^{1 / 2}-r \cos (\tau)\right) /\left(z_{s}-h\right)
$$

Compreendida a geometria utilizada para descrever os parâmetros da superfície, passamos a descrever o método utilizado para calcular a elevação relativa $(z=h(r, \phi))$.

\section{Calculando elevação a partir das imagens de Plácido}

A pergunta que se faz agora é justamente o problema que se encontra na prática: dada a imagem dos Discos de Plácido conseguimos calcular a elevação da superfície, ou seja, $h(r, \phi)$ ? Em geral a resposta é não. Entre os anéis não há informação sobre a 
tangente à superfície, então descontinuidades podem estar presentes [42]. Além disso, o ângulo de "tilt" $\tau$ pode variar arbitrariamente em torno do anel, e poderíamos então ter um número infinito de superfícies que implicam numa mesma imagem de Plácido. Se, no entanto, fizermos uma aproximação razoável sobre a continuidade da superfície entre um anel e outro, daí então poderemos calcular uma superfície única que satisfaz as condições iniciais.

Para calcular $h(r, \phi)$ sabendo-se o "slant" $(\sigma(r, \phi))$ precisamos assumir que a superfície tem continuidade suficiente. Klein [43] apresentou um argumento para unicidade baseado em parâmetros discretos. A única hipótese assumida foi de que o formato da córnea poderia ser representado por uma série de Taylor finita. Isto é, de acordo com a precisão desejada, pode-se determinar o número de termos necessários na série. Klein fez sua análise em coordenadas Cartesianas usando uma expansão em série de potências $\left(x^{m} y^{n}\right)$, mas um argumento muito similar pode ser feito em coordenadas cilíndricas usando expansões de Zernike. A seguir vamos mostrar os passos do algoritmo para cálculo da superfície a partir dos Discos de Plácido.

\section{Passo 0:}

Obter a elevação, tangente e curvatura do primeiro anel. É assumido que o eixo do topógrafo intersecciona a córnea no centro do primeiro anel, normal à superfície. Se o sistema estiver levemente desalinhado os erros introduzidos são desprezíveis [41].

$\mathrm{O}$ "slant" do primeiro anel é obtido usando a equação:

$$
\tan (2 \sigma(\phi, 1))=\left(r_{s}(\phi, 1)-r(1)\right) / z_{s}(1)
$$

A equação (3.49) foi obtida desprezando-se o termo $h$ na equação (3.48), pois $h$ para o primeiro anel é muito pequeno quando comparado a $z_{s}$ e no primeiro anel o "tilt" da córnea é desprezível [44]. Estaremos incluindo o meridiano, $\phi$, e o número do anel, $i$, como variáveis em nossa discussão do algoritmo.

Para obter maior precisão, o valor de $h$ na equação (3.52) pode ser usado na equação (3.48) (ao invés de usar 3.49). Como o "tilt" é desprezível no primeiro anel, o ângulo "slant" $\sigma$ na equação (3.49) pode ser substituído pela ângulo da tangente ao plano meridional, $\theta$. Este método simples para calcular a tangente meridional não será usado além do anel 1. Aliás, um dos aspectos inovadores deste algoritmo é de como fazer a conexão da tangente ao plano meridional $(h=\tan (\theta)$, veja equação 17$)$ ao "slant" $\sigma$.

Para o primeiro anel, $r_{s}-r$ é muito pequeno comparado com $z_{s}$. Portanto a tangente meridional, $h_{r}$, e curvatura $k$ na imagem do primeiro anel são bem aproximadas por:

$$
\begin{array}{r}
h_{r}(\phi, 1)=\tan (\theta(\phi, 1)) \\
\approx \tan (2 \sigma(\phi, 1)) / 2 \\
\approx\left(r_{s}(\phi, 1)-r(1)\right) / 2 z_{s}(1) \\
K(\phi, 1)=\sin (\theta(\phi, 1)) / r(1) \\
\approx\left(r_{s}(\phi, 1)-r(1)\right) /\left(2 z_{s}(1) r(1)\right)
\end{array}
$$


onde $r_{s}(1)$ e $z_{s}(1)$ especificam a localização do primeiro anel de Plácido no cone. A elevação da córnea no primeiro anel é dada por

$$
h(\phi, 1)=k(\phi, 1) r(1)^{2} / 2=\left(r_{s}(\phi, 1)-r(1)\right) r(1) / 4 z_{s}(1)
$$

Agora que temos a elevação, tangente, e curvatura no primeiro anel, estamos prontos para calcular a elevação nos anéis seguintes.

Passo 1:

Calcular a elevação $(h(i))$, no i-ésimo anel baseado na elevação, $h(i-1)$, tangente $h_{r}(i-1)$, e curvatura $k(i-1)$, no anel $i-1$, usando a equação:

$$
h(\phi, i)=h(\phi, i-1)+h_{r}(\phi, i-1) \Delta+0.5 k(\phi, i-1) \Delta^{2}
$$

onde $\sin (\theta)=(y+h) / r_{i}$ é a distância entre anéis adjacentes, i.e., $\Delta=(r(i)-r(i-1))$.

Passo 2:

Calcular a derivada com relação a $\phi$ (equação 3.30) no novo anel:

$$
h_{\phi}(\phi, i)=((h(\phi+\delta, i)-h(\phi-\delta, i)) / 2 \delta) / r(i)
$$

onde $\delta$ é o ângulo entre meridianos adjacentes. O fator extra de $r(i)$ no denominador é necessário para calcularmos $h_{\phi}$ nas mesmas unidades que $h_{r}$.

Passo 3:

Calcular o ângulo de "tilt" a partir da equação (3.32):

$$
\tau(\phi, i)=\arctan \left(h_{\phi}(\phi, i) / h_{r}(\phi, i)\right)
$$

\section{Passo 4:}

Calcular a "slant" pela equação (3.48):

$$
\sigma(\phi, i)=0.5 a \tan \left(\left(r_{s}(\phi, i)^{2}-r(i)^{2} \sin ^{2}(\tau(\phi, i))^{1 / 2}-r(i) \cos (\tau(\phi, i))\right) /\left(z_{s}(i)-h(\phi, i)\right)\right)
$$

\section{Passo 5:}

Calcular a derivada meridional pela equação (3.31):

$$
h_{r}(\phi, 1)=\left(\tan ^{2}(\sigma(\phi, i))-h_{\phi}(\phi, i)^{2}\right)^{1 / 2}
$$

Esta é a importante etapa do algoritmo que elimina o erro relativo às normais à superfície que não estão contidas no plano meridional, através da conversão do "slant" na direção normal para a tangente na direção meridional. 


\section{Passo 6:}

Calcular uma estimativa da curvatura meridional no novo anel:

$$
k(\phi, 1)=\left(h_{r}(\phi, i)-h_{r}(\phi, i-1)\right) / \Delta
$$

esta é na realidade uma estimativa da curvatura entre os dois anéis adjacentes.

\section{Passo 7:}

Repetir os passos 1, 2 e 5 de tal maneira a obter uma melhor estimativa de $h_{r}$.

Passo 8:

Voltar ao Passo 0 para o próximo anel. Com isso serão calculados todos os valores de $h_{\phi}(\phi, i)$.

\section{Simulando Discos de Plácido para superfícies arbitrárias}

O objetivo principal de construir um algoritmo para simular o traçado de raios do cone (Discos de Plácido) até a superfície e finalmente até a formação da imagem na matriz do CCD é poder averiguar quão preciso é nosso algoritmo para cálculo das elevações da superfície. Ou seja, num primeiro passo, para uma superfície teórica arbitrária, aplicamos nosso algoritmo para geração das imagens dos Discos de Plácido; num segundo passo fazemos o processo inverso, i. e., aplicamos nosso algoritmo de elevação nestas imagens para obter a superfície e comparamos esta com a superfície teórica. Quão menor for o erro entre as duas superfícies, mais preciso será o algoritmo. Embora estas simulações sejam somente teóricas, elas refletem bem próximo daquilo que ocorre na realidade, com poucas aproximações.

Para facilitar a análise, vamos assumir que a câmera do topógrafo está bem focalizada na imagem virtual dos anéis. O propósito disto é poder fazer a aproximação de raios paraxiais. Se a imagem no $\mathrm{CCD}$ está bem focalizada podemos assumir que todos os pontos refletidos pela córnea formam imagem no plano do CCD. Como ilustrado na figura 3.21, podemos traçar um raio partindo de um dos anéis do cone, refletindo na córnea e partindo paraxialmente em direção ao CCD. Este raio passa então pelo ponto focal secundário da lente e forma sua imagem no plano do CCD. Para uma câmera corretamente focalizada, cada ponto na câmera corresponde a um par ordenado $(r, \phi)$ na córnea. Pela figura 3.21 é fácil ver que a posição radial do ponto da córnea, $r$, é diretamente obtida sabendo-se a posição radial na imagem, pela equação simples:

$$
r=\frac{r_{\text {imagem }} \cdot f}{(v-f)}
$$




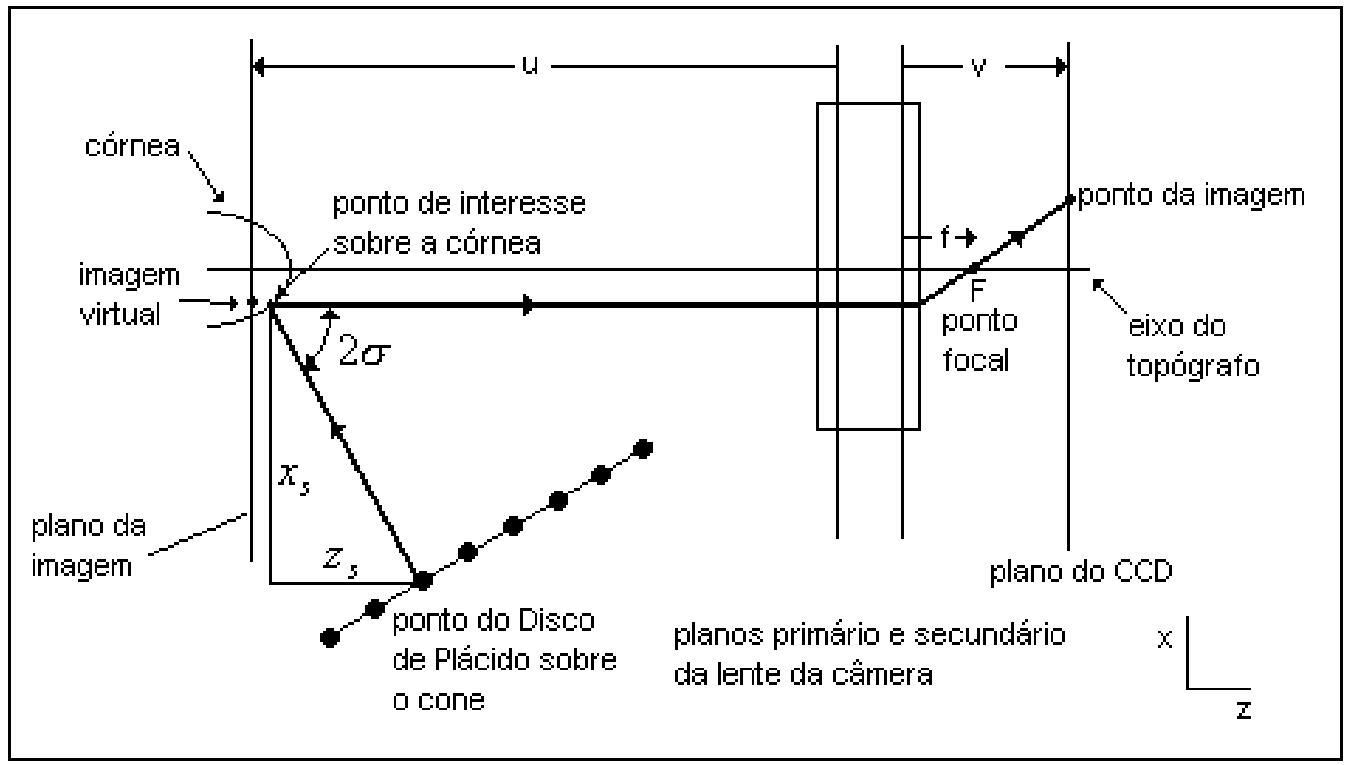

Figura 3.21. Sistema óptico para simulação do traçado de raios, mostrando corte que contém o eixo do topógrafo. Podemos ver na figura o cone com os Discos de Plácido, o contorno da córnea, a imagem virtual do ponto do cone, o plano do CCD e etc. Começamos o traçado de raio partindo do ponto sobre o Disco de Plácido no cone, refletindo na córnea e saindo paralelo ao eixo do topógrafo. Este raio é refratado pela lente da câmera de maneira a passar pelo ponto focal secundário $\mathrm{F}$ e finalmente incide no plano do CCD, a uma distância $r_{\text {imagem }}$ do eixo do topógrafo.

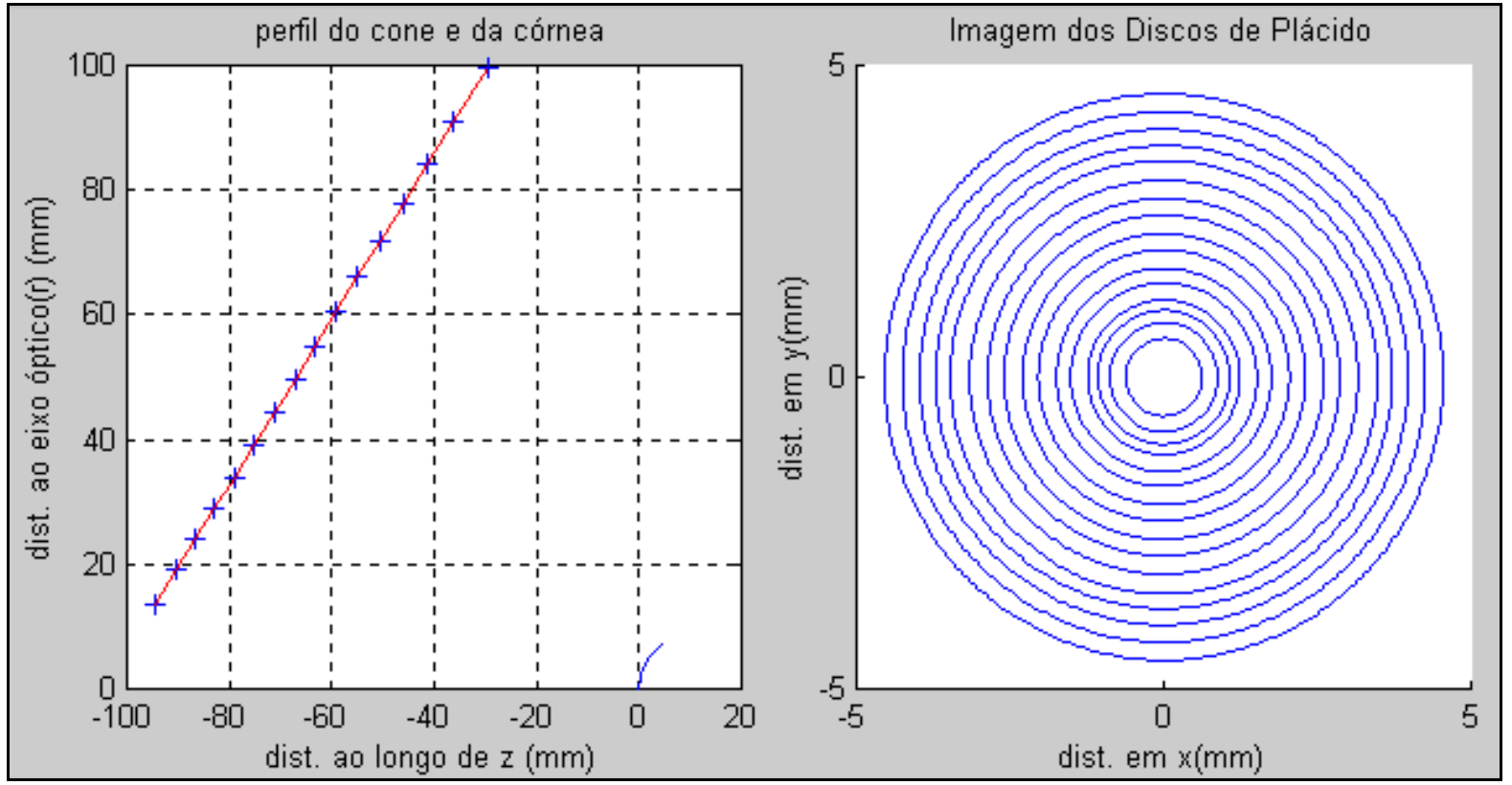

Figura 3.22. Princípio de simulação dos Discos de Plácido baseado no algoritmo de Klein [41]. O gráfico da esquerda mostra em escala reduzida um corte do cone (aqui com 16 anéis) e de uma superfície esférica. Os dados das posições físicas reais dos anéis foram medidos no cone. O gráfico da esquerda mostra a imagem do reflexo dos anéis de Plácido na esfera. Pode-se perceber que são anéis perfeitamente concêntricos e simétricos, como realmente deve ser para uma esfera.

onde $f$ é a distância focal da lente da câmera e $v$ é a distância imagem. Como esta equação é rotacionalmente simétrica basta variar o meridiano e calcular o valor $r$ para cada um deles. Como exemplo fizemos um programa em MatLab baseado nos 
algoritmos de Klein [41] para testar este princípio. Observação: para manter compatibilidade com os algoritmos do Klein, utilizamos parâmetros do cone com Discos de Placido do instrumento EyeSys, com 16 anéis. Como aqui estamos fazendo apenas simulações computacionais, este dado não influencia nas precisões ou nos cálculos, e absolutamente tudo que descrevemos para o cone com 16 anéis (8 Discos de Plácido) é válido para o nosso com 10 anéis (5 Discos de Plácido). Criamos algumas superfícies artificiais esféricas, elípticas, e simulação de córnea com pós RK (Ceratotomia Radial - técnica de cirurgia refrativa [45], hoje em dia em desuso, onde se fazia cortes radiais na córnea para provocar o achatamento e conseqüentemente prolongar a distância focal. Pelo princípio de funcionamento esta cirurgia era utilizada para correção de miopia). Na figura 3.22 podemos ver o resultado do algoritmo de simulação para uma esfera. O diagrama da esquerda mostra em escala o corte de nosso cone (as setas representam as bordas dos Discos de Plácido) e uma superfície esférica. À direita temos a imagem do reflexo dos Discos de Plácido.

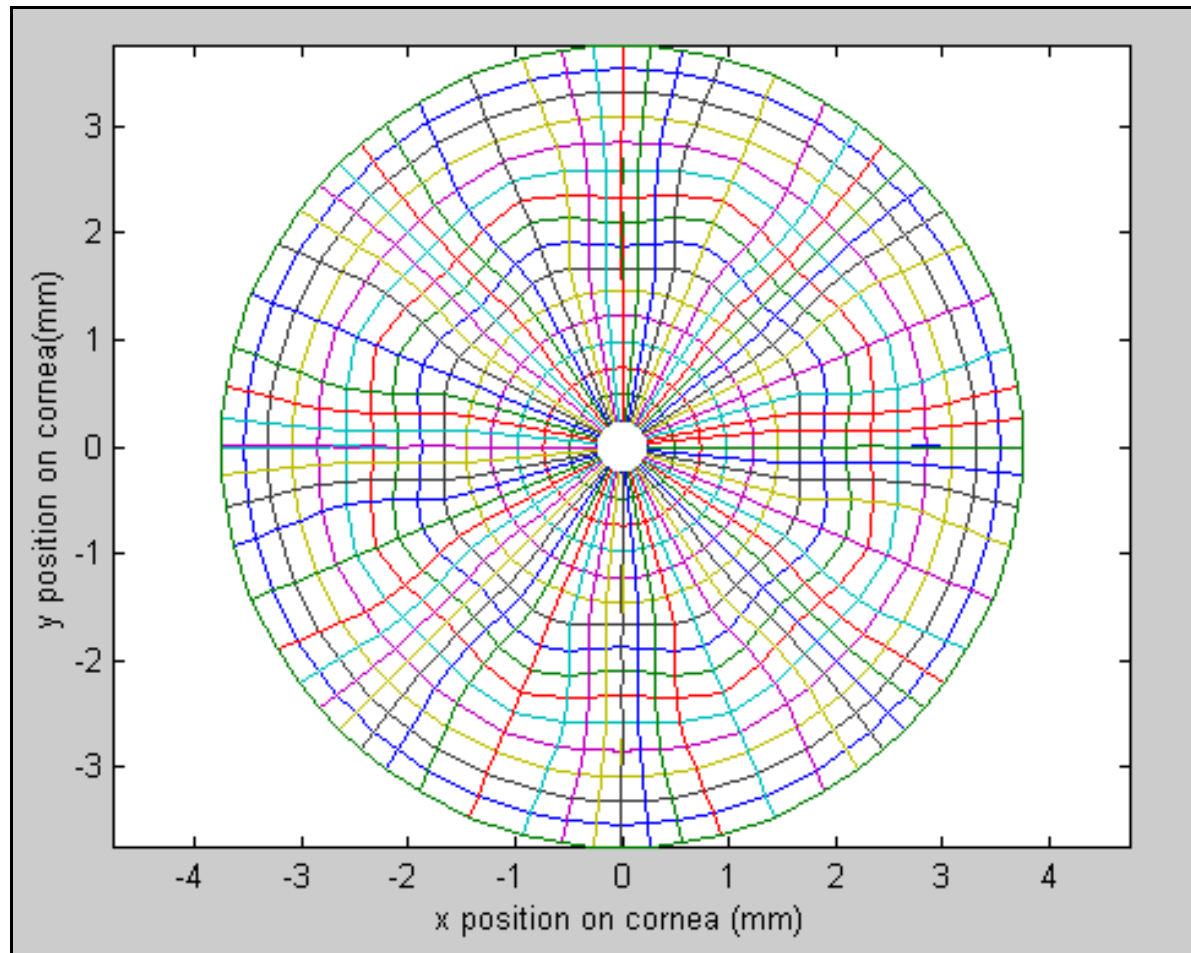

Figura 3.23. Discos de Placido obtidos para uma superfície que simula cirurgias pós-RK [45]. A equação que define esta superfície pode ser vista em (3.60) e (3.61).

Para todas as imagens de Plácido simuladas existem equações matemáticas que representam as superfícies. A forma esférica e elíptica são mais simples. A forma que simula a cirurgia de RK é dada por:

$$
h(r, \phi)=r_{0}-\left(r_{0}^{2}-r^{2}\right)^{1 / 2}+a \cdot \cos (8 \phi) \cdot R(r)
$$

Onde 


$$
\begin{gathered}
R(r)=0 \text { para } r \leq r_{1} \\
R(r)=\left[1-\cos \left(\pi\left(r-r_{1}\right) /\left(r_{2}-r_{1}\right)\right)\right] / 2 \text { para } r_{1} \leq r \leq r_{2} \\
R(r)=1 \text { para } r_{2} \leq r
\end{gathered}
$$

O resultado destas imagens de Plácido simuladas serão, na apresentação dos resultados no capítulo IV, inseridos no algoritmo para cálculo de elevação descrito neste capítulo; poderemos então averiguar a precisão (teórica) do algoritmo. Em termos experimentais, fica aqui como sugestão para um trabalho futuro, a construção em alumínio (ou vidro) das superficies simuladas e a realização de medidas reais de elevação.

\section{Modelo Refrativo}

No modelo refrativo utiliza-se a Lei de Snell para calcular o desvio na direção de propagação dos raios de luz que incidem na córnea. Para simplificar as contas assumimos que a normal à superfície intersecciona o eixo óptico (isso não necessariamente é verdadeiro para superfícies generalizadas [46]). Na figura 3.24 temos um esquema da óptica geométrica envolvida, onde o ponto focal $\mathrm{F}$ é a intersecção do raio refratado com o eixo óptico. Baseado nessa geometria podemos calcular o ângulo de incidência:

$$
\theta_{i}=\operatorname{arcsen}\left(\frac{y}{r_{a}}\right)
$$

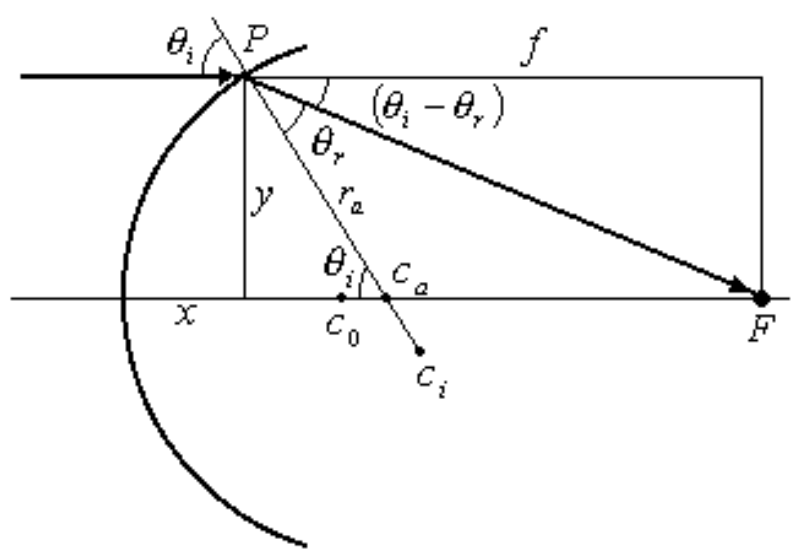

Figura 3.24.: Óptica geométrica para cálculo do poder Refrativo. $\theta_{i}$ é o ângulo de incidência, $\theta_{r}$ é o ângulo de refração, $y$ é a distância ao eixo óptico, $x$ é a distância sagital, $c_{a}$ o centro de curvatura axial e $c_{i}$ o centro de curvatura instantâneo. A distância axial é $r_{a}$.

E aplicando a Lei de Snell encontramos o ângulo de refração: 


$$
\theta_{r}=\operatorname{arcsen}\left(\frac{y}{1.3375 \cdot r_{a}}\right)
$$

Pela figura também se pode ver que a distância focal F é:

$$
f=\frac{y}{\tan \left(\theta_{i}-\theta_{r}\right)}
$$

E finalmente podemos calcular o poder refrativo $(\mathrm{K})$ relativo ao ápice da córnea:

$$
K=\frac{1.3375}{(x+f)}
$$

Podemos calcular as distâncias $x$ (elevação) usando o método descrito anteriormente. Pode-se imprimir mapas planos com códigos de cor para os poderes refrativos da mesma maneira implementada para os mapas Axiais. Este modelo tem a vantagem de calcular o poder de refração para cada ponto da córnea a partir da normal à superfície, sem assumir que cada ponto sobre a córnea pertence a uma lente convexa, como é o caso do modelo Axial.

\section{Algoritmos para o modelo Axial}

Na página 34 descrevemos os princípios básicos do modelo Axial baseado em esferas de calibração. Foi exposto um algoritmo que resume a maneira de funcionamento do modelo, mas não entramos em muitos detalhes práticos. Vamos descrever a seguir características importantes do modelo e algoritmos práticos de implementação.

O modelo Axial é baseado em informações colhidas de superfícies perfeitamente esféricas, e para uma superfície arbitrária (a córnea), os raios de curvatura de cada ponto são calculados com base nestas informações. Tendo como referência o algoritmo resumido visto anteriormente, a seguir descrevemos o algoritmo prático utilizado para implementar o modelo Axial.

Imagens de 4 superfícies perfeitamente esféricas de raios de curvatura 7.73, $8.06,8.34$ e $8.91 \mathrm{~mm}$ foram digitalizadas e armazenadas. Cada imagem foi processada segundo o método exposto na página 30 , partindo do centro em direção radial à periferia, detectando as bordas interna e externa para cada anel, sobre 360 semimeridianos igualmente espaçados de $1 \mathrm{em} 1$ grau e as distâncias de borda foram armazenadas numa matriz (vamos chamá-la de MatDist (ângulo de 1 a 360, borda de 1 a 10) ). Como tratam-se de superfícies esféricas faz-se uma média das 360 distâncias para cada borda, ou seja, considera-se que nas esferas as bordas formem contornos perfeitamente simétricos (circunferências). Teremos então, no caso do projetor com 5 anéis, distâncias médias (em $\mathrm{mm}$ ) de 10 bordas para cada uma das quatro esferas. 
Imprime-se um gráfico de raio de curvatura versus posição $(\mathrm{em} \mathrm{mm})$ para cada uma das 10 bordas (figura 3.26). Estes pontos são aproximados linearmente usando-se o método dos mínimos quadrados para encontrar os parâmetros da equação de cada reta

$$
R=a \cdot d i s t+b
$$

onde $R=$ raio de curvatura, dist $=$ distância de borda em mm, $a$ e $b$ são os parâmetros da reta.

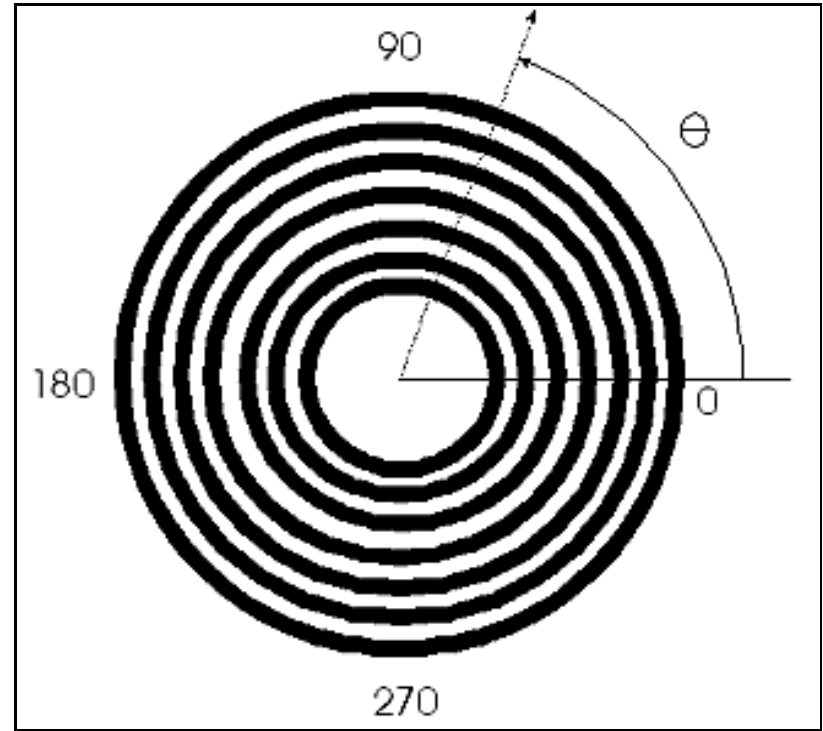

Figura 3.25. Ilustração do método usado para armazenar as distâncias de borda na matriz MatDist. Para cada semi-meridiano temos um certo número de bordas (número de anéis na figura é apenas ilustrativo). São 360 semi-meridianos, com $\theta$ variando de 1 em 1 grau.

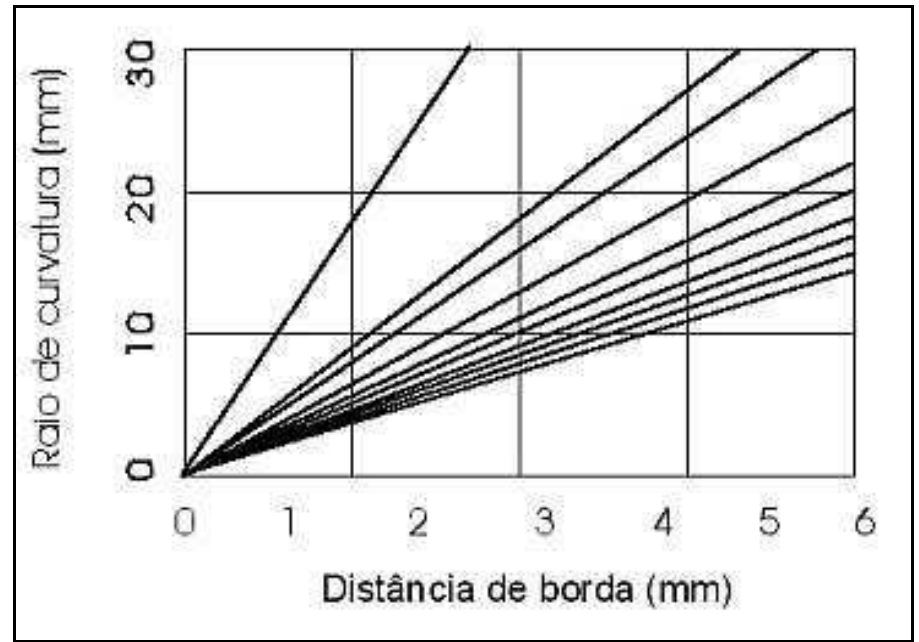

Figura 3.26. Curvas de calibração traçadas a partir de quatro esferas. Para cada borda (de 1 a 10) temos uma curva de calibração, traçada pelo método dos mínimos quadrados. 
Suponha agora que desejamos medir os raios de curvatura sobre uma superfície arbitrária. Detecta-se os pontos de borda da mesma maneira e armazenamos os valores de distância em MatDist(ângulo,borda). Basta substituir cada distância em MatDist no valor de dist na equação (3.66) para a borda correspondente (de 1 a 10) e calcular o valor de $R$.

\section{Novos algoritmos para comparações quantitativas e cálculo do astigmatismo}

Nesta seção vamos descrever os algoritmos que foram implementados para leitura de arquivos de exames realizados no Topógrafo comercial Eyesys (modelo: EyeSys 2000 Corneal Analysis System, fabricante: EyeSys Inc., endereço: 2776 Bingle Road, Houston, Texas, 77055 - EUA ) e subseqüente comparação com os exames realizados em nosso instrumento. Esta etapa é essencial para que possamos comparar de maneira quantitativa nossas medidas em córneas com aquelas de outros instrumentos. Mais adiante, no caso de medidas em superfícies artificiais e com formatos prédeterminados este processo não é necessário, mas mesmo assim pode ser utilizado para medir a confiabilidade de nosso instrumento quando comparado com um aparelho que está no mercado e é considerado confiável.

Os arquivos do sistema EyeSys são basicamente de dois tipos: um para armazenamento de raios de curvatura (veja listagem 3.1) e outro para armazenamento de distâncias nas imagens de Plácido (veja listagem 3.2). Como o nosso sistema, além de arquivos estáticos de imagens, também armazena estes dois tipos de arquivos, pudemos implementar um algoritmo para comparação ponto a ponto dos valores obtidos pelo EyeSys e por nosso instrumento.

Trecho de listagem dos dados da EyeSys para dioptrias calculadas a partir do modelo Axial de curvatura:

listagem 3.1: arquivo com as dioptrias de cada ponto na imagem de Plácido

(1) 48.8748 .3847 .8547 .3146 .7746 .2645 .8045 .3945 .0544 .7944 .6144 .4844 .3700 .0000 .0000 .0000 .00 (2) 48.8748 .4047 .8947 .3646 .8346 .3345 .8645 .4545 .1144 .8544 .6744 .5544 .4500 .0000 .0000 .0000 .00 (3) 48.8748 .4247 .9347 .4246 .9046 .4045 .9345 .5245 .1744 .9244 .7444 .6344 .5400 .0000 .0000 .0000 .00 (4) 48.8748 .4547 .9847 .4746 .9646 .4746 .0045 .5845 .2444 .9844 .8144 .7144 .6400 .0000 .0000 .0000 .00 (5) 48.8748 .4748 .0247 .5347 .0346 .5446 .0745 .6545 .3145 .0544 .8944 .7944 .7300 .0000 .0000 .0000 .00 (6) 48.8748 .4948 .0647 .5847 .0946 .6146 .1445 .7245 .3845 .1244 .9644 .8844 .8300 .0000 .0000 .0000 .00 (7) 48.8748 .5148 .1047 .6447 .1646 .6846 .2245 .8045 .4545 .2045 .0544 .9844 .9400 .0000 .0000 .0000 .00

(360) 48.8748 .3647 .8247 .2646 .7146 .2045 .7445 .3344 .9944 .7444 .5544 .4144 .2900 .0000 .0000 .0000 .00

listagem 3.2: arquivo com as distâncias radiais (em pixels) de cada ponto na imagem de Plácido

(1) 00.0019 .5028 .8437 .8247 .7758 .4869 .5781 .1594 .09106 .29118 .23130 .32142 .3000 .0000 .0000 .0000 .00 (2) 00.0019 .4928 .8137 .7647 .6958 .3869 .4681 .0393 .98106 .19118 .13130 .20142 .0500 .0000 .0000 .0000 .00 (3) 00.0019 .4828 .7737 .7047 .6158 .2969 .3580 .9093 .86106 .07118 .03130 .07141 .7900 .0000 .0000 .0000 .00 (4) 00.0019 .4628 .7437 .6447 .5358 .1969 .2480 .7793 .74105 .95117 .92129 .94141 .5100 .0000 .0000 .0000 .00 (5) $00.0019 .4528 .7137 .5847 .4458 .0969 .1280 .6493 .60105 .82 \quad 117.80129 .80141 .2100 .0000 .0000 .0000 .00$ (6) 00.0019 .4428 .6737 .5247 .3657 .9869 .0080 .5093 .47105 .69117 .67129 .66140 .9100 .0000 .0000 .0000 .00 (7) 00.0019 .4328 .6437 .4647 .2757 .8868 .8980 .3693 .32105 .55117 .54129 .51140 .5900 .0000 .0000 .0000 .00 
Em ambas as listagens, as primeiras colunas com números entre parênteses foram editadas manualmente para ilustrar a seqüência de linhas do arquivo. São 360 linhas representando 360 semimeridianos de um em um grau, e 16 colunas representando 16 bordas de anéis de Plácido. Na segunda listagem podemos ver as distâncias radiais em pixels para cada valor de dioptria do primeira listagem. Como nosso algoritmo também tem como base a simetria cilíndrica da córnea, ou seja, utiliza um sistema polar de coordenadas para cálculos, a comparação de medidas entre ambos instrumentos fica mais simples. Mas mesmo assim precisamos determinar quais regiões no mapa comercial correspondem ao nosso mapa, pois o número de anéis é diferente. Felizmente basta determinar a relação pixels $/ \mathrm{mm}$ para cada instrumento, transformar as distâncias polares (originalmente em pixels) para milímetros e daí fazer a comparação das dioptrias de cada instrumento para estas distâncias.

No diagrama 1 podemos ver um trecho do programa que foi implementado em PASCAL para leitura destes arquivos. Para poder comparar regiões absolutamente equivalentes da mesma córnea medimos o fator número de pixel/mm para ambos os aparelhos e assim pudemos determinar quais regiões eram equivalentes em ambas as medidas. Observação: colocamos aqui os trechos dos programas em linguagem PASCAL apenas como ilustração das implementações envolvidas no processo de leitura de arquivos; não nos preocuparemos aqui em dissecar linha por linha do código pois estaríamos saindo do enfoque principal desta seção. Para uma compreensão detalhada dos códigos abaixo sugerimos a leitura de [47].

Diagrama 3.1. Trecho do programa em PASCAL que chama as rotinas para leitura dos arquivos de Dioptria e distâncias

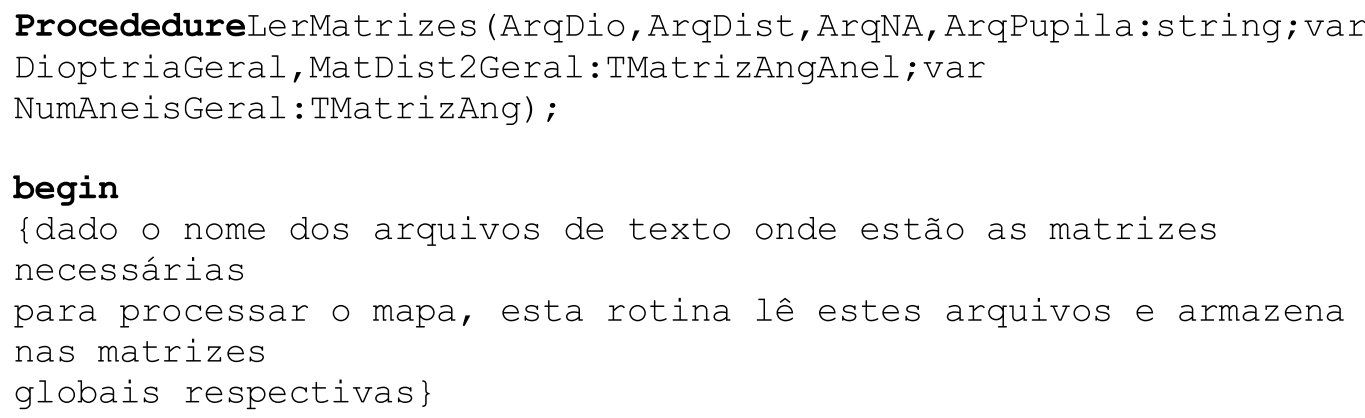

end;

Diagrama 3.2. trecho do programa que faz a leitura dos arquivos de dioptria

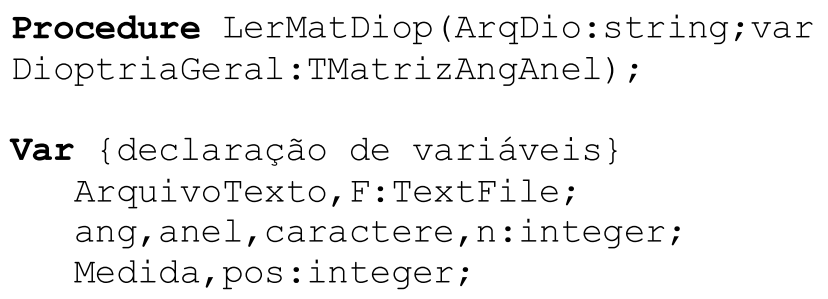




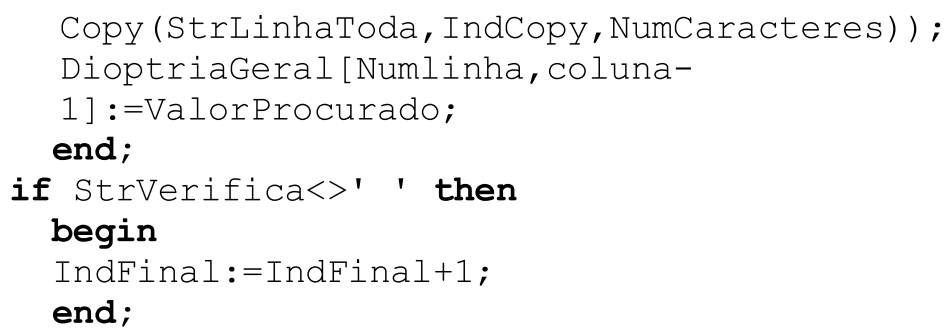

end;

Foi implementado um outro recurso para comparação de exames que serve também para cálculo preciso do astigmatismo para diferentes distâncias radiais. $\mathrm{Na}$ figura 3.27 podemos ver um gráfico do Poder Refrativo vs. Ângulo do Semi-Meridiano para uma distância radial fixa de $3 \mathrm{~mm}$ sobre a córnea. Percebe-se que, como trata-se de um olho com astigmatismo, este gráfico comporta-se de maneira muito parecida a uma curva senoidal. A partir destes valores calculamos com precisão o eixo de maior curvatura. Por analogia ao funcionamento do ceratômetro, assume-se o outro eixo, aquele de menor curvatura, a 90 graus do eixo de maior curvatura. $O$ grau do astigmatismo é simplesmente a diferença em Dioptria do poder máximo e mínimo. $\mathrm{Na}$ seção seguinte mostramos uma tabela comparativa com os valores que obtivemos para astigmatismo e os valores obtidos pelo EyeSys.

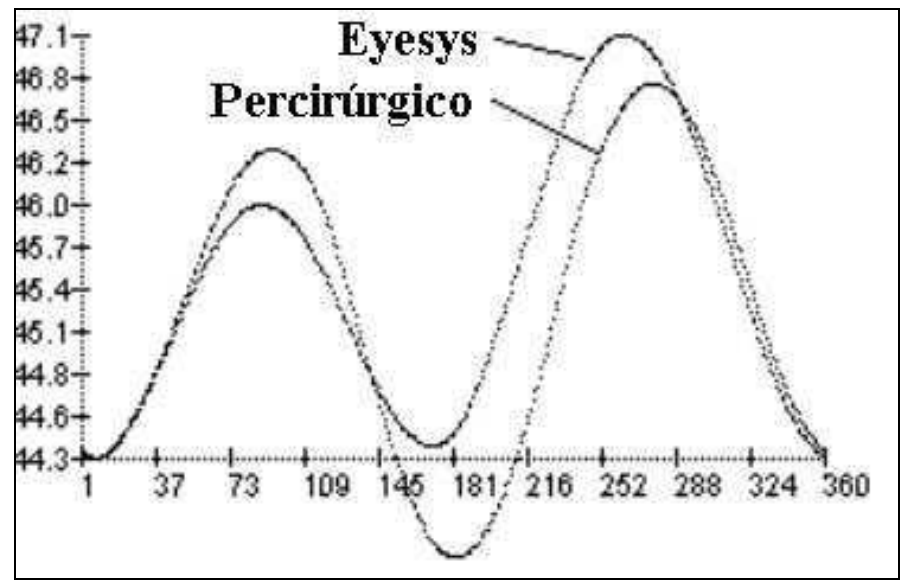

Figura 3.27. Astigmatismo de um paciente voluntário. Neste gráfico temos no eixo das abcissas o valor da dioptria e no eixo das ordenadas o ângulo do semi-meridiano, para uma distância radial fixa de $3 \mathrm{~mm}$. Uma das curvas foi impressa a partir de resultados do EyeSys, e a outra em nosso instrumento. Além de comparar as medidas através da análise destas curvas, podemos medir com precisão o eixo e o grau do astigmatismo. 


\section{Algoritmos para impressão}

Antes do surgimento dos topógrafos computadorizados no início dos anos 80 , os cálculos das dioptrias eram feitos manualmente baseados nas fotos dos Fotoceratoscópios (capítulo II, página 13) e os resultados eram dispostos geralmente na forma de números ou gráficos. Mas com os computadores a rapidez dos cálculos e impressão na tela permitia que novas maneiras de disposição dos dados fossem experimentadas. Destas experiências surgiram os primeiros mapas topográficos planos e coloridos, sugeridos inicialmente por Klyce [15], e hoje em dia são praticamente um padrão. Estes mapas foram inspirados basicamente nos tradicionais mapas geográficos coloridos, onde cores quentes (vermelho, laranja) representam altas altitudes, cores intermediárias (amarelo, verde) representam altitudes médias e cores frias (azul, azul escuro) representam altitudes a nível do mar (figura 3.28).

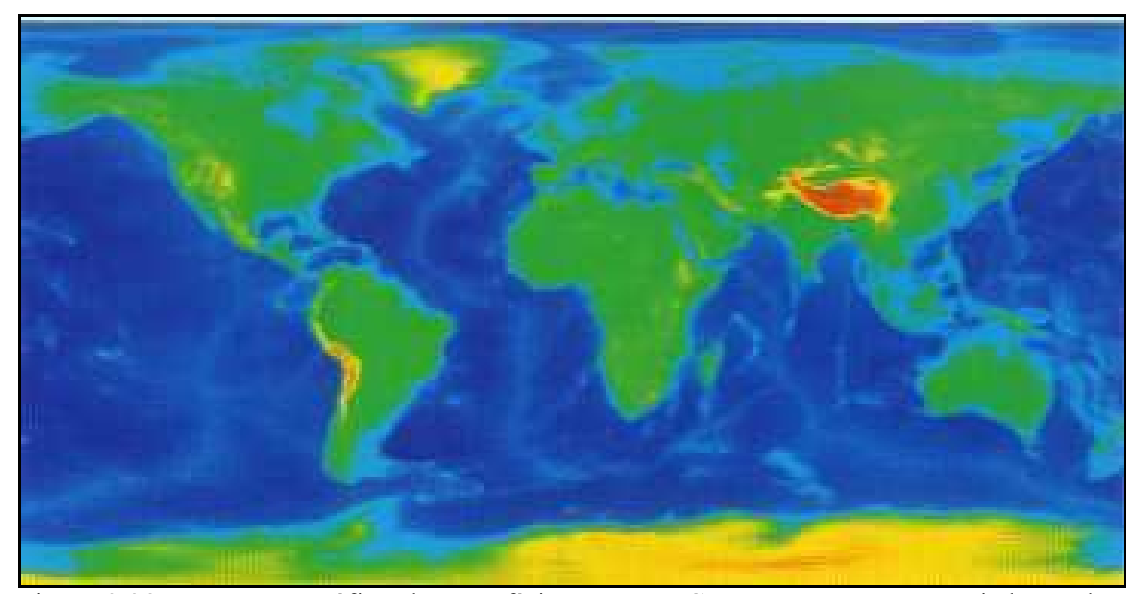

Figura 3.28. Mapa topográfico da superfície terrestre. Cores quentes são associadas a altas altitudes, cores médias a médias altitudes e cores frias ao nível do mar. Foram estes tipos de mapas que inspiraram os primeiros mapas de curvatura da córnea.

Utilizando-se o algoritmo exposto anteriormente calculamos 360 valores de raio de curvatura para cada uma das 10 bordas e armazenamos estes valores numa matriz Raio(ângulo, borda). Cada valor desta matriz é inserido na equação para o poder de refração (Dioptria) do olho esquemático resumido de Gullstrand [1]:

$$
D=\frac{n_{c}-n_{a r}}{R}
$$

onde $n_{c}=1.3375=$ indice de refração da córnea

$n_{a r}=1.0000=$ indice de refração do ar

$R=$ raio de curvatura da córnea

Armazena-se então cada valor de dioptria numa matriz Dioptria(ângulo,borda). Para que se possa imprimir o mapa topográfico colorido, a cada intervalo de valores de dioptria deve ser associada uma cor específica. Algumas questões surgem nesta fase, como: quais as cores mais interessantes para representar os diferentes poderes de refração; quais os valores máximo e mínimo da escala de dioptrias, e quais os intervalos 
associados a cada cor; como imprimir o mapa da maneira mais suave possível dado que não temos pontos distribuídos continuamente sobre a córnea.

Após os cálculos de dioptria temos então uma matriz Dioptria (ângulo, borda) com 3600 pontos distribuídos sobre a córnea. Para associar estes valores a uma tabela de cores fizemos o seguinte: dos 3600 pontos calculamos o valor máximo e mínimo de dioptria, somamos estes valores e dividimos por dois. Este valor médio é associado ao valor intermediário de uma tabela com um total de 15 cores. Cada cor é então associada a intervalos que variam de $0.5 \mathrm{em} 0.5$ dioptrias, para baixo e para cima na tabela a partir da cor intermediária (figura 3.29).

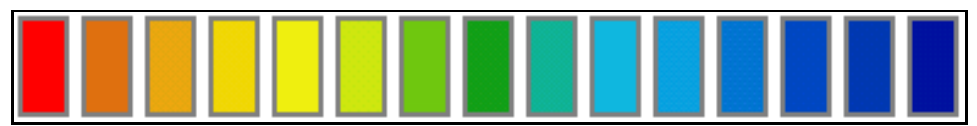

Figura 3.29. Conjunto fixo de 15 cores utilizadas para imprimir todos os mapas topográficos. Estas cores jamais variam. O que varia são os intervalos de dioptria associados a cada uma. Às cores quentes associa-se valor alto de dioptria e assim por diante. A cor verde central é associada ao valor médio das dioptrias e depois os valores para as outras cores são determinados de 0.5 em 0.5 dioptrias. Os valores de dioptria que extrapolam a escala pela direita são impressas na cor azul escuro e vice-versa.

Para cada ângulo (de 1 a 360) temos então 10 valores de poder dióptrico(um para cada borda). Para podermos imprimir um mapa colorido suave, interpolamos na direção radial os valores de poder dióptrico para cada ângulo (figura 3.30) Utilizamos para isto curvas de terceiro grau denominadas em computação gráfica de cubic splines $[48,49]$.

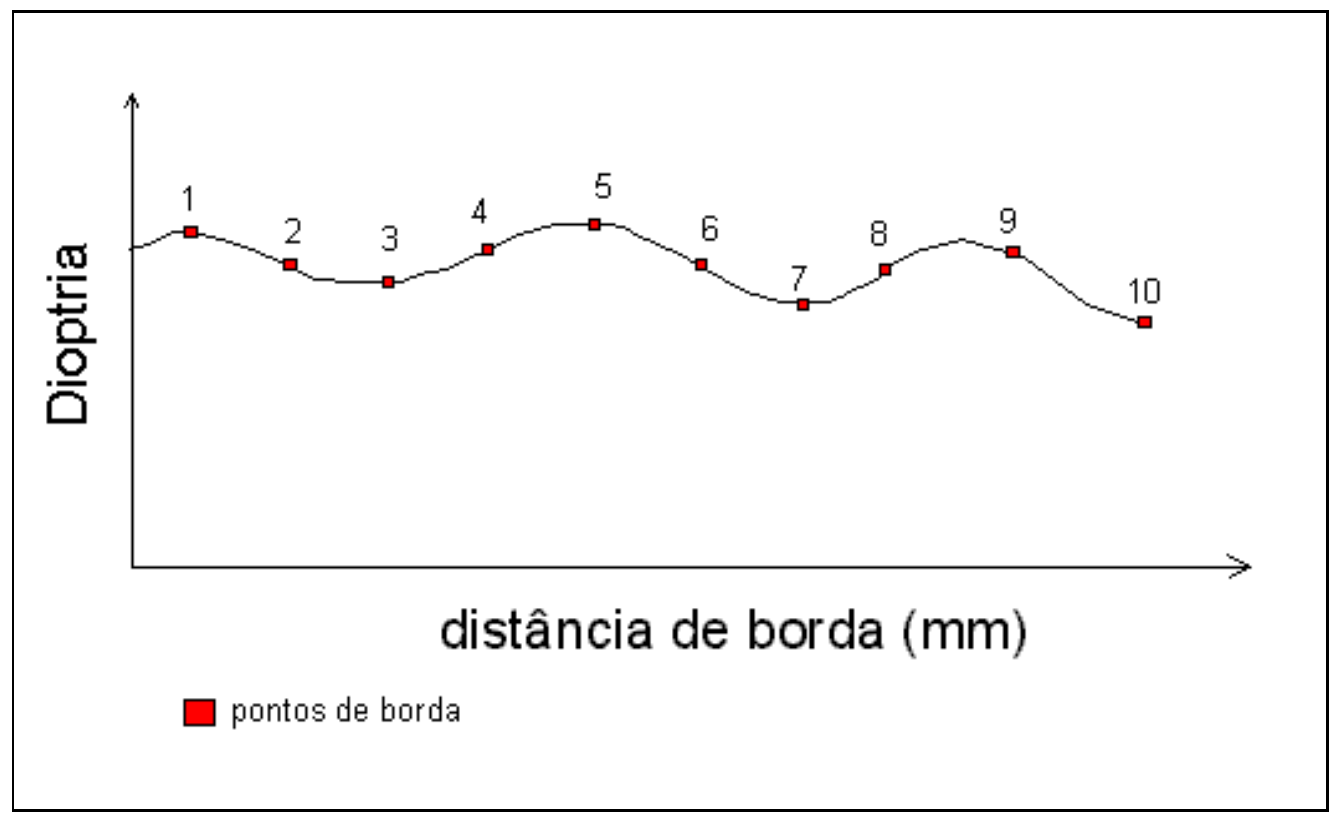

Figura 3.30. Perfil para um dos 360semi-meridianos (ângulo $\theta$ )mostrando como é feita a interpolação dos valores de poder dióptrico calculados nos pontos de borda (neste caso temos 10 bordas, ou seja, projetor com 5 anéis). Interpola-se tais pontos usando "cubic splines". Desta maneira pode-se imprimir o mapa colorido com transições suaves entre uma cor e outra. 
Repetindo estas interpolações para cada um dos 360 ângulos e associando os valores RGB (as cores da tabela são determinadas por trios de valores Red - Green Blue) a intervalos de dioptrias, foram impressos os primeiros mapas topográficos do instrumento. Como exemplo mostramos um dos primeiros mapas obtidos para uma esfera de $8.91 \mathrm{~mm}$ de raio na figura 3.31. Outros mapas para esferas, córneas e comparações com mapas de um aparelho comercial são mostrados na próxima seção.

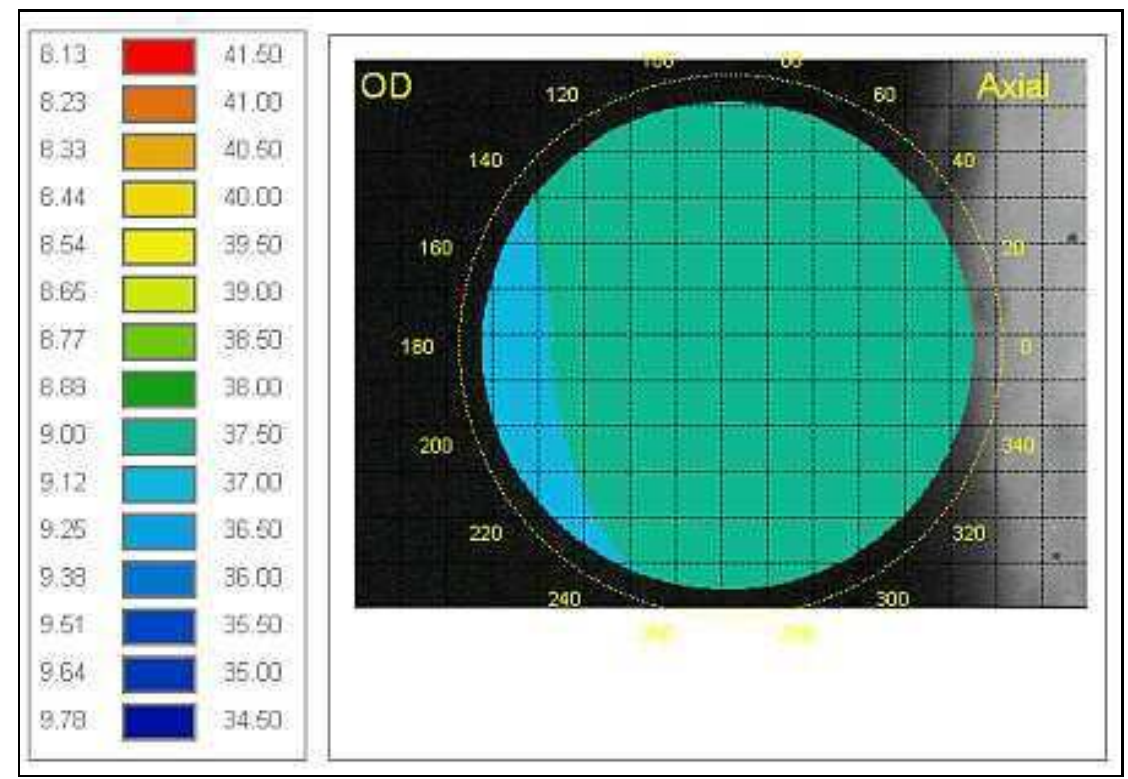

Figura 3.31. Um dos primeiros mapas obtidos pelo instrumento. Trata-se de uma das esferas de calibração (de raio $8.91 \mathrm{~mm}$ ). Podemos perceber pelas cores que a maior parte da superfície esta localizada entre 8.88 e $9.00 \mathrm{~mm}$ de raio. O fato de aparecerem cores no mapa fora deste intervalo significa que o sistema é sensível a pequenos erros de alinhamento e centralização, focalização e ruído na imagem dos Discos de Plácido. Mas para esferas este mapa está condizente com as topografias de esferas em aparelhos comerciais.

\section{Visualização tridimensional da córnea}

Ao longo da implementação dos vários algoritmos para cálculo dos elementos da córnea percebemos a possibilidade de visualização destes dados de maneiras diferentes dos usuais mapas planos coloridos. Utilizando técnicas de visualização computacional $[50,51]$ e computação gráfica [48] implementamos um algoritmo de visualização das curvaturas da córnea em 3 dimensões. No eixo $\mathrm{Z}$ imprimimos curvatura e nos eixos $\mathrm{X}$ e $\mathrm{Y}$ imprimimos posição $\mathrm{em} \mathrm{mm}$. Além disso, as diferentes altitudes em $\mathrm{Z}$ estão impressas com a mesma escala de cores do mapa plano (figura 3.32).
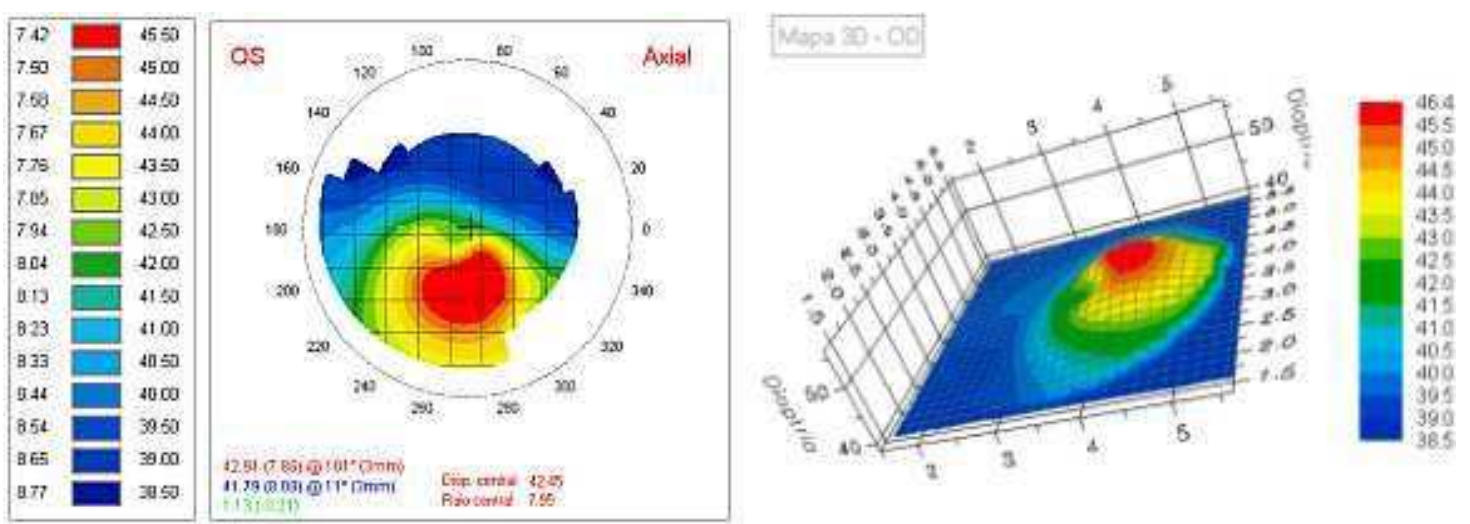

Figura 3.32. Mapas plano e 3D de um ceratocone. 
Além da visualização 3D o usuário pode também girar ou redimensionar o mapa na tela do monitor, com simples movimentos do cursor. A utilidade prática de tais mapas é assunto de debate entre os médicos. Alguns a acham útil para o processo de diagnóstico em si; outros já dizem ser mais útil para explicar ao paciente o formato de sua córnea e as patologias associadas.

\subsection{Resultados e Discussão}

\subsection{Medidas em esferas de calibração}

Utilizando o algoritmo descrito no capítulo anterior fizemos exames topográficos para outras três superfícies esféricas. Demonstramos os resultados destas medidas a seguir.

Os mapas para três esferas $(7.73,8.06$ e $8.34 \mathrm{~mm})$ podem ser vistos nas figuras 4.1, 4.2, e 4.3, respectivamente. Para superfícies esféricas não é necessário fazer medidas em outro aparelho para comparações e análise das precisões, pois basta verificar se os mapas obtidos indicam curvaturas constantes e de valores corretos sobre toda a superfície. Fazendo uma análise no padrão de cores dos mapas e comparando com os valores das escalas de cor, pode-se perceber que a curvatura sobre as esferas varia pouco. E mesmo nas regiões onde há variação de cor, pode-se notar que são cores

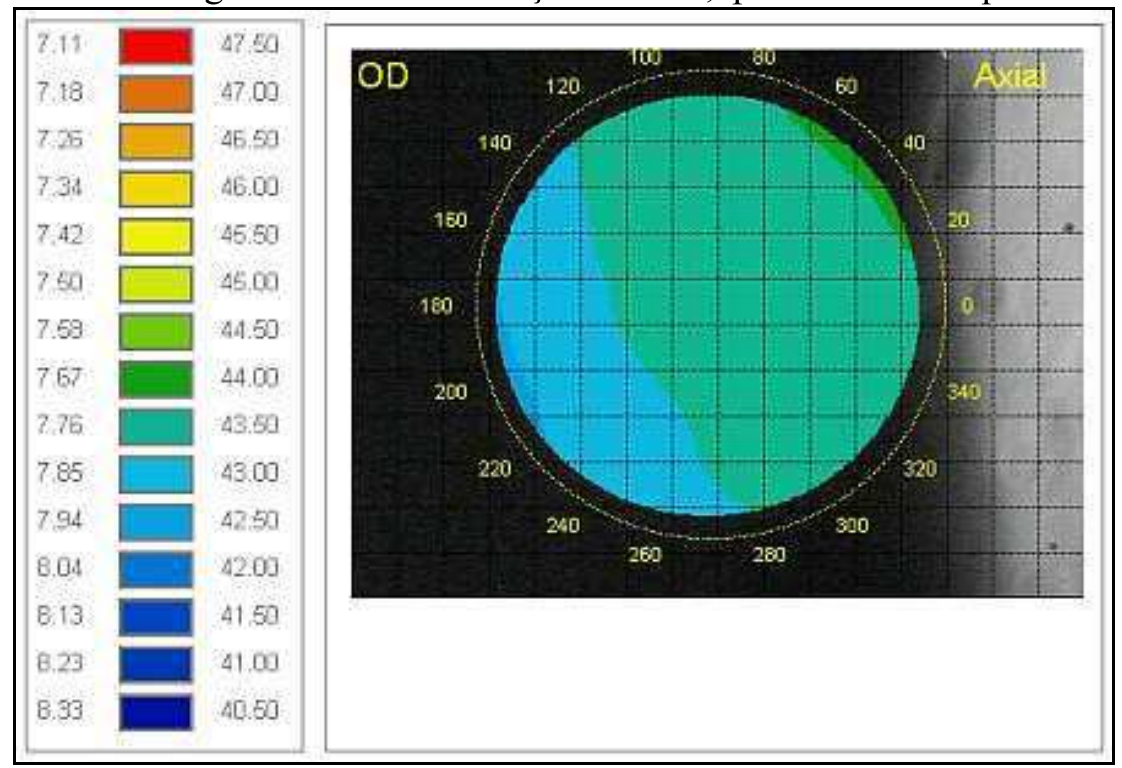

Figura 4.1. Mapa topográfico para esfera de raio $7.73 \mathrm{~mm}$.

vizinhas na tabela, indicando que o raio de curvatura de uma região para outra está variando pouco. Mas há regiões onde a variação é maior, no entanto estas regiões ocorrem devido a erros de focalização, alinhamento e rúdo na imagem dos Discos de Plácido. Calculamos o desvio médio padrão nas dioptrias para cada esfera e obtivemos uma média de: $0.15 \mathrm{D}$. 


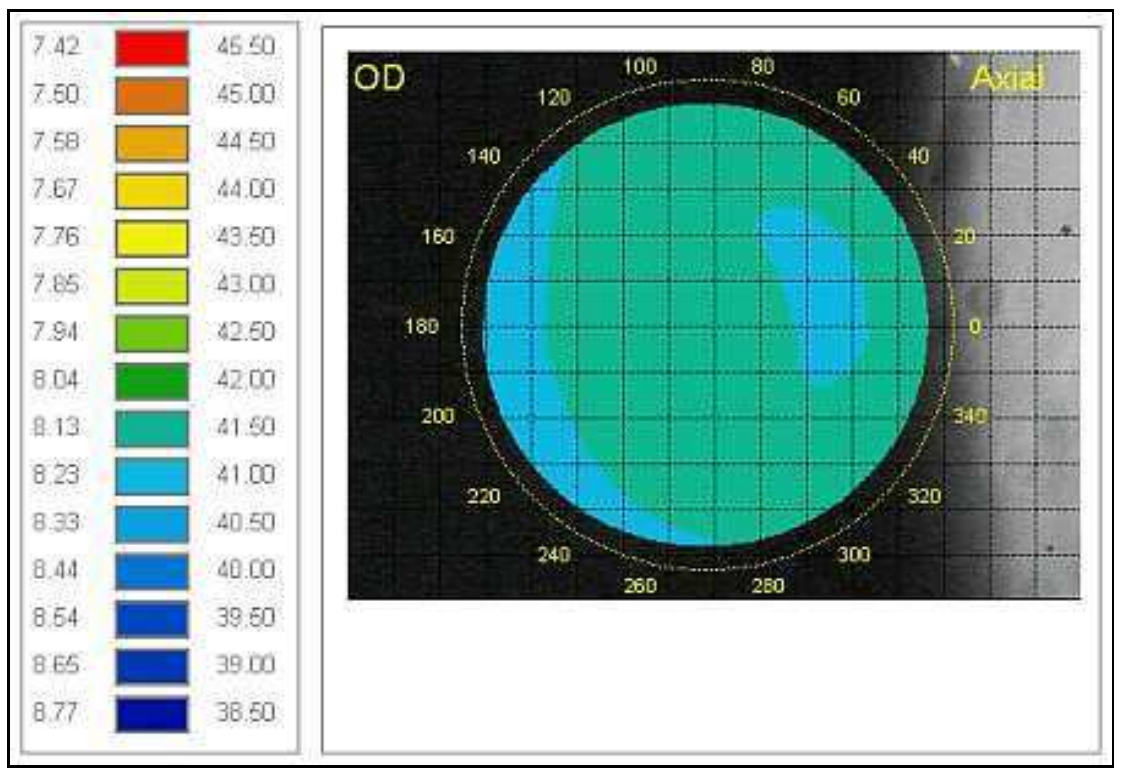

Figura 4.2. Mapa topográfico da esfera de raio $8.06 \mathrm{~mm}$. 


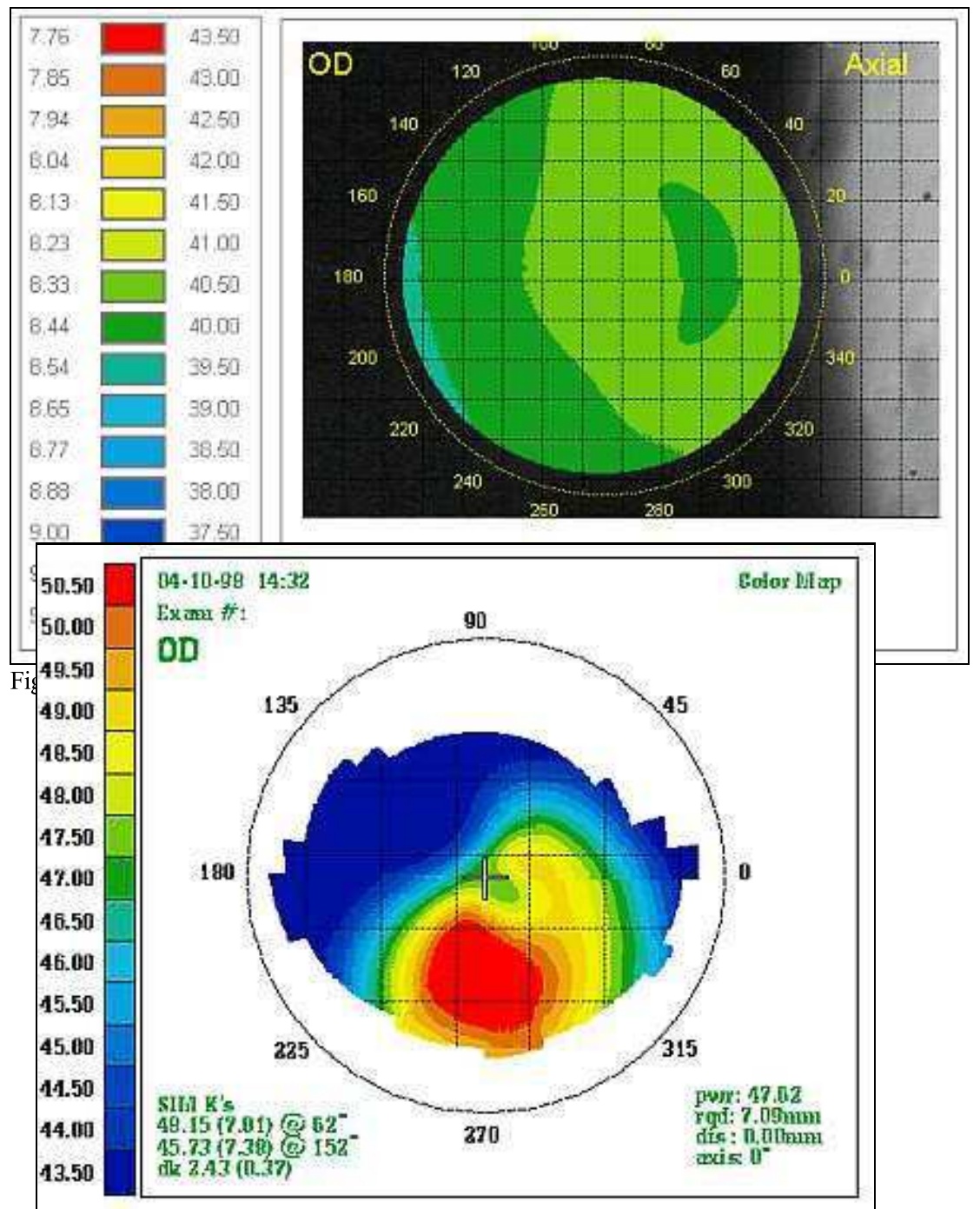

Figura 4.4. Mapa de uma córnea com ceratocone.

\subsection{Medidas em córneas in vivo}

Após verificar que o sistema estava fornecendo resultados coerentes e precisos para esferas, passamos a realizar medidas em córneas in vivo. Não queríamos realizar os testes em córneas do mesmo padrão. Escolhemos então 4 voluntários com problemas típicos de deformação na superfície da córnea, como astigmatismo (córnea mais achatada em um dos eixos) e ceratocone (altas curvaturas localizadas), e uma córnea aproximadamente regular (poucas variações de curvatura). Realizamos medidas destas córneas num aparelho comercial disponível na Escola Paulista de Medicina (EyeSys) e comparamos com medidas em nosso aparelho. Os resultados obtidos para estas córneas podem ser vistos nas figuras 4.4-4.11.

O primeiro caso é o da córnea do olho direito de uma mulher de aproximadamente 40 anos (figuras 4.4 e 4.5 ). 
Trata-se de um ceratocone relativamente protuberante, o qual pode futuramente trazer outras implicações. Percebe-se que o mapa no percirúrgico, embora de menor extensão, indica inferiormente o início do ceratocone, com valores em dioptria bastante parecidos.

O segundo caso (figuras 4.6 e 4.7) é da córnea do olho esquerdo de um homem de aproximadamente 30 anos. Pode-se perceber 0 astigmatismo levemente inclinado no mapa do aparelho comercial (figura 4.6), fato que

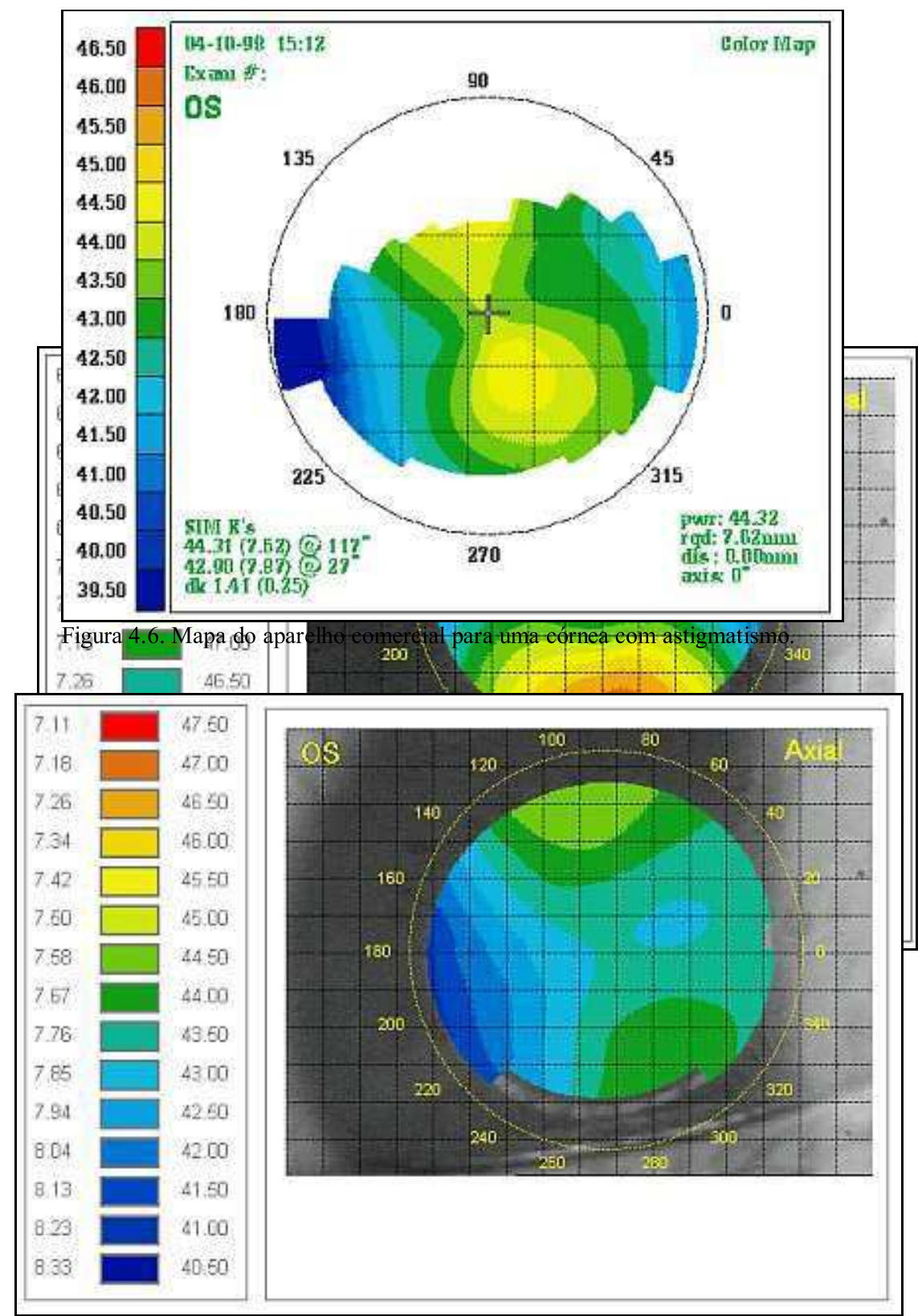

Figura 4.7. Mesma córnea da figura 4.6 medida em nosso instrumento. Padrão de astigmatismo detectado com sucesso, mas sistema demonstra alta sensibilidade ao alinhamento e focalização.

também ficou evidenciado no mapa do percirúrgico. 
A terceira córnea pertence ao olho direito de outro rapaz na faixa dos 25 anos. Podemos perceber que ambos os mapas (figuras 4.8 e 4.9) também evidenciam um

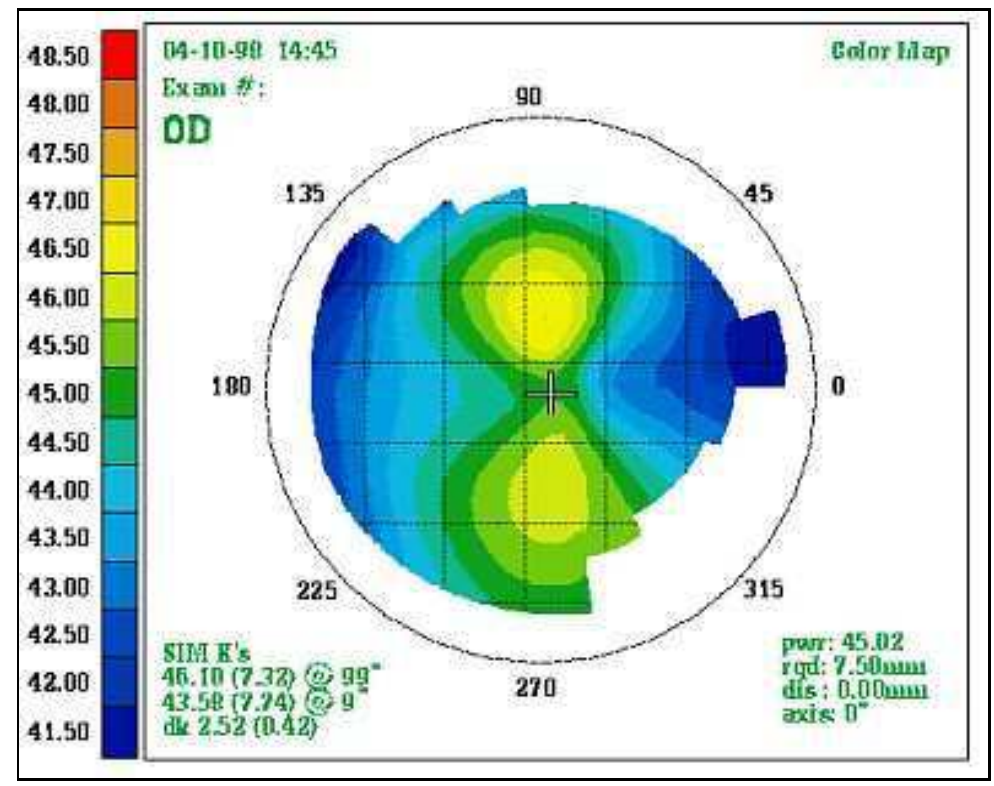

Figura 4.8. Córnea com astigmatismo a favor da regra.

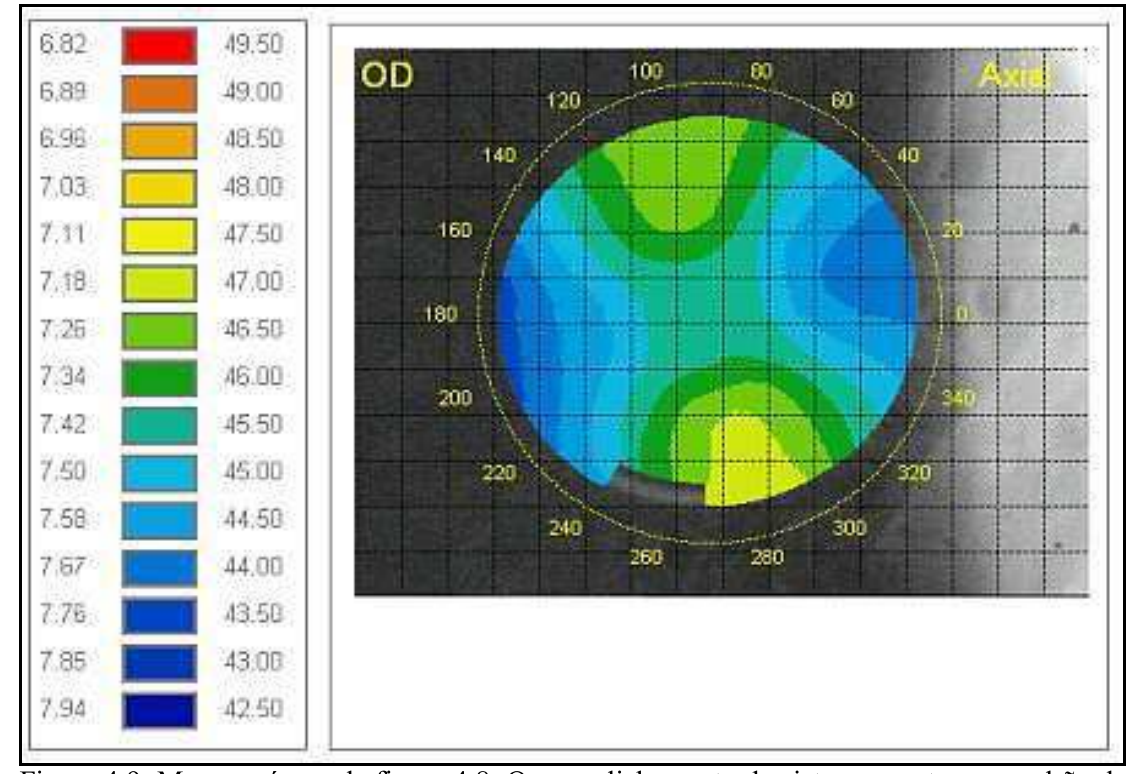

Figura 4.9. Mesma córnea da figura 4.8. O mau alinhamento do sistema mostra um padrão de astigmatismo com padrão de cores coerente, mas o eixo esta suavemente diferente daquele detectado no instrumento comercial.

astigmatismo. 
Finalmente, a quarta córnea pertence ao olho direito de uma mulher de 28 anos (figuras 4.10 e 4.11). Percebe-se em ambos os mapas que se trata de uma córnea aproximadamente esférica.

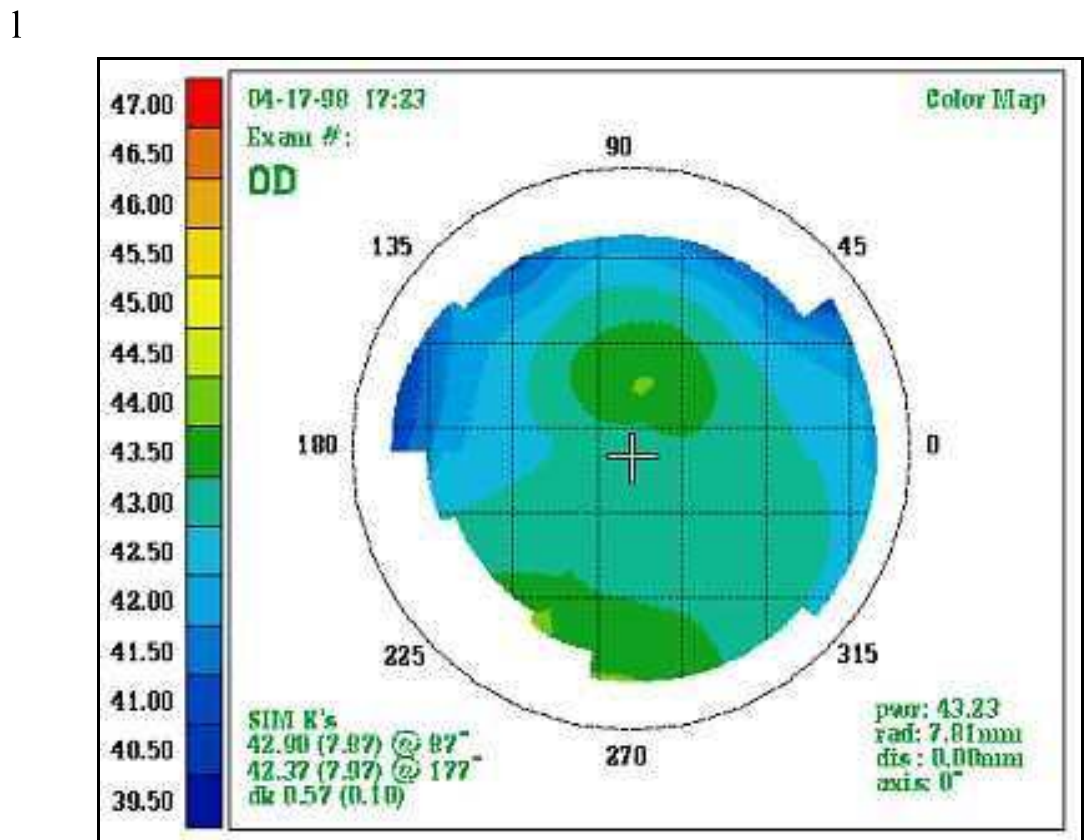

Figura 4.10. Mapa para uma córnea regular.

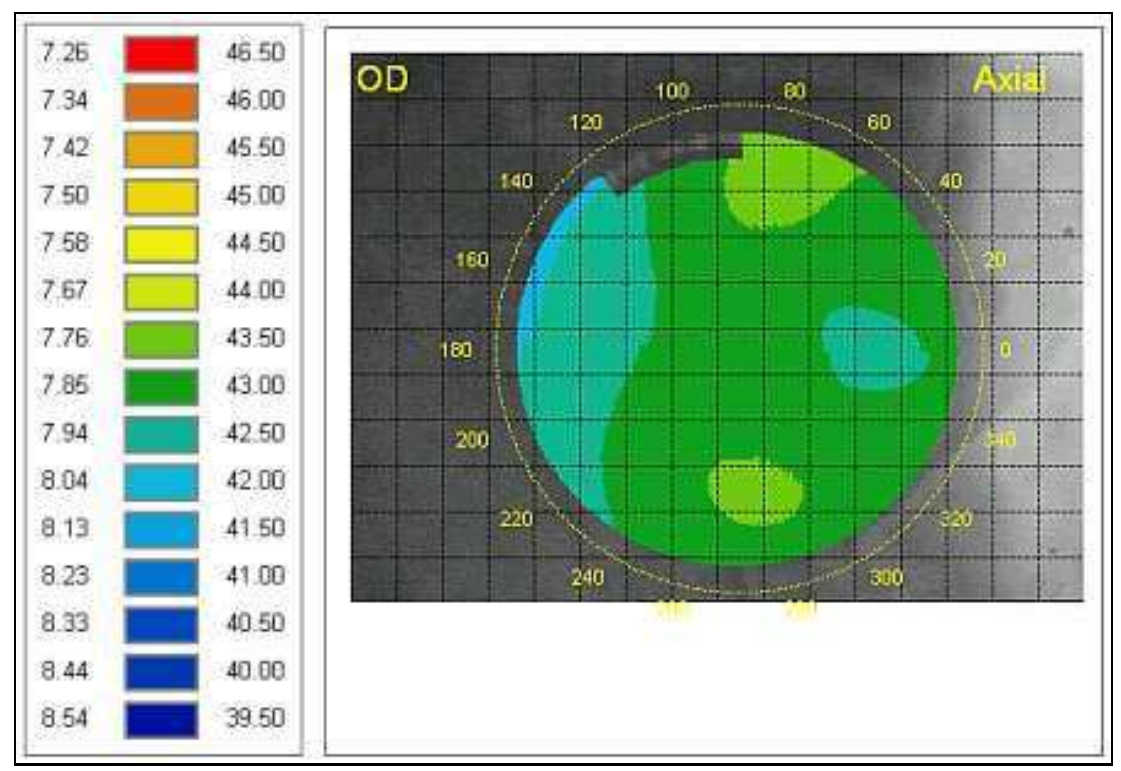

Figura 4.11. Mapa do percirúrgico para córnea regular da figura 4.10. Para córneas muito regulares o padrão de cores parece não ser tão repetitivo quanto aqueles de casos como ceratocone e astigmatismo. Mas os valores de dioptria caem na região adequada da escala de cores.

Para todos os 4 casos pudemos perceber qualitativamente que existem regiões nos mapas de ambos aparelhos que estão na mesma faixa de dioptrias. Isto é um sinal positivo e significa que o instrumento é capaz de identificar córneas destes tipos, mostrando ao médico durante a cirurgia a forma da córnea. Mas para saber se o 
instrumento é preciso tem que ser feita uma análise quantitativa dos milhares de pontos sobre a córnea. Além disso, como pode ser visto no canto inferior esquerdo dos mapas do aparelho comercial, existe o cálculo do astigmatismo (ceratometria), indicando eixos de maior e menor curvatura e diferença em dioptrias. Para comparações do astigmatismo vamos utilizar o algoritmo mostrado na página 52 do capítulo III.

Durante o período de doutorado "sandwich" no exterior foram realizadas medidas em 7 voluntários adultos e sadios (3 mulheres, 4 homens; idades entre 20 e 30 anos) junto ao centro cirúrgico do Departament of Ophthalmology da UCSF (University of California at San Francisco). Todos voluntários foram avisados da natureza experimental e não invasiva do exame. Nosso instrumento foi montado em um microscópio cirúrgico padrão Zeiss e três residentes foram convidados para realizar duas medidas em cada olho. Para comparações, os mesmos olhos foram examinados num aparelho Eyesys (System 2000) do mesmo departamento e as medidas arquivadas em disquete para uso posterior. Utilizando uma pequena régua (100 divisões em $1 \mathrm{~mm}$ ) medimos o fator $\mathrm{mm} /$ pixel de cada um dos aparelhos, de modo a saber quais regiões seriam comparadas (veja Novos algoritmos para comparações quantitativas e cálculo do astigmatismo na página 52 do Capítulo III).

Na tabela 4.1 podemos ver os valores do astigmatismo para as 14 córneas e o desvio padrão para raio e dioptria. Os algoritmos mostrados no item anterior foram utilizados para fazer os cálculos de astigmatismo e do desvio padrão. A diferença em raio de curvatura para os 360 semimeridianos foi menor que ou igual a $0.05 \mathrm{~mm}$ para $78 \%$ dos casos. Para o astigmatismo foi menor que ou igual a $0.25 \mathrm{D}$ para $86 \%$. E no cilindro foi menor que ou igual a 5 graus em $78 \%$ dos casos. O desvio médio foi $0.05 \mathrm{~mm}$ para o raio de curvatura, $0.24 \mathrm{D}$ para a dioptria, e 5 graus para o cilindro.

\begin{tabular}{|c|c|c|c|c|c|c|c|c|c|c|}
\hline \multirow{3}{*}{$\begin{array}{l}\text { Cornea } \\
1\end{array}$} & \multicolumn{4}{|c|}{ Topógrafo de Córnea EyeSys } & \multicolumn{4}{|c|}{ Nosso sistema } & & \\
\hline & \multicolumn{2}{|c|}{$\begin{array}{l}\text { Meridianos } \\
\text { principais (D) }\end{array}$} & \multirow{2}{*}{$\begin{array}{l}\begin{array}{l}\text { Cilindro } \\
\text { (D) }\end{array} \\
1.25\end{array}$} & \multirow{2}{*}{$\begin{array}{l}\begin{array}{l}\text { Eixo } \\
\text { (graus) }\end{array} \\
78 \\
\end{array}$} & \multicolumn{2}{|c|}{$\begin{array}{l}\text { Meridianos } \\
\text { principais (D) }\end{array}$} & \multirow{2}{*}{$\begin{array}{l}\text { Cilindro } \\
\text { (D) } \\
\\
1.78 \\
\end{array}$} & \multirow{2}{*}{$\begin{array}{l}\begin{array}{l}\text { Eixo } \\
\text { (graus) }\end{array} \\
94 \\
\end{array}$} & \multicolumn{2}{|c|}{$\begin{array}{l}\text { Desvio padrão } \mathrm{p} / \text { todos } \\
\text { os } 360 \text { meridianos (raio } \\
(\mathrm{mm}) \text {, dioptria }(\mathrm{D}) \text { ) }\end{array}$} \\
\hline & 43.49 & 42.24 & & & 43.60 & 41.82 & & & 0.05 & 0.22 \\
\hline 2 & 44.32 & 42.63 & 1.69 & 89 & 43.97 & 42.45 & 1.52 & 101 & 0.04 & 0.20 \\
\hline 3 & 42.94 & 42.05 & 0.89 & 89 & 42.73 & 41.65 & 1.08 & 94 & 0.04 & 0.19 \\
\hline 4 & 43.14 & 41.86 & 1.28 & 75 & 43.59 & 41.63 & 1.96 & 70 & 0.07 & 0.32 \\
\hline 5 & 45.02 & 44.33 & 0.69 & 98 & 44.95 & 44.18 & 0.77 & 98 & 0.04 & 0.22 \\
\hline 6 & 44.62 & 43.27 & 1.35 & 65 & 43.98 & 43.09 & 0.89 & 67 & 0.05 & 0.27 \\
\hline 7 & 42.45 & 40.78 & 1.67 & 82 & 42.49 & 40.74 & 1.75 & 80 & 0.03 & 0.18 \\
\hline 8 & 43.67 & 42.53 & 1.14 & 87 & 43.73 & 42.58 & 1.15 & 86 & 0.02 & 0.15 \\
\hline 9 & 43.07 & 42.04 & 1.03 & 96 & 42.69 & 41.61 & 1.08 & 97 & 0.06 & 0.32 \\
\hline 10 & 43.04 & 41.84 & 1.20 & 90 & 43.31 & 41.85 & 1.46 & 89 & 0.05 & 0.25 \\
\hline 11 & 42.78 & 41.32 & 1.46 & 78 & 42.81 & 41.37 & 1.44 & 76 & 0.03 & 0.16 \\
\hline 12 & 44.54 & 43.41 & 1.13 & 56 & 43.98 & 43.12 & 0.86 & 61 & 0.05 & 0.27 \\
\hline 13 & 47.07 & 44.35 & 2.72 & 95 & 46.75 & 43.71 & 3.04 & 80 & 0.06 & 0.38 \\
\hline 14 & 42.91 & 42.33 & 0.58 & 125 & 42.87 & 42.35 & 0.52 & 122 & 0.04 & 0.19 \\
\hline & & & & & & & & & $\begin{array}{l}\text { Média: } \\
0.05\end{array}$ & $\begin{array}{l}\text { Média: } \\
0.24\end{array}$ \\
\hline
\end{tabular}

Tabela 4.1. Tabela com os resultados do astigmatismo do EyeSys e do Intracirúrgico para 14 córneas sadias.

Os resultados obtidos indicam que o instrumento é suficientemente preciso para medir o astigmatismo e a forma da córnea na região central, de 6-7 $\mathrm{mm}$ em diâmetro [52]. Futuros testes em pacientes passando por diversos tipos de cirurgias (catarata, transplante de córnea e etc) devem ser realizados. Sabe-se que novos instrumentos, desde a concepção até a aceitação na área médica passam por várias etapas e podem levar anos, ou até décadas antes que sejam utilizados. 


\subsection{Resultados do algoritmo de elevação para diferentes superfícies}

No Capítulo III apresentamos novos modelos matemáticos da córnea, dentre eles um importante modelo para cálculo da elevação (página 39). E neste mesmo capítulo apresentamos algoritmos que simulam o traçado de raios provindos dos Discos de Plácido, atingindo a córnea e formando a imagem no plano do CCD. Como mencionado, esta é uma maneira teórica e elegante de verificar se o algoritmo de elevação implementado funciona e, mais do que isso, determinar sua precisão. Nosso objetivo nesta seção foi simular uma série de superfícies (esferas, elipsóides, tóricas e até mesmo ceratocones) para avaliar esta precisão. Utilizando o algoritmo descrito no Capítulo III simulamos imagens dos Discos de Plácido para estes quatro tipos de superfícies, variando alguns parâmetros de cada uma. Os parâmetros utilizados para o disco de Plácido são aqueles medidos em nosso disco, e são carregados no início do programa. Observação importante: utilizamos no simulador um cone com 8 discos (16 bordas), ou seja, 3 discos além dos 5 do cone real. Fizemos isto porque num futuro próximo pretendemos comparar nossas medidas de elevação com aquelas de um equipamento importado, que utiliza 8 discos. Salientamos que este detalhe em nada modifica os algoritmos apresentados até aqui ou os resultados obtidos na simulação, pelo contrário, pode indicar até mesmo se valeria à pena construirmos no futuro um cone com maior número de discos.

Além disso, estes algoritmos foram reescritos em Delphi e pela primeira vez ao longo deste projeto, pudemos visualizar mapas coloridos de elevação (bastante diferentes dos mapas de curvatura), os quais serão apresentados aqui. Veremos a seguir como simulamos estas superfícies e o resultado para cada uma delas.

\section{Simulando esferas}

Para o algoritmo que gera os valores da esfera simplesmente inserimos o valor do raio na equação

$$
y=\left(2 x r-x^{2}\right)^{1 / 2}
$$

onde $y$ representa a distância radial, $x$ a profundidade e $r$ o raio da circunferência. Obs: esta é a relação entre as coordenadas utilizadas aqui e aquelas utilizadas no modelo de elevação (veja figura 3.20), ou seja, a elevação denotada por $h$ aqui é denotada por $x$, a distância radial denotada por $r$ aqui é $y$ e o ângulo polar $\phi$ só será utilizado para a superfície tórica, pois todas as outras são rotacionalmente simétricas. $\mathrm{O}$ código em Matlab para gerar os pontos da circunferência pode ser visto no diagrama 4.1. Os outros valores para 360 meridianos são calculados girando esta curva.

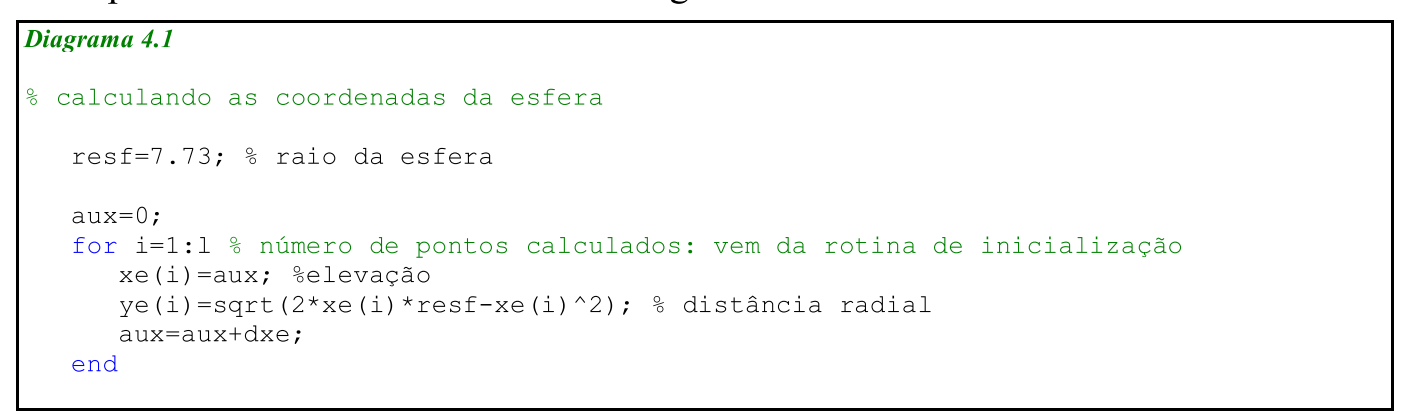


Em seguida variamos os parâmetros de elevação $(x)$ para calcular distância radial $(y)$. O perfil da esfera e sua simulação dos Discos de Plácido podem ser vistos na figura 4.12.

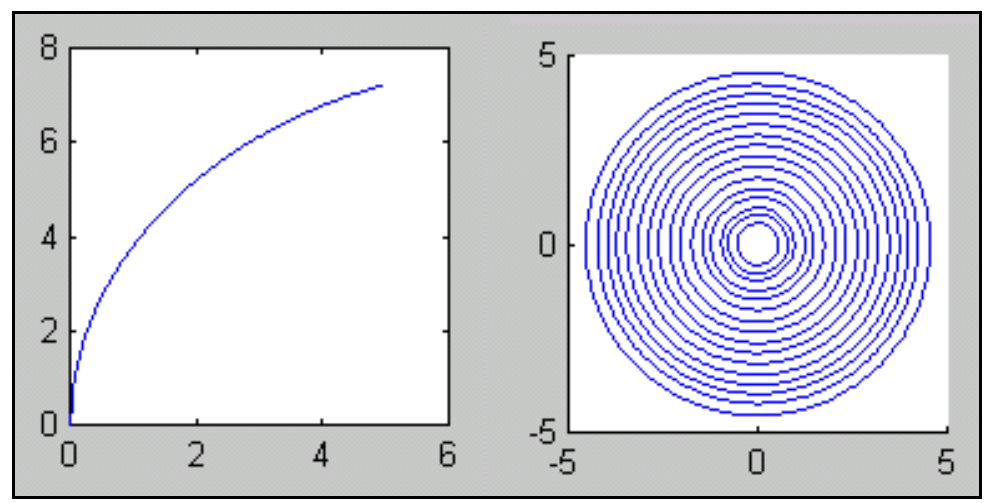

Figura 4.12. (esquerda) Perfil da esfera de raio $7.73 \mathrm{~mm}$ gerado pelo código do diagrama 1; (direita) resultado da simulação para mesma esfera, mostrando a imagem que seria gerada no plano da câmera CCD. Como esperado obtivemos uma imagem com Discos de Plácido concêntricos e uniformemente espaçados. Todas dimensões estão em mm.

\section{Simulando elipsóides}

O mesmo é feito na caso do elipsóide, utilizando a equação

$$
y=\left(2 r_{a} x-p x^{2}\right)^{1 / 2}
$$

onde $r_{a}$ é o raio apical da elipse, e $p=1-e^{2}$, onde $e=$ excentricidade da elipse. $\mathrm{O}$ código em Matlab para o elipsóide é análogo ao da esfera, e pode ser visto no diagrama 4.2 .

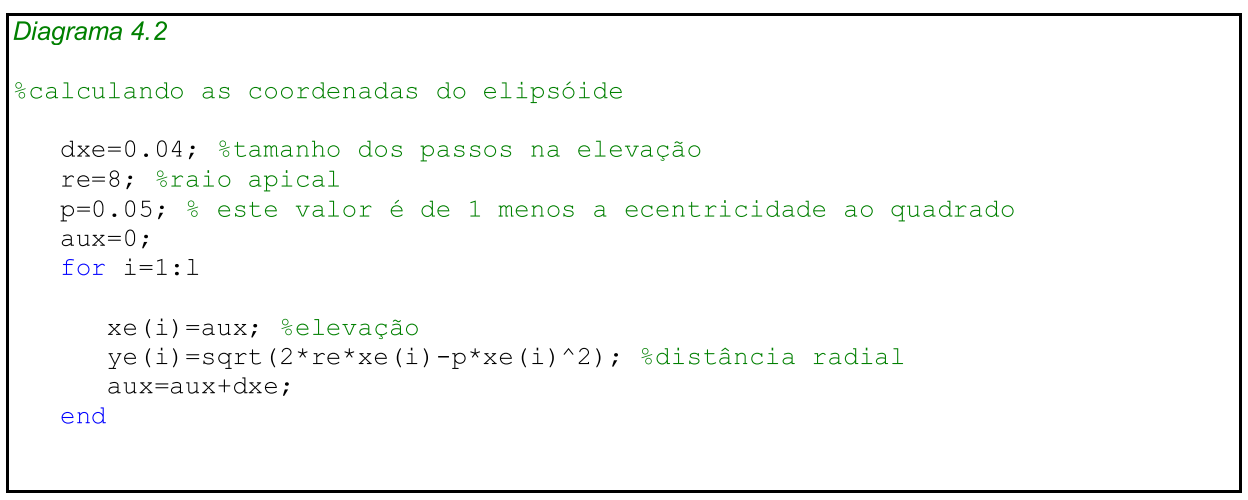

Os resultados para o elipsóide podem ser vistos na figura 4.13. 


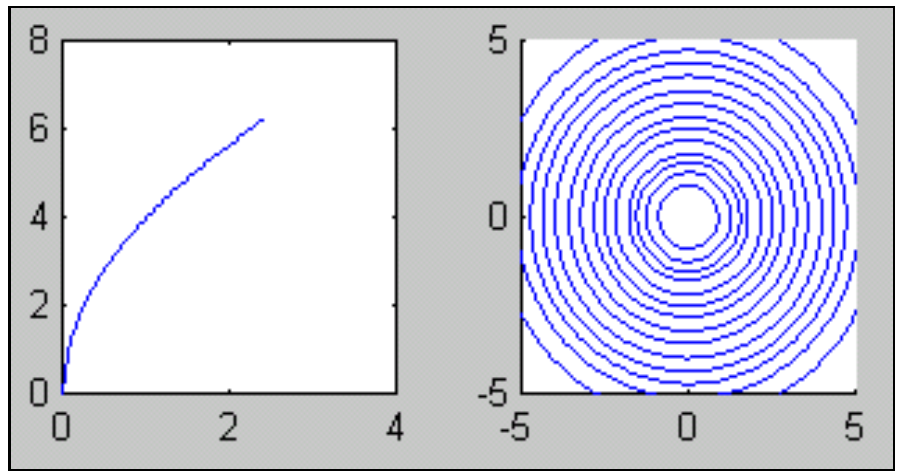

Figura 4.13. (esquerda) perfil da da elipse utilizada para gerar o elipsóide; (direita) Discos de Plácido concêntricos, mas com espaçamentos que vão aumentando do centro para a periferia.

\section{Simulando Tóricas}

A diferença no caso do elipsóide é que neste caso podemos variar o raio apical $\left(r_{a}\right)$ para gerar uma superfície tórica (esfero-cilíndrica), ou seja, uma superfície com astigmatismo, que não é rotacionalmente simétrica. Para isso utilizamos uma equação para calcular o raio apical da elipse de cada meridiano que depende do ângulo $\phi$ deste meridiano:

$$
r_{a}=\frac{1}{\left(\frac{1}{r_{h}}+\left(\frac{1}{r_{v}}-\frac{1}{r_{h}}\right) \operatorname{sen}(\phi)^{2}\right)}
$$

E código para a superfície tórica pode ser visto no diagrama 4.14.

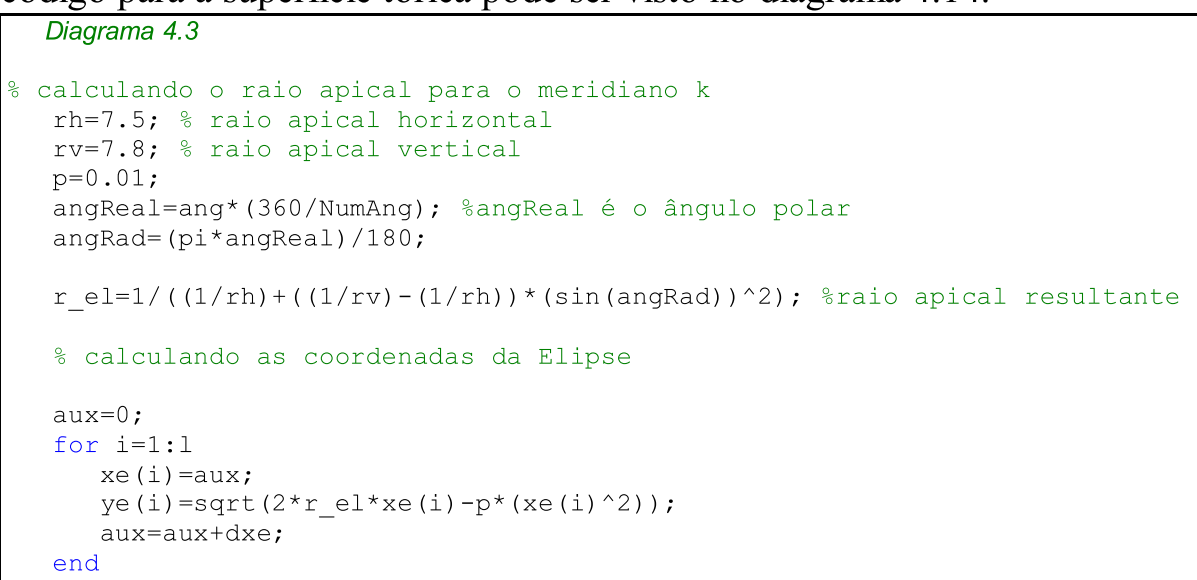


Na figura 4.14 temos os resultados para a superfície tórica.

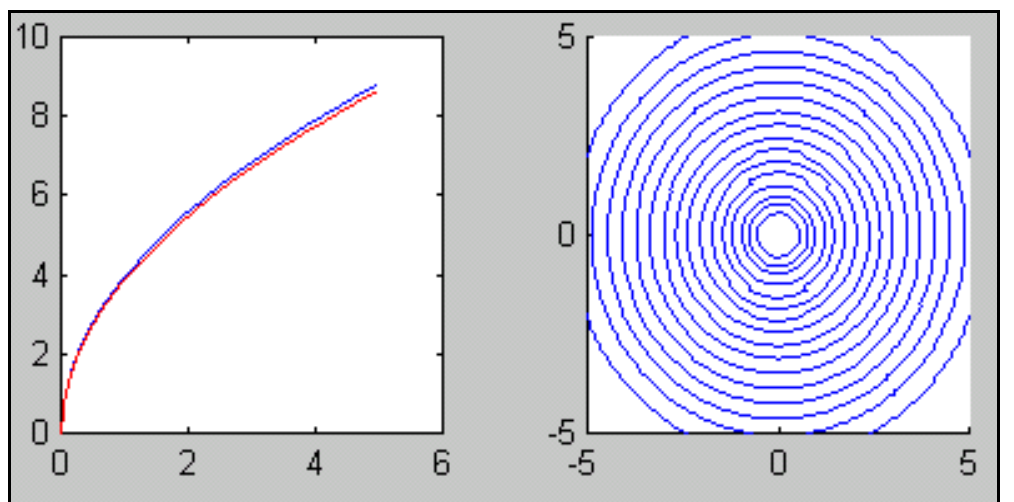

Figura 4.14. Cortes do meridiano mais curvo (vermelho) e menos curvo (azul) para uma superfície tórica (também denominada de esfero-cilíndrica por poder ser representada pela soma de uma esfera mais um cilindro). $O$ resultado disto na imagem de Plácido são anéis levemente achatados no meridiano mais curvo (horizontal) e menos achatados no meridiano menos curvo (vertical).

\section{Simulando Ceratocones}

No caso da superfície com ceratocone é mais complexo criar uma função analítica que o descreva. Inicialmente porque não sabemos exatamente qual o seu formato e em segundo lugar porque esta superfície tem que ter continuidade até a $1^{\underline{0}}$ derivada, ou seja, das tangentes [41, 42]. Como as imagens de Plácido são formadas por reflexão especular, a normal à superfície deve ter transições suaves para que os anéis não se entrelacem e que tenham uma forma que permita o processamento das bordas. Como a tangente à superfície é sempre perpendicular ao vetor normal, isto significa que a superfície deve ter primeiras derivadas contínuas, ou seja, continuidade de ordem 1. Estudamos alguns polinômios que poderiam simular um ceratocone, e a superfície encontrada é a junção de duas parábolas com uma função seno ao meio. As equações paramétricas que descrevem esta superfície são:

$$
x=\left\{\begin{array}{l}
r_{0}-\sqrt{r_{0}^{2}-y^{2}} \quad \begin{array}{c}
p / 0 \leq y<y_{1} \\
r_{0}-\sqrt{r_{0}^{2}-y^{2}}+\frac{a}{2} \cdot\left\{1-\cos \pi\left(\frac{y-y_{1}}{y_{2}-y_{1}}\right)\right\} \\
r_{0}-\sqrt{r_{0}^{2}-y^{2}}+a \quad p / y_{2} \leq y
\end{array} \quad p / y_{1} \leq y<y_{2}
\end{array}\right.
$$

O trecho do código que gera esta superfície está no diagrama 4.4. 


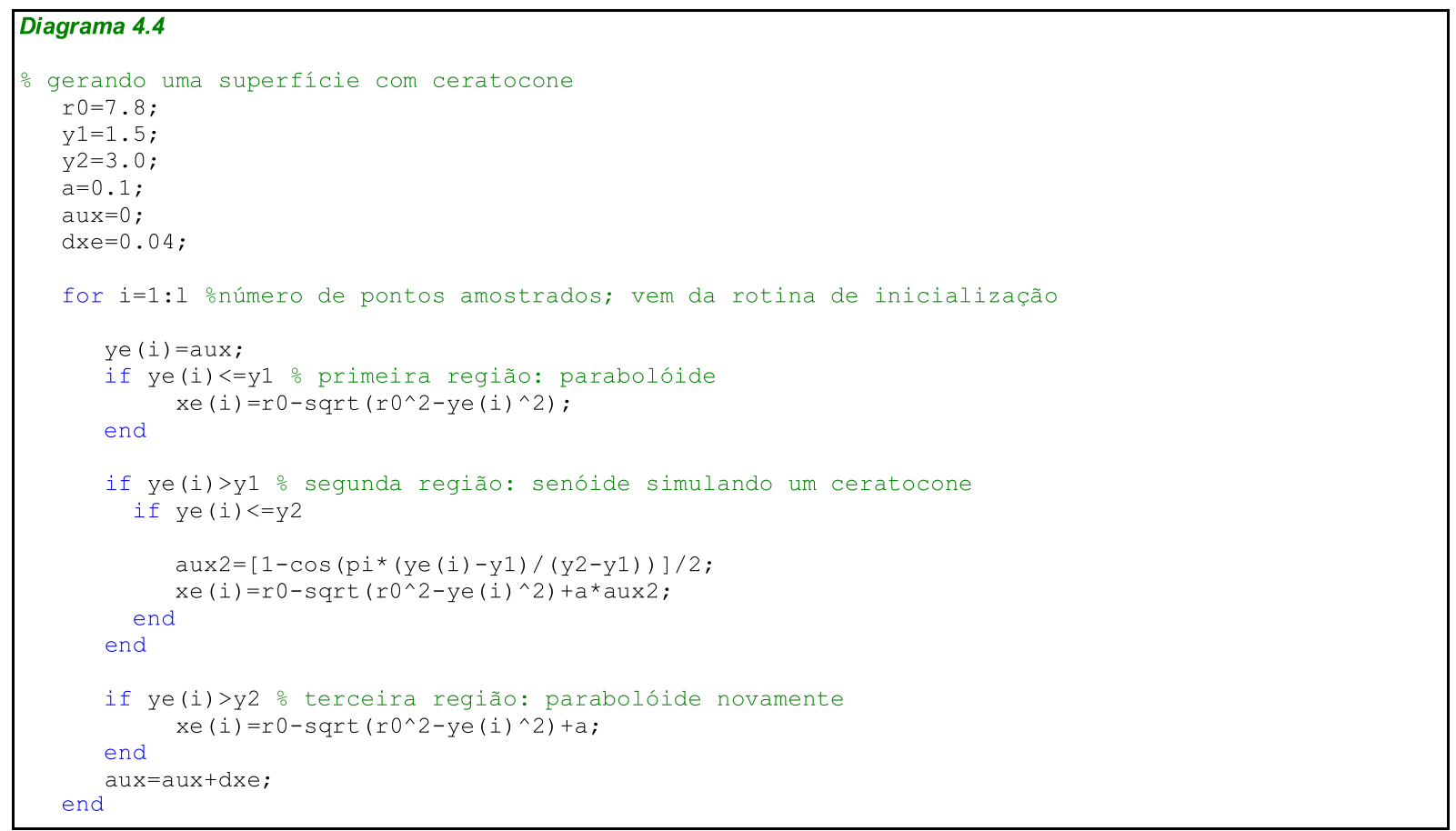

De 0 até yl temos uma parábola. Entre $y_{1}$ e $y_{2}$ temos uma senóide e acima de $y_{2}$ temos outra parábola. O parâmetro de ajuste da "intensidade" do cone é $a$. Através da variação dos valores de $y_{1}, y_{2}$ e $a$, podemos obter várias curvas, com formas de ceratocones diferentes. Para mostrar que esta curva obedece a continuidade até ordem 1 exigida, vamos comparar a expressões em (4.4) e suas derivadas nos pontos de transição.

A continuidade das curvas paramétricas em (4.4) pode ser demonstrada comparando o valor de $x$ nas equações para cada valor de $y$ nas extremidades, ou seja, em $y_{1}$ e $y_{2}$. Para ordem zero, em $y=y_{1}$, ambas as equações 4.4(a) e 4.4(b) valem:

$$
r_{0}-\sqrt{r_{0}^{2}-y_{1}^{2}}
$$

e para $y=y_{2}$ ambas as equações 4.4(b) e 4.4(c) valem:

$$
r_{0}-\sqrt{r_{0}^{2}-y_{1}^{2}}+a
$$

logo estas equações têm continuidade de ordem zero.

Para conferir a continuidade de ordem um, extraímos a primeira derivada de cada equação em (4). A derivada em $x$ da equação 4(a) é:

$$
-\frac{1}{2}\left(r_{0}^{2}-y^{2}\right)^{-1 / 2}(-2 y)
$$

E a derivada da equação 4(b) é: 


$$
-\frac{1}{2}\left(r_{1}^{2}-y^{2}\right)^{-1 / 2}(-2 y)+\frac{a}{2}\left(\frac{\pi}{y_{2}-y_{1}}\right) \operatorname{sen}\left(\pi\left(\frac{y-y_{1}}{y_{2}-y_{1}}\right)\right)
$$

Para $y=y_{1}$ ambas as equações (4.7) e (4.8) assumem o valor:

$$
-\frac{1}{2}\left(r_{0}^{2}-y_{1}^{2}\right)^{-1 / 2}\left(-2 y_{1}\right)
$$

e para $y=y_{2}$ o segundo termo da equação (4.8) também é zero pois $\operatorname{sen}(\pi)=0$ e então ambas equações 4.4(b) e 4.4(c) valem:

$$
-\frac{1}{2}\left(r_{0}{ }^{2}-y_{2}^{2}\right)^{-1 / 2}\left(-2 y_{2}\right)
$$

Portanto as equações em (4.4) também têm continuidade de ordem 1, como queríamos demonstrar. O resultado do algoritmo de simulação para esta superfície com

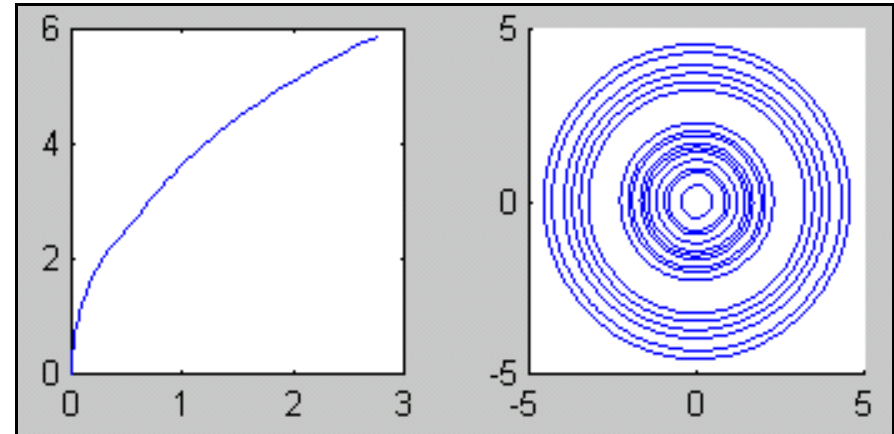

Figura 4.15. Resultado para superfície com ceratocone. Observe no perfil da curva à esquerda uma suave transição entre a região de parábola para senóide e depois parábola novamente. Os valores de $a, y_{1}$, e $y_{2}$ podem ser vistos no diagrama 4.

ceratocone pode ser visto na figura 4.15.

Resultados do algoritmo de elevação

Os parâmetros das imagens de Plácido (distâncias radiais dos anéis) foram inseridos no algoritmo para o modelo de elevação. Desta maneira calculamos o perfil das curvas, e como sabíamos suas expressões analíticas, pudemos testar este modelo e calcular sua precisão teórica. Uma próxima etapa é o cálculo da elevação de superfícies reais. Para todas os tipos de curvas apresentados anteriormente geramos a imagem dos Discos de Plácido e a gravamos na memória rígida do computador na forma de arquivos texto ( $A S C I I$-formato de gravação de arquivos muito popular em computação). Estes arquivos foram então lidos pelo programa que calcula elevação, e os perfis das curvas para cada superfície foram levantados. Cada perfil calculado foi então impresso juntamente com o perfil original. $\mathrm{O}$ módulo da diferença entre as curvas, para vários 
pontos, foi calculado e obtivemos o desvio médio padrão para todas as superfícies. Mostramos estes resultados a seguir.

$\mathrm{Na}$ figura 4.16 podemos ver o resultado do algoritmo de elevação para três superfícies diferentes (para a tórica os resultados são análogos àqueles obtidos para a elipse, com mudanças apenas na excentricidade dos meridianos). A curva verde é o perfil teórico e em azul temos o calculado. Podemos perceber que ambos perfis praticamente se sobrepõe, visualmente indicando a precisão do algoritmo. O desvio médio padrão para as superfícies foi de apenas $2 \mu \mathrm{m}$, um valor bastante pequeno e que só é possível em simulações como esta, mas que mostram o poder do algoritmo. $\mathrm{Na}$ prática a história é diferente, pois existem erros de focalização e alinhamento. Por este motivo gostaríamos de numa próxima etapa usar este algoritmo para medir elevações em superfícies reais. Estamos no momento fabricando estas superfícies em vidro e tornos de alta precisão. Somente assim poderemos saber a precisão deste algoritmo em termos práticos.

Sugerimos como trabalho futuro a análise do desvio médio padrão de acordo com os parâmetros de cada curva. No caso da esfera deve-se variar o raio, e no caso da elipsóide a excentricidade, e na tórica o valor do astigmatismo. No ceratocone deve-se variar o valor de $y_{1}, y_{2}$, e $a$. Em alguns testes preliminares percebemos que o erro aumenta bastante com a variação da "intensidade" do ceratocone. Depois destas análises, conforme sugerimos acima e ao final deste parágrafo, seria interessante testar este algoritmo em superfícies reais, inclusive com aplicações interessantes na previsão de quanto necessita-se ablar a córnea para obter uma correção mais precisa em cirurgias refrativas [53].

Imprimimos também mapas planos com códigos de cor para estas superfícies. Um detalhe interessante que percebemos ao imprimir estes gráficos é que todos são muito semelhantes. Analisando este detalhe percebemos que isso ocorre devido ao fato dos

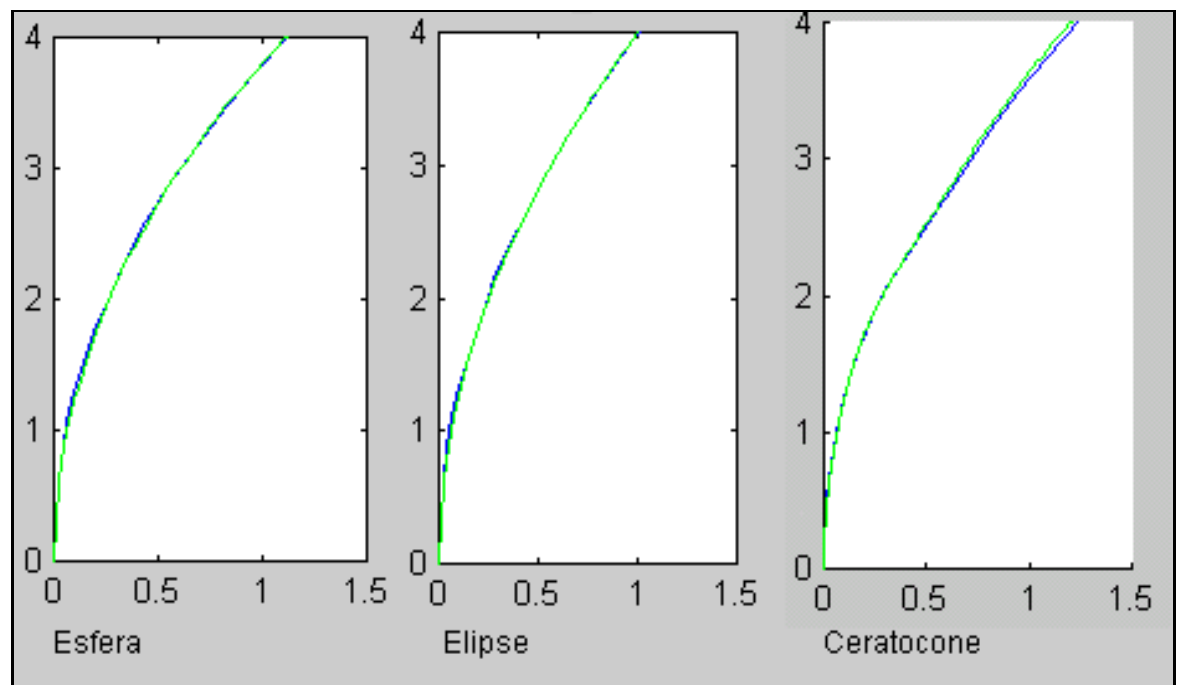

Figura 4.16. Resultado do algoritmo de elevação (em azul) para as superfícies simuladas (em verde). À esquerda temos a esfera de raio $7.73 \mathrm{~mm}$, ao centro uma elipse com $r_{a}=8.00 \mathrm{~mm}$, $p=0.05$, e à direita temos um ceratocone cujos parâmetros estão no Diagrama 4 . Perceba que o algoritmo é bastante preciso e por este motivo a linha verde praticamente encobre a linha azul. No caso do ceratocone foi utilizado um parâmetro de "intensidade" bastante alto $(\mathrm{a}=0.1)$, e mesmo neste caso o algoritmo se comportou bem.

desvios na superfície serem muito menores que a elevação total da mesma. Desta 
maneira um elipsóide fica muito parecido com uma esfera quando impresso em códigos de cor. Uma das soluções para este "problema" de visualização, sugerido por Salmon et. al. [54] e Applegate et. al. [55], é a subtração de duas superfícies. Uma das superfícies seria aquela que realmente desejamos analisar; a outra pode ser, por exemplo, uma esfera de determinado raio. Então esta passa a ser a superfície de referência, e não necessariamente um plano de referência (veja figura 3.15 na página 32). Para imprimir os mapas de elevação, utilizamos o mesmo princípio dos mapas apresentados anteriores, mas desta vez as cores estão relacionadas à elevação local da superfície e não ao poder de refração (Dioptria). Nas figuras seguintes podemos ver mapas de uma esfera, elipsóide, tórica e ceratocone. 


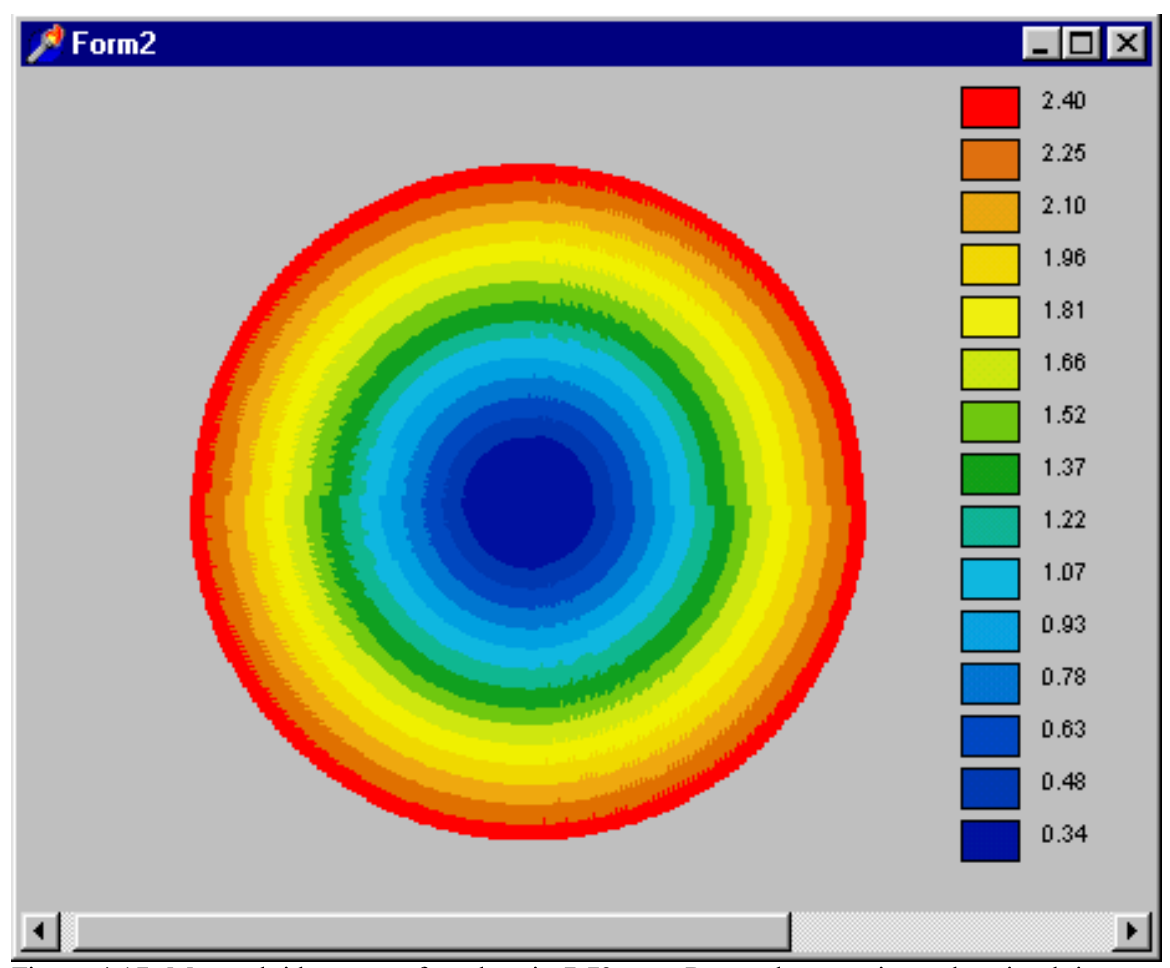

Figura 4.17. Mapa obtido para esfera de raio $7.73 \mathrm{~mm}$. Para valores maiores do raio obtivemos mapas com diâmetros maiores, o que faz sentido pois superfícies de raios maiores geram imagens de Plácido maiores.

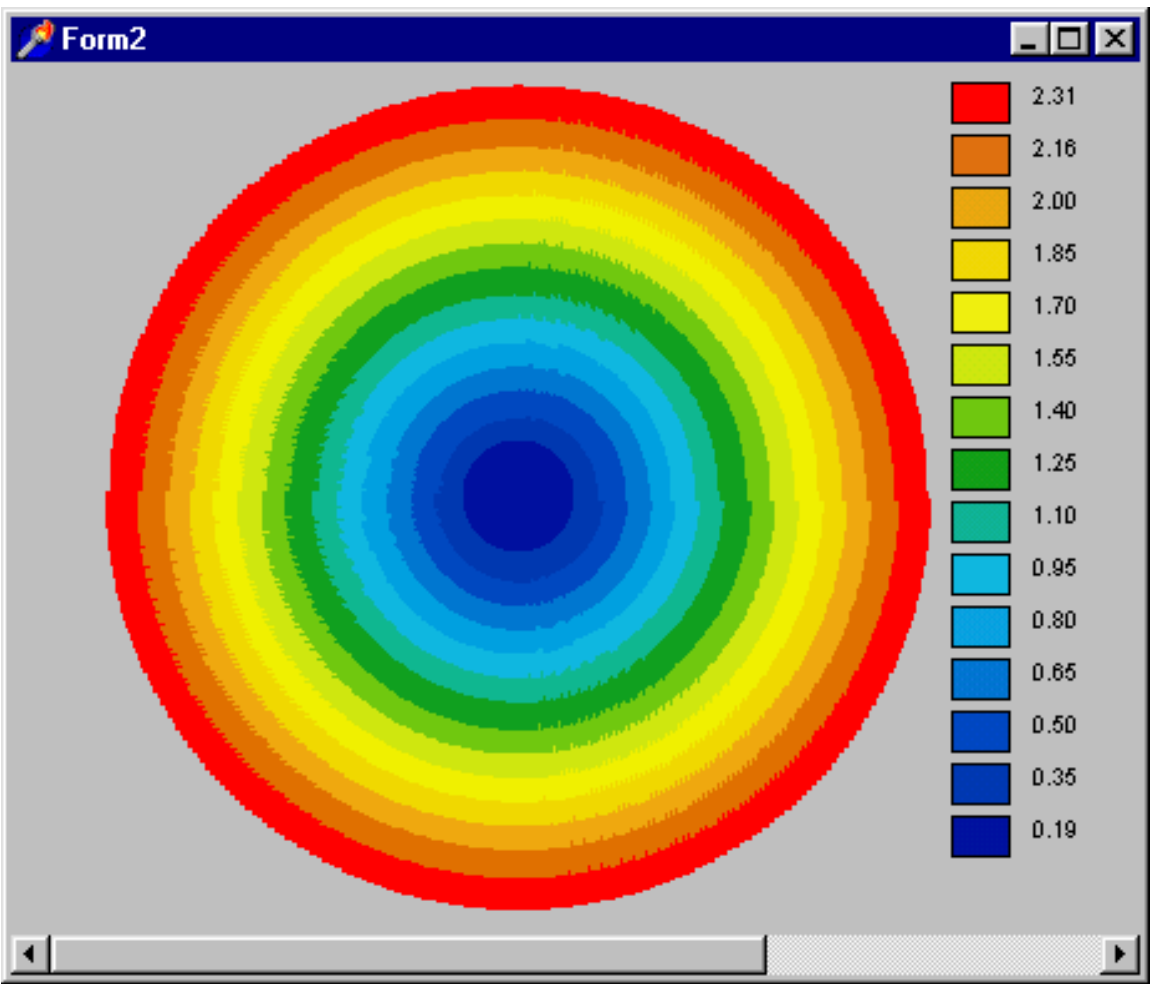

Figura 4.18. Mapa colorido obtido para elipsóide de raio apical de $8.00 \mathrm{~mm}$. O padrão de cores é parecido com aquele da esfera, mas as cores variam mais lentamente e a escala tem intervalos maiores que o mapa da esfera. Isto está coerente com a excentricidade escolhida (veja Diagrama 4.2). 


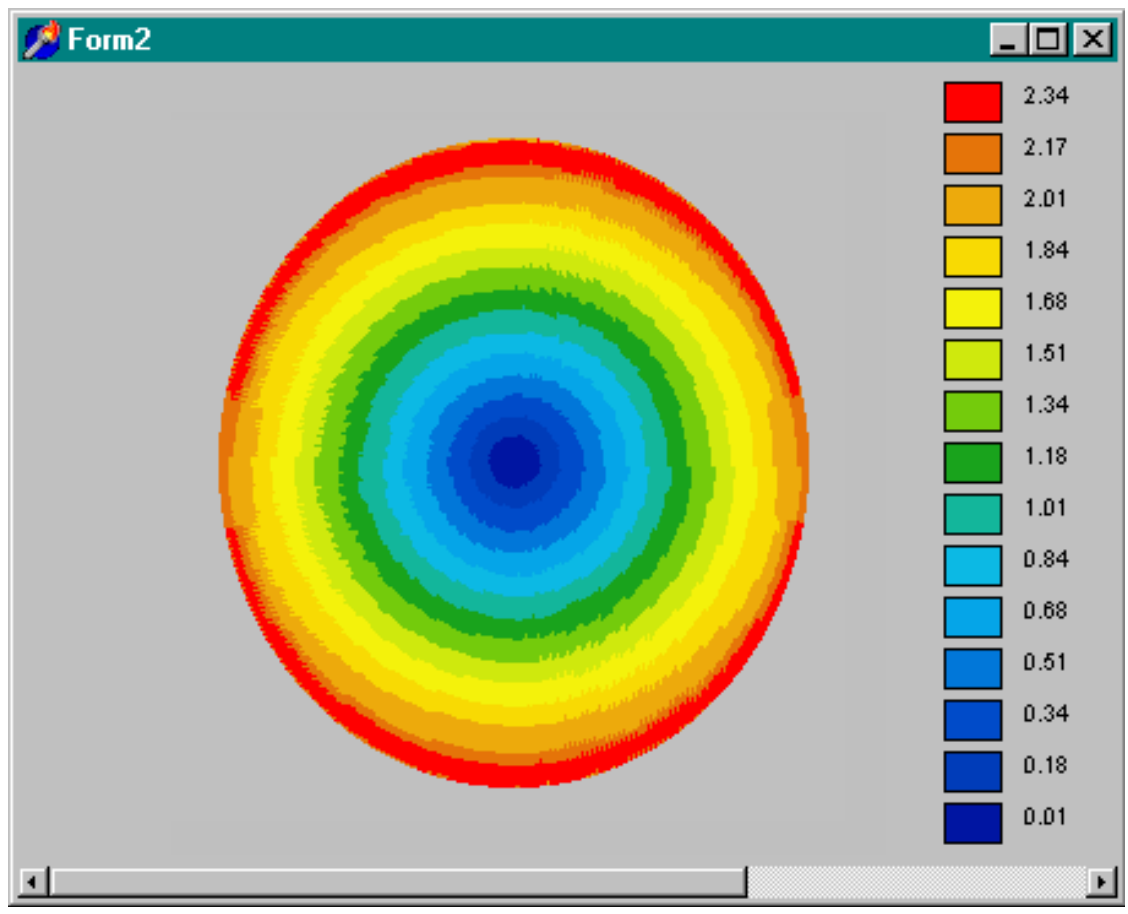

Figura 4.19. Mapa para a superfície tórica com $r_{v}=7.5 \mathrm{~mm}$ e $r_{h}=6.8 \mathrm{~mm}$. A toricidade fica mais evidente nas bordas do que ao centro, devido ao valor relativamente próximo dos raios apicais. Mas o formato oval da região periférica fica evidente.

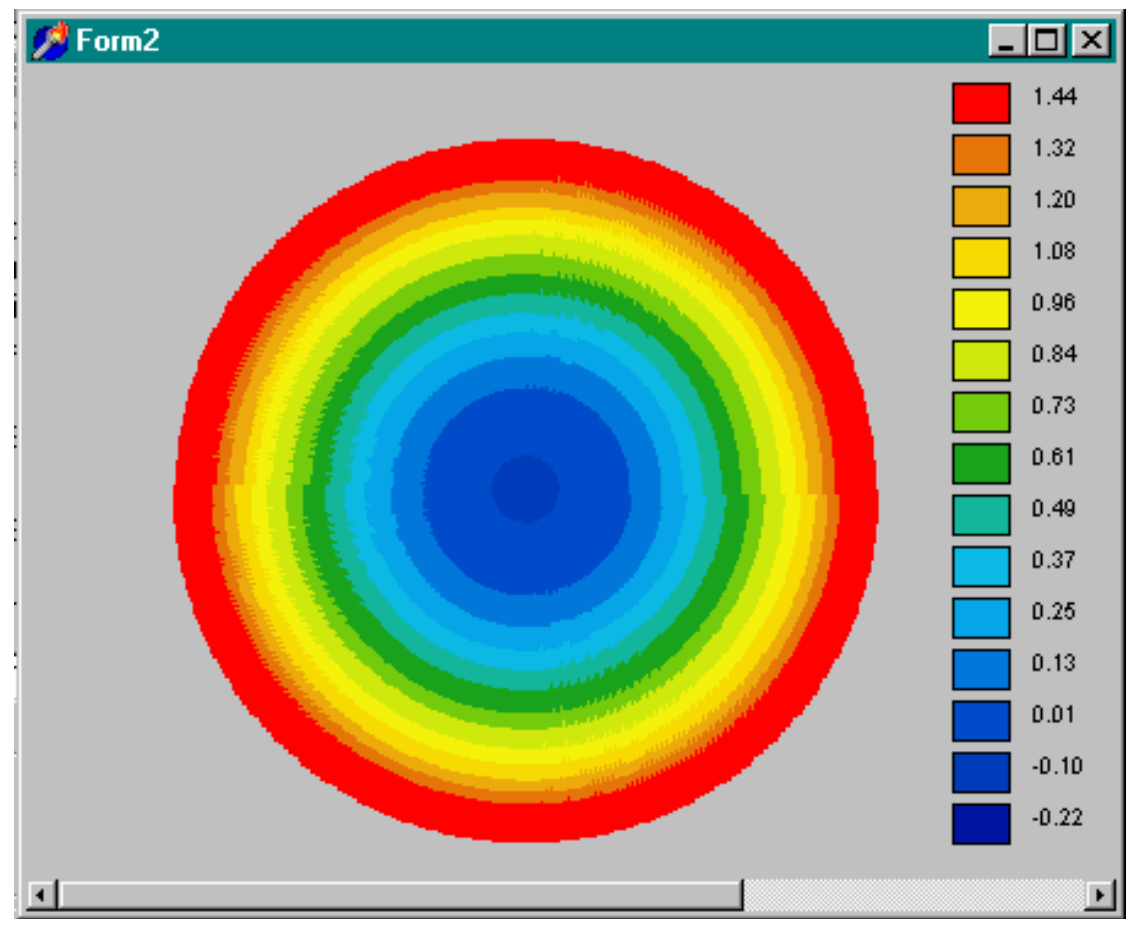

Figura 4.10. Mapa de um ceratocone com parâmetros $a=0.1, y_{1}=1.5 \mathrm{~mm}$ e $y_{2}=3.0 \mathrm{~mm}$. Podese notar nitidamente que existe uma região azulada com anéis coloridos mais largos, depois uma região de transição rápida, com grande variação de cores, e em seguida o vermelho constante. Esta variação de padrões está bem de acordo com aquilo que realmente acontece no Conclusão ceratocone. A região de maior variação de cor corresponde à função seno. 
Com os resultados obtidos até aqui, acreditamos ter atingido o objetivo principal da tese, ou seja, o desenvolvimento de técnicas e instrumentação para realização de exames que medem a curvatura (e elevação) da córnea durante procedimentos cirúrgicos. Este instrumento, da maneira que se encontra hoje, está pronto para testes futuros de campo, e sugerimos a instalação de algumas versões em diferentes salas cirúrgicas de hospitais e clínicas. Vamos deixar outras considerações na forma de sugestões na seção seguinte.

\subsection{Sugestões para trabalhos futuros e aprimoramentos do ceratógrafo percirúrgico}

Sugestões para trabalhos futuros:

- Novos modelos matemáticos: quão maior o número de modelos para cálculos de parâmetros da córnea, melhor será o diagnóstico do médico, pois nem todos costumam utilizar o mesmo modelo. Alguns utilizam mais o modelo Axial, outros o Tangencial, e assim por diante.

- Novo cone: sugerimos que o cone do instrumento continue passando por melhorias no "design", sem necessariamente mudar o número de anéis. Uma das mudanças deve ser no sentido de melhorar sua utilização durante a cirurgia. $O$ cone atual, embora eficiente, incomoda a movimentação das mãos do cirurgião, por ter um diâmetro e profundidade relativamente grandes. Outra sugestão, e que certamente seria bem mais trabalhosa, mas com certas vantagens, é dar continuidade na implementação de um topógrafo com sistema móvel dos Discos de Plácido. $\mathrm{O}$ cirurgião ou um auxiliar poderia puxar o braço com os Discos de Plácido para a posição de medida somente quando na realização de um exame. Durante os outros instantes da cirurgia o instrumento ficaria afastado do microscópio e não atrapalharia os movimentos do cirurgião. Outra vantagem deste instrumento é que não dependeria do divisor de feixe do microscópio ou do diâmetro da objetiva, ou seja, seria utilizável em qualquer microscópio cirúrgico, pois teria uma óptica própria para capturar as imagens de Plácido.

- Sistema de iluminação com LED ("Light Emitting Diode"): apesar das vantagens de utilizar um sistema de iluminação com fibras ópticas, acreditamos que a utilização de vários LED de alta intensidade seria possível. Se esta alternativa funcionar, acreditamos que o cone com Discos de Plácido ficaria até $1000 \%$ mais barato, pois LED são bem mais baratos que o cabo de fibra óptica (100 LED custariam aproximadamente $\mathrm{R} \$ 30,00$, enquanto o cabo com iluminador custa $\mathrm{R} \$ 500,00)$.

- Sistema de focalização mais preciso: o atual sistema de focalização, através da análise visual do tamanho do LED central, é muito subjetiva. Isto pode levar a diferenças não desprezíveis entre uma medida e outra, prejudicando o diagnóstico. Seria importante pesquisar e desenvolver um sistema mais preciso de focalização.

- Novos módulos no "software" para auxiliar o médico no diagnóstico: existem pesquisadores, como Rabinowitz et. al. [56] e outros, que sugerem a utilização de algoritmos que calculam parâmetros relacionados à superfície da córnea, e que podem 
auxiliar o médico no sentido de indicar os possíveis diagnósticos, como o índice de probabilidade de ceratocone.

- Intergração do percirúrgico com os novos sistemas de medida de aberrações oculares ("wave-front"). Pesquisas atuais [57-60] demonstraram a viabilidade e importância da integração dos dados da topografia de córnea com dados dos sensores Hartmann-Shack [61]. O objetivo é gerar algoritmos mais precisos para cirurgias refrativas, possibilitando a correção de aberrações de ordem mais alta e, portanto possibilitando maior acuidade visual aos pacientes. 
Referências

1. Le Grand, Y., El Hage, S. G., Physiological Optics, Springer Series in Optical Sciences, Springer-Verlag, 1980;13.

2. Born M, Principles of Optics, Pergamon Press,1975: 464-466.

3. Williams CS, Becklund OA, Introduction to the optical transfer function, WileyInterscience Publication, New York, 1989.

4. Schanzlin DJ, Robin JB, Corneal Topography-Measuring and Modifying the Cornea, Springer-Verlag, 1991.

5. Sanders DR, Koch DD, An Atlas of Corneal Topography, Slack, 1993.

6. Placido, A., Novo Instrumento de Exploração da Cornea, Periodico d'Oftalmológica Practica, Lisboa, 1880;5:27-30.

7. Troutman, R. C., Buzard, K. A., Corneal Astigmatism, Mosby Year Book, St. Louis.

8. Bicas, H. E. A., Sobre um Novo Princípio de Ceratometria (e da sua Aplicação através de um Instrumento Servindo também a outras Finalidades, adaptável aos Biomicroscópios), Departamento de Oftalmologia, EMRP-USP, 1967.

9. Frantz J. M. , Reidy J. J., McDonald M. B. ,. A Comparison of Surgical Keratometers, Refract. \& Corneal Surgery. 1989; 5:409-413.

10. Carvalho, L. A.V., Desenvolvimento de um instrumento computadorizado para medida da curvatura da córnea durante o ato cirúrgico, Tese apresentada ao IFSC-USP para obtenção do título de mestre em Física Aplicada, São Carlos-1996.

11. Schor P, Idealização, Desenho, Construção e Teste de um Ceratômetro Cirúrgico Quantitativo, Tese Apresentada à Universidade Federal de São Paulo - Escola Paulista de Medicina para obtenção do título de Doutor em Medicina, São Paulo, 1997.

12. Mandell, R. B., York, M. A., A New Calibration System for Photokeratoscopy, Am. J. Optom.,46, n0 11:818-825.

13. Stone, J., The Validity of Some Existing Methods of Measuring Corneal Contour Compared with Suggested New Methods, Brit. J. Physiol. Opt., 1962;19:205-230. 
14. York, M. A., Mandell, R. B., Corneal Counters From Birth to Five Years $3 / 4$ a Cross Section Study, Am. J. Optom., 1969; 46, n0 11:818-825.

15. Klyce, S.D., Computer-Assisted Corneal Topography, High Resolution Graphics Presentation and Analyses of Keratoscopy, Invest. Ofthalmol.Vis. Sci., 1984;25:426435.

16. Koch, D. D., G. N. Foulks, T. Moran, The corneal EyeSys system: accuracy, analysis and reproducibility of first generation prototype, Refract. Corneal. Surg., 1989;424-429.

17. El Hage SG: Computerized Corneal Topographer. Contact Lens Spectrum, 1989; 45-50.

18. Mammone, R. J., Gersten, M., Gormley,D. J., Koplin ,R. S., Lubkin,V. L., 3D Corneal Modeling System, IEEE Trans. Biomedical Eng, 1990;37:66-73.

19. Belin. M. W., D. Litoff, S. J. Strods, The PAR Technology corneal topography system, Refract. Surg., 1992; 88-96.

20. Mandell, R. B.,St Helen R., Mathematical Model of the Corneal Contour, Brit. J. Physiol. Optics., 1971;26:183-197.

21. Doss, James D., Hutson, Richard L., Rowsey, J., Brown, R., Method for Calculation of Corneal Profile and Power Distribution, Arch Ofthalmol, 1981;99:1261-1265.

22. Wang, J., Rice, D.A., Klyce, S.D., A New Reconstruction Algorithm for Improvement of Corneal Topographical Analysis, Refract. Corneal Surg.1989;5:379387.

23. van Saarlos, Paul P., Constable, Ian J., Improved Method for Calculation of Corneal Topography for Any Photokeratoscope Geometry, American Academy of Optometry, 1991;68:960-965.

24. Mandell, Robert B., The Enigma of the Corneal Contour, CLAO J, 1992;18:267273.

25. Halstead, Mark A.,Barsky, Brian A., Klein, Stanley A., Mandell, R. B.,Geometric Modeling of the Cornea Using Videokeratography, Mathematical Methods for Curves and Surfaces, 1995;213-223.

26. Halstead, Mark A.,Barsky, Brian A., Klein, Stanley A., Mandell, R. B. “A Spline Surface Algorithm for Reconstruction of Corneal Topography from a Videokeratographic Reflection Pattern”. Optometry and Vision Science. 1995;72: n0 11: 821-827.

27. Colliac, J. P., Shammas, H. J., Dilys, J. B., Photorefractive keratectomy for the correction of myopia and astigmatism, Am. J. Ophthalmol., 1994;117:369-380. 
28. Carvalho L, Tonissi SA, Castro JC, Preliminary tests and construction of a computerized quantitative surgical keratometer, J Cataract Refract Surg 1999;25:821826.

29. Carvalho LAV, Sidney Julho de Faria e Souza, Castro,J. C., Desenvolvimento de um Sistema para Medida da Esfericidade da Córnea Durante a Cirurgia, Revista de Física \& Instrumentação, 1997;12, n0 3: 81-90.

30. Troutman RC, Kelly S, Kaye D, Clahance AC,. The use and preliminary results of the Troutman Surgical Keratometer in cataract and corneal surgery. Trans Am Acad Ophthalmol Otorarygol. 1977; 83:232-238.

31. Press WH, Flannery BP, Teukolsky SA, Vetterling WT, Numerical Recepies in Pascal, The Art of Scientific Computing, Cambridge University Press, 1989.

32. Carvalho, Luis; Schor, Paulo; Topografia de Córnea - Atlas Clínico; Editora Cultura Médica, Paulo Polisuk, Capítulo 1 (Introdução e Histórico da Topografia de Córnea), 1999.

33. Carvalho, L. A. V.; Tonissi, S. A.; Romão, A. C.; Santos, L. E.; Yasuoka, F.; Oliveira, A. C.; Schor, P., Chamon, W., Castro, J. C., Desenvolvimento de um Instrumento Computadorizado para Medida do Poder Refrativo da Córnea (Videoceratógrafo), Arq. Bras. Oftal. 61(6), Dezembro/1998.

34. Paranaguá, E., Carvalho, L.A.V, Castro, J.C., Construção de um Topógrafo de Córnea, III Fórum Nacional de Ciência e Tecnologia em Saúde, Campos de JordãoOutubro de 1996.

35. Carvalho, L. A., Silva, E. P., Santos, L. E. R., Tonissi, S. A., Romão, A. C., Castro, J. C., Detecção de Bordas de Imagens Refletidas pela Superfície Anterior da Córnea, III Fórum Nacional de Ciência e Tecnologia em Saúde, Campos de Jordão-Outubro de 1996.

36. Gonzales RC, Woods R. E., Digital Image Processing, Addison-Wesley,1992.

37. Salmon, T.O., Horner, DG, Comparison of Elevation, Curvature, and Power Descriptors for Corneal Topographic Mapping, Optometry and Vision Science, 1995; 72: 800-808.

38. Klein SA, Mandell RB, Shape and refractive powers in corneal topography, Invest Ophthalmol Vis Sci 1995;36:2096-2109.

39. Roberts, C., Caracterization of the Inherent Error in a Spherically-Biased Corneal Topography System in Mapping a Radially Aspheric Surface, Refract. Corneal Surg., 1994; n010:103-111.

40. Klein SA, Mandell RB, Axial and Instantaneous Power Conversion in Corneal Topography, Invest Ophthalmol Vis Sci, Setembro 1995; n0 36:2156-2159. 
41. Klein SA, Corneal topography algorithm that avoids the skew ray ambiguity and the skew ray error, Optometry and Vision Science, vol. 74, 1997; n0 11: 945-962.

42. Rand RH, Howland HC, Applegate RA, Mathematical model of a Placido Disk keratometer and its implications for recovery of corneal topography, Optom Vis Sci 1997;74;926-930.

43. Klein SA, Mandell RB, Representing Corneal Shape, Vision Science and its Applications, vol. 1, Technical Digest Series, Washington, DC: Optical Society of America, 1996:37-40.

44. Klein SA, Axial curvature and the skew ray error in corneal topography, Optom Vis Sci 1997; 74: 931-944.

45. Hanna KD, Jouve FE, Waring GO, Preliminary computer simulation of the effects of radial keratotomy, Arch. Ophthalmol.,1989;107:911-918.

46. Applegate RA, Howland HC, Noninvasive measurement of corneal topography, IEEE Eng Med Biol 1995; 1995:30-42.

47. Marco Cantú, Mastering Delphi 4.0, Editora SYBEX, 1151 Marina Village Parkway, Alameda - CA, 1998.

48. Foley J., Feiner S., Hughes J., Phillips R., Introduction to Computer Graphics, Addison-Wesley, 1993.

49. Barsky, BA, Computer Graphics and Geometric Modeling Using Beta-Splines, Springer-Verlag, 1987.

50. Earnshaw R. A. , Watson D., Animation and Scientific Visualization, Tools and Applications, Academic Press, 1993.

51. Oliveira, M. C. F., Minghim, R., Uma Introdução à Visualização Computacional, XVI JAI - Jornada de Atualização em Informática, Brasília-DF, 2-8 Agosto de 1997, p. $85-127$.

52. Carvalho, L. A.; Tonissi, S. A.; Castro, J. C., Preliminary results of a computerized Placido disc surgical corneal topographer, SPIE conference on Ophthalmic Technologies IX, San Jose, California, January 1999, vol. 3591:53-62.

53. Klein, S. A., Optimal corneal ablation for eyes with arbitrary Hartmann-Shack aberrations, J. Opt. Soc. Am. Vol. 15, No. 9/ Setembro 1998, 2580-2588.

54. Salmon, T.O., Horner, DG, Comparison of Elevation, Curvature, and Power Descriptors for Corneal Topographic Mapping, Optometry and Vision Science, 1995; 72: 800-808.

55. Applegate RA, Howland HC, Noninvasive measurement of corneal topography, IEEE Eng Med Biol, 1995:30-42. 
56. Rabinowitz YS, Rasheed K., KISA\% index: a quantitative videokeratography algorithm embodying minimal topographic criteria for diagnosing keratoconus.

J Cataract Refract Surg. 1999 Outubro, 25(10):1327-35.

57. Klein SA, Optimal corneal ablation for eyes with arbitrary Hartmann-Shack aberrations, J. Opt. Soc. Am. Vol. 15, No. 9, Setembro, 1998: 2580-2588.

58. Schwiegerling J, Snyder RW, Custom photorefractive keratectomy ablations for the correction of spherical and cylindrical refractive error and higher-order aberration, J. Opt. Soc. Am. A/ Vol. 15, n0 9, Setembro 1998, 2572-2579.

59. Carvalho LAV, Castro JC, Schor P, Chamon W, A software simmulation of Hartmann-Schack patterns for real corneas, International Symposium: Adaptive Optics: from telescopes to the human eye, Murcia, Spain, November 13-14, 2000.

60. Carvalho LA, Castro JC, Chamon W, Schor P, Carvalho LAV, Wave-front measurements of the human eye using the Hartmann-Shack sensor and current state-ofthe-art technology for excimer laser refractive surgery, ASCRS 2001 - USA, in press.

61. Liang, J., Grimm, B., Goelz, S., Bille, J. F., Objective measurement of wave aberrations of the human eye with the use of a Hartmann-Shack wave-front sensor. J. Opt. Soc. Am. Vol. 14, n0 11/ Julho 1994, 1949-1957.

\section{Apêndice}

\section{Dedução de fórmulas matemáticas para o Modelo Tangencial}

\section{Equação recursiva para o Modelo Tangencial}

Com base na figura 1 e fazendo os ângulos $t_{1}$ e $t_{2}$ infinitamente próximos,

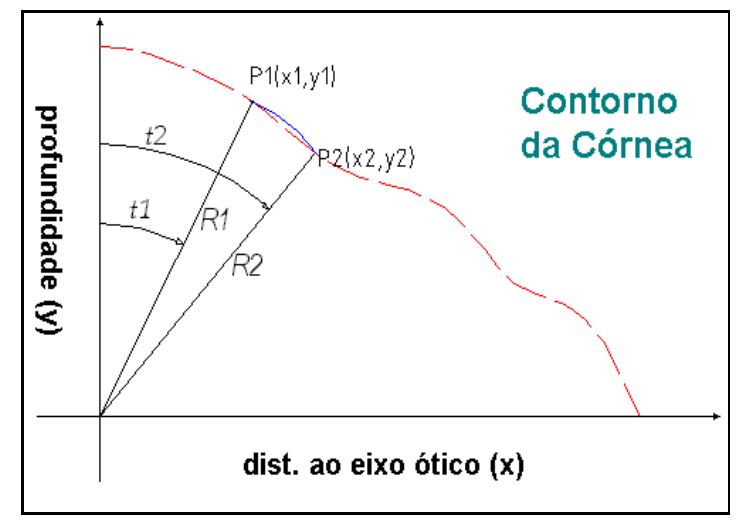

Figura 1. Traçando arcos para descrever uma superfície desuniforme.

podemos fazer $R_{1} \approx R_{2}=R \mathrm{e}$ 


$$
y_{2}-y_{1}=R \cos t_{2}-R \cos t_{1}
$$

isolando para $y_{2}$ temos

$$
y_{2}=y_{1}+R\left(\cos t_{2}-\cos t_{1}\right)
$$

podemos ainda escrever

$$
R=\frac{x_{2}}{\text { sent }_{2}} \text { e } R=\frac{x_{1}}{\text { sent } 1}
$$

fazendo

$$
\operatorname{sent}_{2}-\operatorname{sent}_{1}=\frac{x_{2}-x_{1}}{R}
$$

isolando (4) para $R$ e substituindo em (1) temos

$$
y_{2}=y_{1}-\frac{\left(x_{1}-x_{2}\right)}{\operatorname{sent}_{1}-\operatorname{sent}_{2}}\left(\cos t_{1}-\cos t_{2}\right)
$$

generalizando esta equação para todos os pontos $i$ analisados sobre a córnea chegamos à equação recursiva desejada:

$$
y_{i}=y_{i-1}-\frac{\left(x_{i-1}-x_{i}\right)\left(\cos t_{i-1}-\cos t_{i}\right)}{\operatorname{sent}_{i-1}-\operatorname{sent}_{i}}
$$

Equação utilizada para calcular o valor de $y_{0}$ 


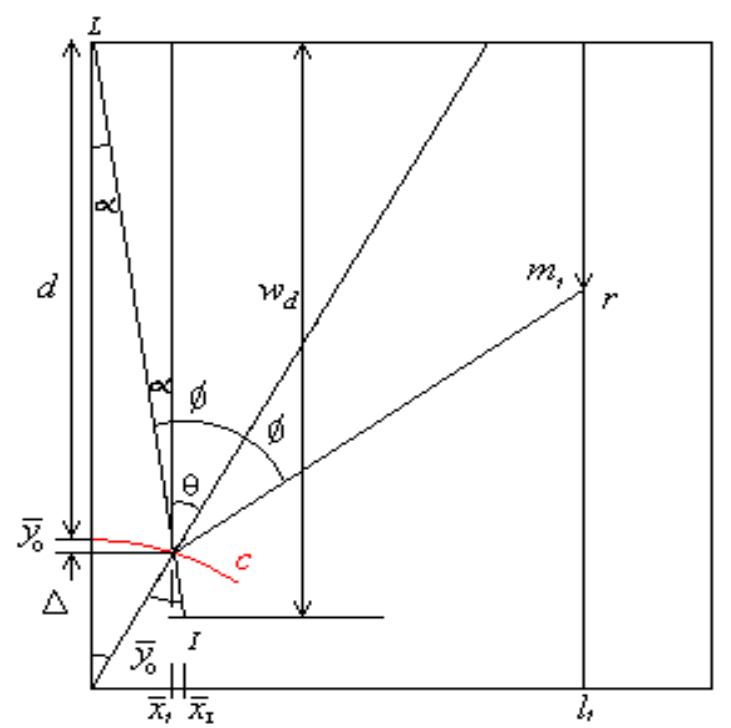

Figura 2. Caminhos ópticos utilizados por van Saarlos.

Pela figura 2 , utilizando conceitos simples de óptica geométrica podemos escrever

$$
\begin{aligned}
\tan \alpha & =\frac{\bar{x}_{I}}{w_{d}} \\
\tan (2 \phi-\alpha) & =\frac{\left(l_{1}-\bar{x}_{1}\right)}{d+\Delta-m_{1}} \\
\operatorname{sen} \theta & =\frac{\bar{x}_{1}}{y_{0}}
\end{aligned}
$$

Isolando $y_{0}$ em (9) temos

$$
y_{0}=\frac{\bar{x}_{1}}{\operatorname{sen} \theta}
$$

e pela figura podemos fazer

$$
\theta=\phi-\alpha=\frac{1}{2}(2 \phi-2 \alpha)=\frac{1}{2}((2 \phi-\alpha)-\alpha)
$$

substituindo este valor de $\theta$ na equação (10) temos

$$
y_{0}=\frac{\bar{x}_{1}}{\operatorname{sen}\left[\frac{1}{2}((2 \phi-\alpha)-\alpha)\right]}
$$


Podemos reescrever está equação em função dos valores dos arco-tangentes de $\alpha$ e $(2 \phi-\alpha)$ extraídos das equações (7) e (8):

$$
\bar{y}_{0}=\frac{\bar{x}_{1}}{\sin \left\{\frac{1}{2}\left[\tan ^{-1}\left(\frac{l_{1}-\bar{x}_{1}}{d+\Delta-m_{1}}\right)-\tan ^{-1}\left(\frac{\bar{x}_{I}}{w_{d}}\right)\right]\right\}}
$$

que é a equação desejada. 